Saulo Ferreira Maciel

\title{
Desenvolvimento de Ferramenta Computacional de Alta Ordem para a Solução de Problemas de Propagação Acústica
}

\author{
Dissertação apresentada à Escola Politécnica \\ da Universidade de São Paulo para obtenção \\ de título de mestre em Engenharia Mecânica.
}

São Paulo

2013 
Este exemplar foi revisado e corrigido em relação à versão original, sob responsabilidade única do autor e com a anuência de seu orientador.

São Paulo, 27 de junho de 2013.

Assinatura do autor

Assinatura do orientador

FICHA CATALOGRÁFICA

Maciel, Saulo Ferreira

Desenvolvimento de ferramenta computacional de alta ordem para a solução de problemas de propagação acústica /

S.F. Maciel. -- versão corr. -- São Paulo, 2013. $90 \mathrm{p}$.

Dissertação (Mestrado) - Escola Politécnica da Universidade de São Paulo. Departamento de Engenharia Mecânica.

1.Acústica 2.Transmissão do som 3.Equação de Euler I.Universidade de São Paulo. Escola Politécnica. Departamento de Engenharia Mecânica II.t. 
Saulo Ferreira Maciel

\section{Desenvolvimento de Ferramenta Computacional de Alta Ordem para a Solução de Problemas de Propagação Acústica}

Área de Concentração: Engenharia Mecânica

Opção: Energia e Fluidos

Orientador: Prof. Dr. Bruno Souza Carmo

São Paulo

2013 


\section{Agradecimentos}

Agradeço ao Prof. Dr. Bruno Souza Carmo pela ajuda e envolvimento nos momentos importantes desse trabalho. Pelo suporte computacional oferecido junto ao Núcleo de Dinâmica de Fluidos (NDF-USP) e pelo contato com a equipe de desenvolvedores do Nektar++ no Imperial College em Londres.

À Embraer S.A. junto com o Prof. Dr. Julio Romano Meneguini por estabelecerem a parceria com o NDF através do projeto Aeronave Silenciosa, que forneceram motivação e recursos financeiros para o desenvolvimento de pesquisa no ramo de acústica e aeroacústica.

Ao Prof. Dr. Ernani Vitillo Volpe e ao Prof. Dr. Fábio Saltara que com contribuições pontuais ao longo desse trabalho, esclareceram dúvidas, orientaram e discutiram problemas além de participarem da banca de qualificação quando contribuíram com valiosas sugestões.

À equipe do NDF, em particular à Ivone Margarido e ao Amir Afif que estiveram sempre dispostos e ajudando muitas vezes além de suas atribuições.

À Coordenação de Aperfeiçoamento de Pessoal de Nível Superior (CAPES) que fornecendo uma bolsa de estudos permitiu a dedicação exclusiva ao projeto. 


\section{Resumo}

O desenvolvimento de uma ferramenta de Dinâmica de Fluidos Computacional que utiliza Método de Elementos Finitos baseada na discretização de Galerkin descontínuo é apresentado neste trabalho com objetivo de resolver a equação de Euler linearizada para escoamento compressível em duas dimensões usando malhas estruturadas e não estruturadas. Procuramos utilizar esta ferramenta como um propagador de ondas sonoras para estudar fenômenos aeroacústicos. O problema de Riemann presente no fluxo convectivo da equação de Euler é tratado com um método upwind HLL e para o avanço da solução no tempo é usado o método de Runge-Kutta explícito de 4 estágios com segunda ordem de precisão. A eficiência computacional, a convergência do método e a precisão são testadas através de simulações de escoamentos já apresentadas na literatura. A taxa de convergência para altas ordens de aproximação é assintótica que é um resultado compatível com a formulação Galerkin descontínuo.

Palavras chave: Galerkin descontínuo, equação de Euler linearizada, aeroacústica. 


\begin{abstract}
The development of a Computation Fluid Dynamic Tool based on the Finite Element Method with discontinuous Galerkin discretization is presented in this work. The aim of this study is to solve the compressible linearized Euler's equation in two dimensions on structured and non structured meshes. This tool has been used as a means to study aeroacoustics phenomena. The Riemann's problem presented on a convective flow in Euler's equation is tackled by a HLL's method and the time integration being used is the four-stage Runge-Kutta explicit method with second order of accuracy. The computational efficiency, the convergence of the method and the accuracy are tested by comparing our results for flow simulations with those that are available in the literature. The convergence rate to high approximation order is asymptotic and it shows a result which is compatible with a discontinuous Galerkin formulation.
\end{abstract}

Key words: discontinuous Galerkin, linearized Euler equation, aeroacoustics. 


\section{Desenvolvimento de Ferramenta Computacional de Alta Ordem para a Solução de Problemas de Propagação Acústica}

Saulo Ferreira Maciel

Escola Politécnica - Departamento de Engenharia Mecânica USP - São Paulo, BRASIL

Abril de 2013 


\section{Sumário}

1 Introdução geral 1

1.1 O estudo do som . . . . . . . . . . . . . . . . . . . . 1

1.2 Aeroacústica computacional . . . . . . . . . . . . . . . 2

1.3 Revisão bibliográfica . . . . . . . . . . . . . . . . . . . . . . 4

1.4 Objetivos e motivação . . . . . . . . . . . . . . . . . . . . 9

2 Fundamentos teóricos $\quad 13$

2.1 Escoamento Compressível . . . . . . . . . . . . . . . . . . . . . . . . . . . . . . . . . . . 13

2.2 Grandezas envolvidas . . . . . . . . . . . . . . . . . . . . . . . . 14

2.3 Aeroacústica . . . . . . . . . . . . . . . . . . . . . . 17

2.4 Fontes sonoras . . . . . . . . . . . . . . . . . . . . . . 22

2.5 Equação de Euler linearizada - LEE . . . . . . . . . . . . . . . . . . 24

2.5.1 Variáveis conservadas . . . . . . . . . . . . . . . . . . 24

2.5.2 Variáveis primitivas . . . . . . . . . . . . . 26

2.6 Condições de contorno . . . . . . . . . . . . . . . . . . . 27

3 Formulação numérica $\quad 29$

3.1 Discretização espacial . . . . . . . . . . . . . . . . . . . 30

3.1 .1 Galerkin Descontínuo . . . . . . . . . . . . . . . 33

3.1 .2 Mapeamento polimórfico . . . . . . . . . . . . . . . 36

3.1.3 Base de expansão multidimensional . . . . . . . . . . . . . . . . . 39

3.2 Integração temporal . . . . . . . . . . . . . . . . . . . . . . 41

4 Resultados e Discussões $\quad 42$

4.1 Validação do método . . . . . . . . . . . . . . . . . . . . . . 44

4.1.1 Descrição do problema - solução analítica . . . . . . . . . . . . . 45

4.1 .2 Convergência $p$ - solução analítica . . . . . . . . . . . . . 46

4.1.3 Descrição do problema - monopolo . . . . . . . . . . . . . . . . . 48

4.1.4 Convergência $p$ - monopolo . . . . . . . . . . . . . 48

4.1.5 Convergência $h p$ - monopolo . . . . . . . . . . . . . . . 50

4.2 Pulso Gaussiana . . . . . . . . . . . . . . . . . . . 51

4.2 .1 Descrição do problema . . . . . . . . . . . . . . . . . . . 51

4.2 .2 Solução analítica . . . . . . . . . . . . . . . . . . . 52 
4.2 .3 Resultados numéricos . . . . . . . . . . . . . . . . . 53

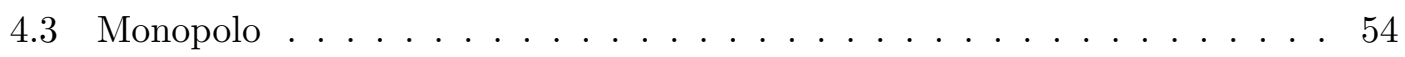

4.3 .1 Descrição do problema . . . . . . . . . . . . . . . . . . . . . . . . 54

4.3 .2 Solução analítica . . . . . . . . . . . . . . . . . . . . . . . . . . . . 56

4.3 .3 Caso Subsônico . . . . . . . . . . . . . . . . 57

4.3 .4 Caso Supersônico . . . . . . . . . . . . . . . . . 57

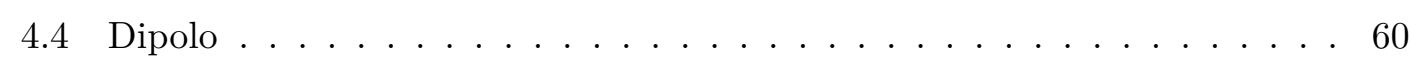

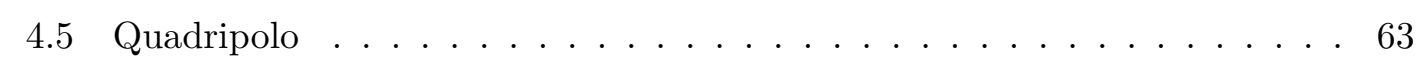

5 Conclusão e trabalhos futuros $\quad 65$

$\begin{array}{ll}\text { Referências } & 67\end{array}$

$\begin{array}{ll}\text { A Solução analítica - Pulso gaussiana } & 71\end{array}$

$\begin{array}{ll}\text { B Transformada de Hankel } & 74\end{array}$

$\begin{array}{ll}\text { C Fluxo numérico - HLL e HLLC } & 75\end{array}$

$\begin{array}{lr}\text { D Polinômios de Legendre } & 79\end{array}$ 


\section{Lista de Figuras}

1.1 Estratégia híbrida, E.Mahona - 2004. . . . . . . . . . . . . . . . 10

2.1 Particionamento do domínio matemático para a analogia de Ffowcs WilliansHawkings . . . . . . . . . . . . . . . . . . . . . . . . . . 19

2.2 Diferentes apresentações da equação de Euler . . . . . . . . . . . . . . . . 24

3.1 Mapeamento de elementos pela correspondência de vértices. . . . . . . . 38

3.2 Mapeamento do triângulo no quadrilátero padrão. . . . . . . . . . . . . . 39

3.3 Espaço polinomial modificado em termos do triângulo de Pascal. . . . . . . 41

4.1 Malha estruturada com $9 x 9$ quadrados e dimensão $-100 \leq x, y, \leq 100$. . 43

4.2 Malhas não estruturadas com dimensão $-100 \leq x, y \leq 100$. . . . . . . . 44

4.3 Convergência do erro na norma $L^{2}$ para $P=2-20$. (a)-(b) Malha estruturada de 81 quadrados. (c)-(d) Malha não estruturada de 110 triângulos. (e)-(f) Malha não estruturada mista de 27 triângulos e 83 quadriláteros. . 47

4.4 Superfície de pressão do monopolo - Mach $=0,5, \mathrm{P}=20$ e t=100. . . . . . 49

4.5 Convergência do erro na norma $L^{2}$ para pressão do monopolo - $\mathrm{y}=0$, $P=2-20, t=100$ em malha de $9 \mathbf{x} 9$ quadrados. . . . . . . . 50

4.6 (a)Teraflops $-P=2-20$ e $\mathrm{t}=100$. (b) Produto Erro $\mathrm{x}$ teraflops $-P=$

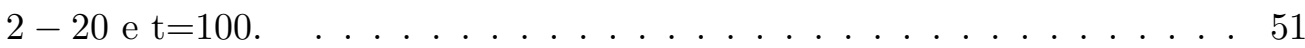

4.7 (a) Convergência $h p$ para $P=2-7$. (b) Convergência $p$ e $h . \ldots 51$

4.8 Superfície de pressão do pulso gaussiana $-\mathrm{Mach}=0.0, \mathrm{P}=20$ e $\mathrm{t}=50$. . . . 54

4.9 Perfil de pressão do pulso gaussiana - $\mathrm{y}=0, \mathrm{Mach}=0,0, \mathrm{P}=20$ e $\mathrm{t}=30$. . . 54

4.10 Perfil de pressão do pulso gaussiana $-\mathrm{y}=0, \mathrm{Mach}=0.0$ e $\mathrm{P}=20$. . . . . . . 55

4.11 Superfície de pressão do monopolo - Mach=0.5 e $\mathrm{P}=20$. . . . . . . . . . 58

4.12 Perfil de pressão do monopolo - $\mathrm{y}=0, \mathrm{Mach}=0,5, \mathrm{P}=20$ e $\mathrm{t}=150 . \quad \ldots \quad \ldots 9$

4.13 Superfície de pressão do monopolo - Mach $=2,0$ e $\mathrm{P}=20$. . . . . . . . . . . 60

4.14 Perfil de pressão do monopolo - $\mathrm{y}=0$, Mach $=2,0, \mathrm{P}=20$ e t=250. . . . . . 61

4.15 Perfil de pressão do monopolo $-\mathrm{x}=59$, Mach $=2,0, \mathrm{P}=20$ e $\mathrm{t}=250 \ldots$. . . . 61

4.16 Superfície de pressão do dipolo - Mach=0,0, $\mathrm{P}=20$ e $\mathrm{t}=90 \ldots \ldots 2$

4.17 Perfil de pressão do dipolo $-\mathrm{y}=0, \mathrm{Mach}=0,0, \mathrm{P}=20 \ldots \ldots$. . . . . . 63

4.18 Superfície de pressão do quadripolo - $\mathrm{Mach}=0,0, \mathrm{P}=20$ e $\mathrm{t}=90 . \quad \ldots \ldots .64$

4.19 Perfil de pressão do quadripolo $-\mathrm{y}=0$, Mach $=0,0, \mathrm{P}=20$ e $\mathrm{t}=90 . \quad \ldots .65$

C.1 Plano $x \times t$ dividido em 3 estados pelas velocidades características $S_{R}=$ $\max \left(u \pm c_{0}\right)$ e $S_{L}=\min \left(u \pm c_{0}\right) \ldots \ldots \ldots \ldots \ldots$ 
C.2 Plano $x \times t$ dividido em 4 estados pelas velocidades características $S_{R}, S_{*}$

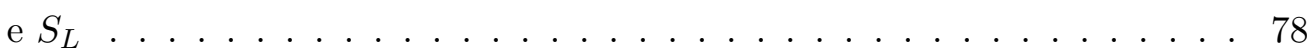

\section{Lista de Tabelas}

1 Funções teste usadas no método dos resíduos ponderados . . . . . . . . . 32

2 Campo médio em variáveis primitivas - Validação $\mathrm{Mach}=0,5$. . . . . . . . 46

3 Campo médio em variáveis primitivas - Monopolo Mach=0,5. . . . . . . . 48

4 Campo médio em variáveis primitivas - Pulso gaussiana. . . . . . . . . . 52

5 Campo médio e condições iniciais - Monopolo Mach=2,0. . . . . . . . . . 57 


\section{Nomenclatura}

$c_{0}:$ Velocidade do Som

$E$ : Energia Total por unidade de volume

$e_{i}$ Energia interna

$\mathbf{F}=\mathbf{F}_{E}-\mathbf{F}_{V}$ : Vetor de Fluxo

$\mathbf{F}_{E}$ : Vetor de fluxo de Euler ou Inviscido

$\mathbf{F}_{V}$ : Vetor de fluxo Viscoso

$\hat{\imath}=\left\{\hat{\imath}_{x}, \hat{\imath}_{y}, \hat{\imath}_{z}\right\}$ : Vetor de unidade cartesiana

$\mathbf{J}=\frac{\partial \mathbf{F}}{\partial \mathbf{Q}}:$ Fluxo Jacobiano

$k$ : Energia cinética turbulenta

$M$ : Numero de Mach

$\mathbf{n}=\mathbf{S} /|\mathbf{S}|$ : Vetor de unidade de área

$p$ : Pressão estática

$\operatorname{Pr}$ : Número de Prandtl

Q : Vetor de variável conservada

Re : Número de Reynolds

$\mathbf{S}:$ Vetor de área

$\mathbf{V}=\{u, v, w\}$ : Vetor de velocidade cartesiana

$\delta_{i j}$ : Delta Kronecker

$\Delta t$ : Passo de tempo

$\rho$ : Massa específica

$c_{v}$ : Calor específico a volume constante

$c_{p}$ : Calor específico a pressão constante

$\gamma:$ Razão entre $c_{v}$ e $c_{p}$

$\omega$ : Freqüência angular do som

$\lambda$ : Comprimento de onda

$\tau^{t}$ : Tensor de tensões de Reynolds 


\section{Introdução geral}

\subsection{O estudo do som}

O som que ouvimos é compreendido do ponto de vista físico como compressões e rarefações em um fluido e não se aplica apenas quando produzido no ar, mas sim em qualquer meio que pode ser líquido ou sólido. Ele é caracterizado pela sua intensidade, expressa em decibel $(\mathrm{dB})$ e pela sua freqüência, expressa em Hertz (Hz). O ouvido humano é capaz de perceber sons na freqüência de $20 \mathrm{~Hz}$ a $20 \mathrm{kHz}$ com intensidades de $1 \mathrm{~dB}$ até 120-125dB quando inicia o limiar da dor. O som quando articulado é a base da comunicação humana através da fala e pode provocar sensações agradáveis como ouvir uma boa música. Quando não articulado, intermitente ou aleatório produz irritação e incômodo e neste caso é denominado ruído e sobre ele um ramo da ciência, denominado acústica, que é a ciência do som, volta seu olhar para melhor compreendê-lo e identificar suas fontes. O ruído tornou-se um problema na sociedade moderna com o desenvolvimento tecnológico e conseqüente mecanização das atividades humanas, pois as máquinas para executarem a função para as quais foram desenvolvidas, invariavelmente produzem quantidades significativas de ruído nos ambientes onde executamos nossas atividades diárias contribuindo para a deterioração da qualidade de vida. A resposta a esse problema veio pelo lado das instituições governamentais definindo regras para o controle de ruído e pelo lado da indústria, em especial pela indústria automotiva e aeroespacial, buscando novas técnicas para produzir máquinas com maior conforto acústico. Muitos avanços foram realizados nos últimos vinte anos de pesquisa no ramo aeroespacial quando as pesquisas se concentraram na redução do ruído de motores e turbinas e hoje os esforços se concentram em reduzir o ruído na fuselagem, elementos de sustentação e apêndices como trem de pouso, e o estudo da geração do som por fenômenos aerodinâmicos e sua propagação tornou-se um campo ativo de pesquisa, denominado aeroacústica. Da mesma forma, a indústria de transporte terrestre percebe que para velocidades acima de $100 \mathrm{~km} / \mathrm{h}$ o ruído aerodinâmico se torna dominante quando ele é produzido pela interação entre o fluido a estrutura do veículo assim como seus acessórios externos. Além das fontes sonoras externas, dispositivos internos em baixas velocidades de escoamento, como sistema de ar condicionado, reduzem o conforto acústico no interior do veículo e o mercado compreendeu que esse fator passa a ser um importante critério de escolha por

parte dos consumidores [1]. Diante desses fatos este trabalho se propõe a desenvolver uma ferramenta computacional para o estudo da propagação do som. 


\subsection{Aeroacústica computacional}

O som gerado pelo escoamento em geral é um problema em várias aplicações da engenharia. Em particular, o ruído causado por aeronaves em operações de pouso e decolagem tomam destaque, pois a legislação que regula o nível ruído nos aeroportos vem se tornando mais exigente. Embora se saiba que o estudo de fenômenos de propagação acústica ainda dependa fortemente de experimentos físicos, a comunidade acadêmica e a indústria envolvidos com a Fluido Dinâmica Computacional (CFD) e reconhecendo a sua eficiência, passaram a apostar em ferramentas de simulação numérica para fenômenos aeroacústicos, com destaque em projetos aeronáuticos e automotivos de baixa emissão de ruído, acreditando que esta ferramenta possa oferecer respostas em prazos e custos reduzidos quando comparado com experimentos físicos em escalas reais.

Na abordagem computacional, as técnicas de predição e propagação de ondas sonoras são chamadas de Aeroacústica Computacional (CAA) e não podem ser dissociadas da Dinâmica de Fluidos Computacional porque estão fortemente relacionadas às fontes de ruído geradas pelo escoamento mas que possuem grande variedade de sistemas físicos, modelos físicos, algoritmos numéricos e estratégias de solução. A primeira teoria aeroacústica foi desenvolvida por Lighthill [2] no início da década de 50 e foi ele quem introduziu o termo som aerodinâmico. Ele definiu que o som é gerado por fluxos instáveis através de interações não lineares da flutuação da velocidade, da entropia e de tensões viscosas e esse complexo processo fluido mecânico atua como uma fonte sonora que é acusticamente equivalente a um termo fonte na equação de onda não homogênea.

Por terem a mesma origem, que é o escoamento, os fenômenos de aeroacústica encontram as mesmas dificuldades e limitações técnicas dos problemas de aerodinâmica quando abordados na forma computacional que são a necessidade de grandes recursos computacionais, a alta densidade da malha e a baixa precisão dos métodos em malhas deformadas. Apesar de serem semelhantes quanto às dificuldades computacionais, os problemas de aeroacústica e aerodinâmica necessitam de abordagens diferentes devido a seus aspectos físicos e objetivos serem distintos (Tam [3]). Na aerodinâmica, as soluções muitas vezes são independentes do tempo enquanto que nos problemas de aeroacústica elas são por definição dependentes dele. Há também a dificuldade no tratamento das diferentes escalas de turbulência na região das fontes sonoras (campo próximo) e na região de propagação (campo distante), cuja razão é inversamente proporcional ao número de Mach. Da mesma forma a razão entre os níveis de energia também é inversamente proporcional ao número de Mach (Sarkar [4]). Além disso, as freqüências são relativa- 
mente altas, assim como as distâncias de propagação, e o uso de métodos numéricos introduzem efeitos numéricos indesejáveis como a dissipação e dispersão numérica que respectivamente amortecem a amplitude da vibração e alteram a velocidade da propagação e quanto maiores forem a freqüência e a distância, maior será a influência desses efeitos numéricos.

Como em situações reais de propagação o domínio é muitas vezes infinito ou semiinfinito, na CAA o domínio computacional precisa ser grande o suficiente para representar de forma satisfatória a realidade física e a densidade da malha precisa ser alta no campo distante, por isso é comum truncar o domínio computacional a certa distância do campo próximo. Esse processo exige que as condições de contorno sejam mais próximas o possível da solução do problema e devem ser tratadas com cuidado, pois podem gerar reflexões que contaminam a solução. Por isso, o desenvolvimento de condições de contorno não reflexivas é em geral difícil e também um tópico de pesquisa.

Mesmo diante das dificuldades citadas acima podemos estudar os fenômenos de geração e propagação do som adotando duas abordagens distintas (Colonius \& Lele [5]) que trabalhando juntas e resolvendo cada uma diferentes problemas, formam hoje o conjunto de técnicas disponíveis para CAA.

- Método direto: Nesse método resolvemos a equação de Navier-Stokes compressível tanto para o campo próximo (região turbulenta) quanto para o campo distante com o uso de simulação numérica direta (DNS), modelando as pequenas escalas de turbulência e simulando os grandes turbilhões (LES) ou resolvendo as equações de Navier-Stokes com média de Reynolds (RANS). Em qualquer uma destas formas, o domínio precisa ser grande o suficiente para acomodar mais de um comprimento de onda acústica. Devido ao realismo físico da solução computacional obtida, esses resultados são tomados como dados de "benchmark" para teste e desenvolvimento de modelos de escoamento instável e geração de ruídos, mas pelo seu alto custo computacional, apenas configurações de escoamento simples são estudadas usando este método.

- Método hibrido: Como alternativa ao método direto, no método híbrido o escoamento turbulento é desacoplado do campo de propagação sonora possibilitando que o problema seja resolvido em duas etapas:

- Obtenção da fonte sonora: As fontes sonoras podem ser obtidas por métodos usuais de CFD (DNS, LES, RANS) resolvendo o campo aeroacústico da superfície de interesse em um domínio pequeno, mas mesmo assim suficiente 
para capturar todos os fenômenos físicos do escoamento que são responsáveis pela geração de ruído. Neste domínio são impostas condições de contorno artificiais que serão utilizados como fontes sonoras na etapa seguinte. A fonte sonora pode ser também obtida por modelos semi-empíricos que acoplam a solução estacionária de um método do tipo RANS a métodos estocásticos para a geração e propagação de ruído (SNGR) [6], ou pelo escoamento quase-incompressível onde a variação de pressão (necessárias para manter o campo de velocidades com divergência nula) é acoplada a uma perturbação isentrópica da densidade (Lele [7]).

- Propagação do som: Uma vez caracterizada a fonte sonora, a propagação até um observador ao longe pode ser realizada de várias formas utilizando a solução na fronteira da etapa anterior. 1) Essa solução pode ser utilizada como um termo fonte de um conjunto simplificado ou reduzido de equações como a equação de Euler linearizada (LEE). 2) Essa solução pode ser transformada em uma superfície de Kirchhoff onde uma relação integral é usada para relacionar a pressão e suas derivadas sobre a superfície com o campo acústico fora da superfície, nesta formulação deve-se assumir que o fluxo através da superfície de Kirchhoff é linear e isso implica que a fronteira deve estar distante o suficiente da região turbulenta e isso é difícil de estimar onde as perturbações são pequenas para serem linearizadas. 3) Essa solução pode ser utilizada com uma analogia acústica, por exemplo, analogia acústica de Lighthill, que relaciona o campo acústico de pontos externos do domínio computacional com integrais de volume de dentro do domínio.

Este trabalho se encaixa na parte de propagação do som do método híbrido resolvendo LEE por métodos numéricos.

\subsection{Revisão bibliográfica}

Com o avanço dos propulsores depois da segunda guerra e a invenção da turbina a jato, o som passou a ser estudado e a primeira apresentação formal do fenômeno acústico é a equação de Lighthill em 1952 (equação 2.25), conhecida como analogia de Lighthill. Neste caso a solução da propagação sonora é dada pela função de Green do tensor de Lighthill [2]. A função de Green pode ser formulada com paredes sólidas (Curle em 1955 [26]) ou de forma mais geral pela abordagem de Fwocs Willians-Hanking publicada em 
1969 (seção 2.3). A analogia de Lighthill alcançou um sucesso considerável na explicação algumas das características mais proeminentes dos jatos observadas experimentalmente, mas quando experimentos mais detalhados foram realizados por Lush (1971) [37] e Ahuja \& Bushell (1973) [38], tornou-se claro que haviam outras características mais sutis que não podiam ser explicadas por essa analogia. As tentativas para explicar as novas observações foram baseados em analogias mais complexas, tais como as desenvolvidas por Phillips (1960)[39], Lilley (1974) [40], Howe (1975) [41], Dowling et al. (1978)[42] e Goldstein (1984) [43]. Todas elas, de uma forma ou de outra, deparavam-se com um operador de onda não-linear que, eventualmente deveria ser linearizado.

Os modelos para tratamento da turbulência seguiram seu desenvolvimento baseado em linearizações até que em 1993 Béchara et al. [6] apresentaram o modelo estocástico de geração e propagação de ruído (SNGR) onde termos analíticos obtidos à partir de informações do campo turbulento representavam as fontes geradoras de som. Os modelos SNGR são baseados em duas idéias principais: Primeiro, o operador exato de propagação de onda é dado pela equação de Euler linearizada (LEE); Segundo, uma vez que a solução do campo turbulento é obtida a partir da equação de Navier-Stokes com média de Reynolds (RANS), o SNGR deve depender de um modelo de turbulência para derivar o campo de velocidade turbulenta a partir do campo médio local, procedimento que é realizado a partir da soma de modos aleatórios de Fourier. Na sua primeira formulação, o modelo de propagação tinha simetria radial, resultando que as fontes eram completamente correlacionadas com a direção azimutal mas isso foi modificado em outras simulações. A LEE foi utilizada no método SNGR como responsável pela propagação sonora, mas não foi só esse o papel que ela desempenhou. Como a simulação numérica direta para altos números de Reynolds em domínios extensos tornava-se (e ainda é) impraticável e resolver a equação de Navier-Stokes com simulação de grandes turbilhões (LES) também exigia grande esforço computacional, especialmente em 3D, Mankbadi em 1998 [44] com a intenção de reduzir o custo computacional, considerou que as hipóteses das equações de estabilidade de onda pudessem ser introduzidas na LEE. Com essa abordagem, ele utilizou-se da LEE para obter as fontes sonoras de um jato, sugerindo que o campo de propagação fosse determinado por analogias acústicas ou expansões assintóticas combinadas.

Em 1999, Bailly \& Juvé [10], utilizaram-se da LEE na mesma abordagem de Béchara. Primeiro o campo médio foi resolvido com RANS utilizando um modelo de turbulência $k-\epsilon$, onde $k$ é a energia cinética e $\epsilon$ a taxa de dissipação de energia turbulenta. Em seguida calcularam o campo de velocidade turbulenta e depois introduziram esse resul- 
tado como um termo fonte na LEE que deveria propagar as perturbações através de um campo de escoamento previamente calculado. A diferença é que o termo fonte não mais possuía simetria radial e o sistema de equações formado era equivalente à equação de Lilley [40] para o escoamento médio cisalhante. Em 2000, [13], estes mesmos autores utilizaram fontes puramente analíticas e realizaram as simulações apresentadas neste trabalho além de um problema típico de ruído de jato. Os autores introduziram termos não lineares da equação de Euler na LEE para controlar as instabilidades que surgiram, já que uma limitação da LEE é permitir que ondas de instabilidade não triviais sejam solução da equação homogênea e essas soluções espúrias crescem comprometendo a estabilidade do método. Esse mesmo problema foi anteriormente enfrentado no âmbito das previsões analíticas do som irradiado usando a analogia acústica de Lilley [43]. Várias técnicas foram propostas para superar esse problema, Bogey et al. [45] modificaram a LEE suprimindo os termos que envolviam os gradientes do fluxo médio. Ewert et al. [46] realizaram a projeção dos termos fonte originários das não linearidades para eliminar qualquer excitação da solução homogênea, ou Bilson et al. em 2002 [11] que baseado no trabalho de Béchara [6], que utilizaram a dissipação artificial para proteger a simulação de ondas espúrias. A dissipação artificial ou amortecimento tem sido um método largamente utilizado para controlar a estabilidade numérica.

Independente da abordagem utilizada, Tam [47] chama a atenção que a solução da equação discretizada não é a mesma da equação original pois invariavelmente, um sistema discretizado se comporta de forma dispersiva, enquanto que as ondas sonoras suportadas pelas equações diferenciais parciais são não dispersivas. Por isso no âmbito de estudos de acústica, um esforço deve ser dedicado a esse fato no sentido de quantificar e minimizar os erros gerados por essa diferença.

Em ferramentas de CFD, a análise de erro e também uma forma de avaliar a qualidade do método, é feita considerando a ordem em que série de Taylor é truncada. Isso implica que, a quarta ordem é mais precisa que a segunda, mas esse método é qualitativo e não quantitativo. Não há uma forma de determinar através dessa análise quantos pontos por comprimento de onda são necessários para obter determinada precisão. Por isso, a análise de número de onda através da transformada de Fourier-Laplace forma uma ferramenta de análise de erro eficiente em acústica computacional. Esse é o único procedimento exclusivo da CAA uma vez que não possui contraparte em CFD. Ele não só pode mostrar o erro produzido pela discretização mas também oferece várias possibilidades de estudo para desenvolver esquemas computacionais otimizadas. Com o uso dessa ferramenta pode-se mostrar que a ordem do esquema não é importante, mas sim, qual a largura da 
banda no espaço dos comprimentos de onda que o método numérico é capaz de resolver.

A análise de Fourier [48] permite analisar o comportamento das equações discretizadas tanto no tempo quanto no espaço. Sabe-se que discretização em diferenças finitas produz dissipação além de dispersão, e analisando essa discretização espacial através da transformada de Fourier, concluiu-se que a solução tem duas naturezas, ela é dispersiva ou é instável [47]. Dessa forma para ter um sistema não dispersivo uma condição de estabilidade upwind precisa ser imposta e apenas um stencil ${ }^{1}$ assimétrico satisfaz a condição de estabilidade. Como as equações de Euler suportam ondas de vorticidade, entropia e acústicas, a condição de upwind precisa satisfazer cada uma dessas ondas para a solução se manter estável. A conclusão é que a derivada espacial da equação de Euler representa termos de propagação e não de amortecimento. Para tratar essa característica da equação na sua forma discretizada, propagando as ondas de interesse e amortecendo as demais, uma família de esquemas especiais de amortecimento seletivo foi criada [49]. Esse procedimento introduz termos dissipativos na equação que vão amortecer os componentes indesejados e terão pouca interferência na solução de interesse. Uma estratégia alternativa são filtros aplicados à solução após um ou mais passos de tempo [50] que produzem resultados semelhantes.

O uso da análise de Fourier mostrou que a discretização temporal também produz amortecimento. Isso pode ser verificado discretizando a parte espacial e resolvendo a parte temporal com métodos de Fourier. Com as integrais de Fourier avaliadas pelo método dos resíduos encontra-se que a taxa de amortecimento no tempo é proporcional ao passo de tempo. Como esse amortecimento neste caso é indesejado, uma simples forma de controlá-lo é reduzir o passo de tempo, técnica que apresenta bons resultados em vários métodos, incluindo os do tipo Runge-Kutta [47].

Como a precisão da discretização está atrelada ao tamanho característico da malha, pode-se supor que comprimentos de onda menores que dois espaços na malha não sejam bem representados. Entretanto resta saber quantos pontos são necessários para representar adequadamente um comprimento de onda. Os métodos de CFD padrão quando utilizados em acústica, exigiam de 18 a 25 pontos. Esse também foi um dos motivos que impulsionara a comunidade acadêmica a elaborar métodos mais adequados para a aeroacústica. Os algoritmos evoluíram e hoje chegam a resolver comprimentos de ondas

\footnotetext{
${ }^{1} \mathrm{O}$ termo stencil é usado no contexto de diferenças finitas para indicar os pontos da malha que serão considerados para a discretização da derivada, por exemplo, um stencil de 5 pontos em duas dimensões significa que ao redor do ponto $(i, j)$, devemos considerar os pontos $(i+1, j)$, $(i-1, j),(i, j+1)$ e $(i, j-1)$.
} 
utilizando entre 6 e 8 pontos. Há métodos que utilizam 15 pontos por stencil e podem resolver um comprimento de onda com apenas 4 pontos, essa é uma das vantagens do método de diferenças finitas compacto, iniciado por Lele [51], ou aqueles que envolvem a relação de preservação e dispersão (DRP) iniciados por Tam \& Webb [52].

A necessidade de reduzir o número de pontos para melhor representar um comprimento de onda levou ao desenvolvimento de novos métodos. Esses métodos buscavam representar a discretização da derivada com a menor quantidade possível de pontos por comprimento de onda. Para isso buscou-se utilizar funções de alta ordem e a base dessa abordagem é simples - funções de alta ordem carregam maior quantidade de informação e por isso a aproximação será mais precisa do que as de baixa order, que carregam menos informações.Então os métodos que usam grande número de pontos para aproximar a derivada geralmente produzem melhores estimativas que aqueles que utilizam 2 ou 3 (Renaut [53]). Esse conceito, aplicado localmente, introduziu os métodos de elementos finitos de alta ordem. Esses métodos se desenvolveram paralelamente ao desenvolvimento de novas abordagens em diferenças finitas, e foram também utilizados no campo da acústica onde encontraram problemas numéricos semelhantes. Hu \& Atkins, em 2001 [54], estudando a propagação de onda pela equação de Euler linearizada (LEE) com discretização do tipo Galerkin descontínuo (DG), afirma que para cada onda física há pelo menos dois modos de propagação espacial, um deles pode representar a onda física com precisão e o segundo representa ondas espúrias. Esses modos em geral possuem direção oposta e o modo espúrio tem uma alta taxa de amortecimento. Em 2006, Thompson [55] discutiu que os maiores desafios de elementos finitos no campo da acústica são: o efetivo tratamento da propagação acústica em um domínio ilimitado, incluindo condições de fronteira, elementos infinitos e camadas de absorção; os erros de dispersão numérica que crescem na aproximação de ondas curtas e o seu tratamento exige grade esforço computacional; eficientes métodos para resolução de sistemas algébricos para os complexos sistema de matrizes (não Hermitianas).

Não há uma palavra final no sentido sobre qual esquema de discretização apresenta melhores resultados. O que existem são métodos com características distintas que favorecem ou dificultam a resolução de determinados tipos de problemas, por isso deve-se levar em conta sempre qual aspecto deve ser priorizado no estudo. Por exemplo, Crivellini em 2003 [56], obteve resultados precisos para a propagação de onda em 3D com método DG utilizando 10 processadores em paralelo. Wilcox em 2010 [57], resolveu vários problemas de propagação de onda no meio elástico-acústico. Ele mostrou que o uso de elementos de alta ordem controlam a dispersão numérica permitindo a pro- 
pagação por vários comprimentos de onda e mostra uma importante característica da escalabilidade da implementação paralela do método DG. Aspecto que aparenta ser um dos mais fortes nesse tipo de discretização, pois ela exige maior esforço computacional. Isso pode ser comprovado com o trabalho de Nogueira et al. em 2000 [58] que, apesar de não ser em acústica, compara dois métodos de alta ordem. O primeiro é uma técnica de interpolação meshfree (isto é, o método de Movimento de Mínimos Quadrados) em combinação com a discretização de volumes finitos (FV-MLS), e o segundo é o método DG. Eles resolveram a equação de Euler e de Navier-Stokes verificando uma boa taxa de convergência para ambos os métodos. Além disso, os resultados para o método FV-MLS tiveram uma precisão tão boa ou melhor do que as soluções do método DG, pelo menos, com a utilização de elementos polinomiais de terceira ordem e a mesma resolução de malha. Neste caso, o método FV-MLS de quarta ordem requer certo número de graus de liberdade, que é aproximadamente 1,78 vezes menor do que o método DG para as equações de Euler, e para a equação de Navier-Stokes, o número de graus de liberdade para DG é aumentado mais de quatro vezes.

Estes trabalhos mostram que o método DG pode ser uma ferramenta eficiente para realizar simulações numéricas em problemas de propagação acústica. Levando em conta as vantagens e as desvantagens do método, optamos por utilizá-lo para desenvolver o código computacional utilizado neste trabalho, pois entendemos que o método DG é promissor para a solução de problemas desse tipo no domínio do tempo.

\subsection{Objetivos e motivação}

Este trabalho se propõe a desenvolver e validar um método numérico para a propagação de informação acústica em um domínio $2 \mathrm{D}$ discretizado com malhas estruturadas ou não, formada por triângulos e/ou quadriláteros. Ele será realizado através da solução numérica da equação de Euler linearizada (LEE) adotando a hipótese de que as ondas sonoras representam pequenas perturbações de pressão na equação da onda e com isso a parte linear prevalece e o erro da linearização torna-se desprezível. Além disso, motivados pela abordagem proposta em Mahona [8], estamos interessados em estudar os fenômenos de propagação acústica na região intermediária (campo médio), região II da figura (1.1) que é localizada imediatamente após o campo próximo onde, pela sugestão desse mesmo autor, a LEE é o método mais adequado para se estudar os fenômenos de propagação. Nossa decisão também é motivada pensando em trabalhos futuros que será acoplar a solução do campo próximo, resolvido com DNS, ao campo de propagação que 
será aqui desenvolvido e validado.

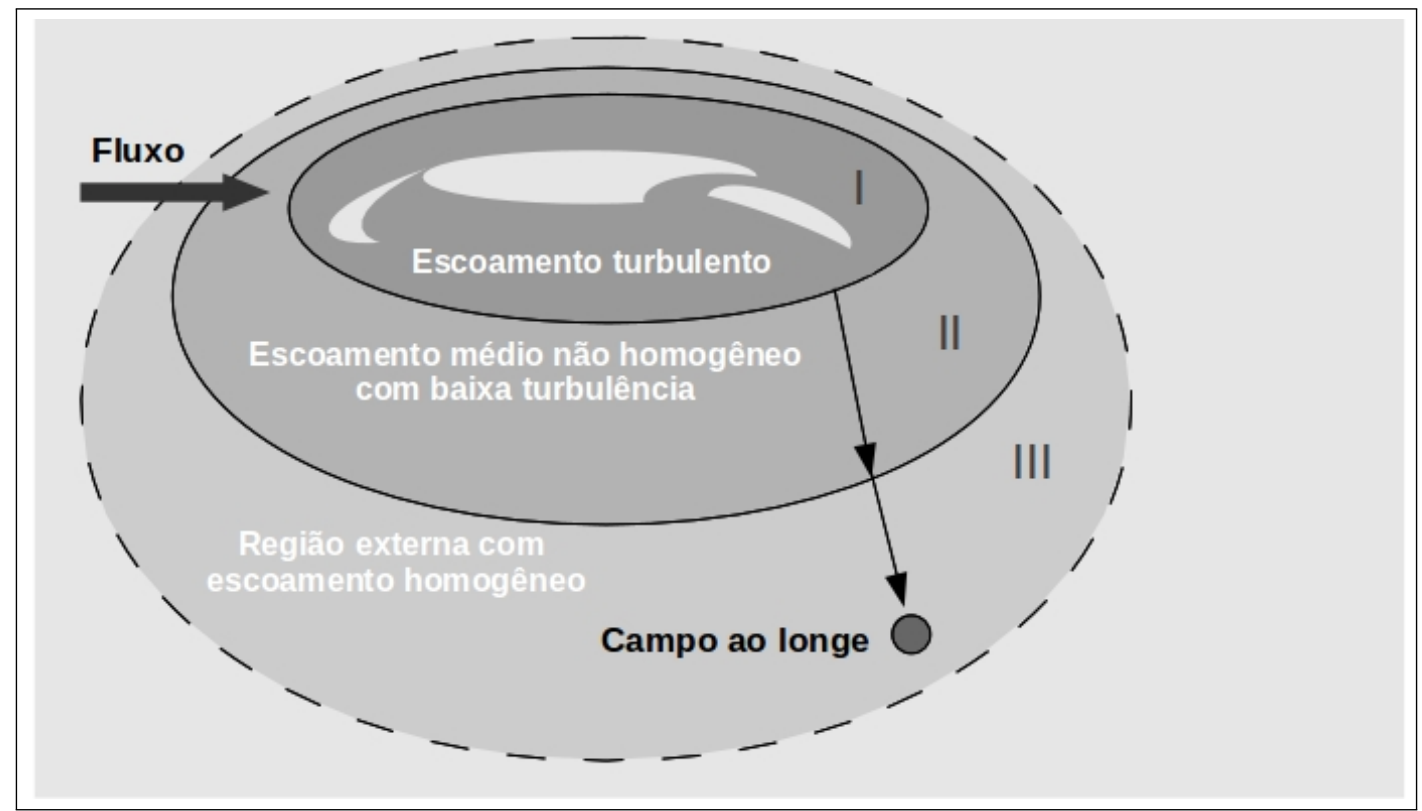

Figura 1.1: Estratégia híbrida, E.Mahona - 2004.

Como explica Colonius \& Lele [5], os métodos numéricos para problemas de geração e propagação sonoras devem superar uma série de dificuldades que surgem devido à baixa energia das ondas acústicas quando comparadas com as flutuações de energia do campo turbulento. Também por causa da impedância acústica do meio em que se propagam, as ondas sonoras devem sofrer uma pequena atenuação em longas distâncias e isso exige que a dissipação numérica seja controlada. Essas necessidades levam ao uso de métodos numéricos com alta ordem de precisão. Com o rápido desenvolvimento de códigos de CAA, surge a necessidade de validação e comparação não apenas da precisão do método mas também do esforço computacional exigido para resolver um mesmo problema uma vez que a escolha do método é importante na eficiência computacional. Além disso, esses autores argumentam que os fatores que determinam a escolha do método computacional são a facilidade de implementação (em especial das condições de contorno), a eficiência em paralelização e a exigência de memória. Diante deste cenário, a formulação Galerkin Descontínuo (DG) foi escolhida como método de discretização espacial e será utilizada através da implementação já existente no software Nektar++. Esse software possui um núcleo que resolve problemas de escoamento compressível invíscido com discretização de alta ordem e foi gentilmente cedido pelo grupo de pesquisa da Universidade de Utah e 
Imperial College liderado pelo professor Spencer Sherwim. O grupo desenvolvedor ainda não utilizou o software em investigações aeroacústicas e esse é mais um dos motivos para a escolha desta ferramenta.

A formulação DG trabalha consistentemente com as necessidades da CAA pois possibilita o refinamento de malha (refinamento $h$ ) juntamente com o aumento da ordem polinomial de aproximação (refinamento $p$ ) e essas técnicas juntas formam a técnica conhecida na literatura como refinamento $h p$ que alcança a convergência numérica exponencial para problemas lineares [9]. Outra característica é a facilidade de paralelização oriunda do caráter descontínuo do método que pode facilmente desconectar fronteiras adjacentes uma vez que a condição de vínculo entre as fronteiras é imposta pelas variáveis de fluxo e não pelos coeficientes dos polinômios, como acontece em outros Métodos de Elementos Finitos (FEM). Outro aspecto importante da formulação DG é a sua baixa sensibilidade em relação à malha pois as diferentes geometrias são mapeadas através de transformações polimórficas de espaço em um elemento padrão, no caso $2 \mathrm{D}$ um quadrado de dimensões $[x, y] \in[-1 ; 1]$, com uma base de expansão do tipo modal com polinômios de Legendre (Apêndice D) que garantem que o número de condicionamento da matriz de massa do problema seja $\kappa_{2}=2 P+1$, onde $P$ é a ordem do polinômio. A desvantagem da formulação DG é que o aumento do número de incógnitas (ou graus de liberdade) por elemento em relação à ordem polinomial é de ordem quadrática em 2D e de ordem cúbica em $3 \mathrm{D}$, com isso, aumentando a ordem dos polinômios com o refinamento $p$ a convergência do erro é exponencial mas o aumento do esforço computacional segue a mesma tendência.

A acoplagem da fonte sonora ao domínio de propagação onde se utiliza a LEE, é realizada através da introdução de um termo fonte na LEE e as primeiras simulações nesse sentido foram realizadas por Bechara [6] e por Bailly [10]. Este último utiliza a LEE com variáveis primitivas mas outra abordagem proposta por Billson [11] utiliza a LEE em variáveis conservadas. Neste trabalho serão apresentados os dois sistemas de LEE mas as simulações foram realizadas com as LEE em variáveis primitivas pois a complexidade da equação de conservação de energia em variáveis conservadas aumenta o custo computacional.

Foram utilizadas dois tipos de fontes sonoras acopladas à LEE. A do primeiro tipo é uma fonte sonora fictícia sem significado físico proveniente de uma solução analítica da LEE criada com o intuito de validar a implementação, as do segundo tipo são fontes sonoras provenientes de modelos semi-empíricos conhecidos da literatura que simulam: pulso gaussiana (Blom [12]); monopolo, dipolo e quadripolo (Bailly [13]); que possuem 
solução analítica porém na forma de equações integrais baseadas na função de Green (Rienstra [14]) onde a solução é obtida para pontos discretos do domínio e essas soluções também foram utilizadas para validar a implementação.

Outro aspecto importante de problemas de aeroacústica está relacionado com as condições de contorno que envolve simular paredes sólidas, espaço livre e condições de entrada e saída. Para as condições de entrada e saída, devemos simular fronteiras que não produzam reflexão acústica. Além disso, no escoamento subsônico essas condições devem permitir a propagação de ondas que se propagam tanto à jusante quanto à montante. Existem diferentes abordagens para a implementação de fronteiras não reflexivas, algumas baseadas nas propriedades físicas do problema, como por exemplos a fronteira de radiação e outras baseadas em técnicas numéricas como a dissipação artificial na região da fronteira. No cronograma desse trabalho esperávamos implementar a fronteira de radiação mas não obtemos êxito nesta tarefa e para realizar a validação e evitar que a reflexão das ondas sonoras contaminassem a solução utilizamos um domínio relativamente extenso de forma que os fenômenos de propagação foram analisados antes das ondas atingirem as fronteiras computacionais.

Este trabalho está divido em três partes. Na primeira (seção 2), é apresentada a formulação teórica das equações de Navier-Stokes, de Euler linearizada e as condições de contorno que modelam os fenômenos tratados juntamente com um estudo da magnitude das quantidades envolvidas para justificar a linearização. Na segunda (seção 3), é apresentada a formulação numérica do método DG e os tratamentos dados aos termos convectivos e na terceira parte (seções 4 e 5), os resultados, onde apresentamos a validação do método, a convergência do erro para o refinamento $p$ e $h p$ e a propagação de um pulso gaussiana, monopolo em escoamento subsônico e supersônico, dipolo e quadripolo, assim como as conclusões e sugestões para trabalhos futuros. 


\section{Fundamentos teóricos}

\subsection{Escoamento Compressível}

Escoamentos compressíveis estão presentes em diversos dispositivos e equipamentos da engenharia, tais como turbinas a gás e a vapor, câmaras de combustão e linhas de transmissão de gás natural. Um escoamento é dito compressível quando a massa específica do fluido, $\rho$, é variável. Em tais escoamentos ocorrem transformações de energia e mudanças de temperatura que influem significativamente na dinâmica do escoamento e, por esse motivo, a Termodinâmica não pode ser dissociada da Mecânica dos Fluidos, ao contrário do que ocorre em escoamentos incompressíveis.

Na prática, é usual considerar compressível o escoamento em que o número de Mach da corrente livre $\left(M=U_{\infty} / c_{0}\right)$ é maior que 0,3 , onde $U_{\infty}$ é a velocidade de corrente e $c_{0}$ a velocidade do som no meio. Essa regra prática é baseada no fato de que para um escoamento isentrópico, se o fluido é acelerado do repouso até $M=0,3$, a massa específica muda menos que $5 \%$ [15]. De acordo com o valor do número de Mach, podemos classificar o escoamento em três categorias:

- Escoamento subsônico ( $M<1$ em todo o domínio): Neste escoamento as perturbações se propagam tanto a jusante quanto à montante.

- Escoamento transônico (regiões mistas onde $M<1$ e $M>1$ ): Se o número de Mach da corrente livre for próximo de 1, o escoamento pode se tornar localmente supersônico, permitindo que ondas de choque apareçam no escoamento. Neste caso tanto as características físicas de escoamentos subsônicos quanto as do supersônicos estão presentes, tornando o tratamento de escoamentos transônicos bastante difícil do ponto de vista computacional.

- Escoamento supersônico ( $M>1$ em todo o domínio de interesse): Neste caso, a velocidade do escoamento é maior do que a velocidade do som em todos os pontos. Sendo assim, as perturbações não se propagam à montante. Esse fato faz com que ondas de choque e de expansão apareçam neste tipo de escoamento.

- Escoamento hipersônico $(M \gg 1)$ : Se o número de Mach é suficientemente alto, as ondas de choque ficam próximas da superfície do corpo e interagem com a camada limite viscosa. Nessa região, as temperaturas aumentam significativamente a ponto de fazer com que reações químicas ocorram no fluido. 


\subsection{Grandezas envolvidas}

O escoamento de fluidos em geral é modelado pelas equações de Navier-Stokes que descrevem com precisão inclusive problemas acústicos. Porém, existem dificuldades importantes no uso dessas equações neste tipo de problema, conforme já foi discutido na seção 2.1. Estamos interessados na propagação do som no ar onde os coeficientes de viscosidade e a condutividade térmica são pequenos e seus efeitos podem ser desprezados pois as perturbações das quantidades físicas do fluido são pequenas e seus gradientes são menores que as próprias perturbações (Goldestein [16]). Sob essas hipóteses as equações de Navier-Stokes se reduzem às equações de Euler. A equação de Euler em duas ou em três dimensões podem ser escritas, na sua forma conservativa (também chamada de forma conservativa forte por alguns autores), da seguinte maneira:

$$
\begin{gathered}
\frac{\partial \rho}{\partial t}+\frac{\partial \rho u_{j}}{\partial x_{j}}=S_{m} \\
\frac{\partial \rho u_{i}}{\partial t}+\frac{\partial}{\partial x_{j}}\left(\rho u_{i} u_{j}+p \delta_{i j}\right)=S_{i} \\
\frac{\partial \rho e_{0}}{\partial t}+\frac{\partial}{\partial x_{j}}\left(\rho h_{0} u_{j}\right)=S_{e}
\end{gathered}
$$

onde $\rho$ representa a massa específica, $u_{i}$ a velocidade na direção $i, p$ a pressão, $e_{0}$ a energia específica e $h_{0}=e_{0}+p$ a entalpia específica. $S_{m}, S_{i}$ e $S_{e}$ representam as fontes de massa, quantidade de movimento e energia respectivmente. Para fenômenos não relativísticos onde a massa é conservada temos $S_{m}=0$ mas esse termo pode ser usado para representar processos complexos como por exemplo a ação de uma esfera pulsante (Rienstra [14]). Os termos $S_{i}$ representam o campo de forças externas e $S_{e}$ representa o trabalho executado pelo campo de forças externas ou fontes de calor.

O sistema de equações descrito acima não está determinado pois em 2 dimensões possui 4 equações e 5 variáveis que são, $\rho, u, v, p$ e $e_{0}$. Em problema aerodinâmicos podemos desprezar as forças intermoleculares e assumindo a teoria dos gases perfeitos com calores específicos constantes, escrevemos a equação de estado:

$$
p=\rho R T=(\gamma-1) \rho e_{i},
$$

onde $T$ é a temperatura, $\gamma$ é a razão entre calores específicos, $R=c_{p}-c_{v}$ é a constante 
do gás e $e_{i}$ a energia interna dada por:

$$
e_{i}=C_{v} T
$$

e neste caso a relação de calores específicos é constante:

$$
\gamma=\frac{C_{p}}{c_{v}}=\text { constante. }
$$

Finalizando, a energia específica total definida pela soma da energia interna e a energia cinética é dada por:

$$
E=\rho\left[e_{i}+\frac{1}{2} \mathbf{v}^{2}\right]
$$

Utilizamos as equações (2.2) e (2.5) para reescrever a equação de estado e obter dessa forma um sistema consistente com 6 equações e 6 incógnitas:

$$
p=\left[E-\frac{1}{2} \rho \mathbf{v}^{2}\right](\gamma-1) .
$$

A equação de Euler (2.1) não é linear. Por isso vamos então estudar as ordens de grandeza dos problemas de propagação acústica para justificar como a LEE representa de forma adequada esses fenômenos. Como definido no início, o som é uma perturbação de pressão $p^{\prime}$ que se propaga como uma onda com velocidade característica do meio. No ar a $20^{\circ} \mathrm{C}$ sua velocidade é $344 \mathrm{~m} / \mathrm{s}$ enquanto que na água o valor típico é de $1500 \mathrm{~m} / \mathrm{s}$. O ouvido humano é capaz de captar sons com freqüências entre $20 \mathrm{~Hz}$ e $20 \mathrm{kHz}$ e a sensibilidade máxima é em torno de freqüências de $3 \mathrm{kHz}$. O som também envolve uma grande faixa de potência indo de $10^{-5} \mathrm{~W}$ quando sussurramos atingindo $10^{5} \mathrm{~W}$ para um avião a jato em operação de pouso (Riestra [14]). Por causa desta gama de potências e também porque o ouvido humano tem a sensibilidade quase logarítmica, usa-se o decibel (dB) para medir o nível de potência sonora (PWL) de uma fonte de potência $P$ em Watts:

$$
\mathrm{PWL}=10 \log _{10}\left(\frac{P}{P_{0}}\right)
$$

onde $P_{0}=10^{-12}$ Watts corresponde à potência de referência do silêncio absoluto. E como o som é uma perturbação na pressão, podemos medir essa quantidade com o nível de pressão sonora (SPL) definido por:

$$
\mathrm{SPL}=20 \log _{10}\left(\frac{p_{r m s}^{\prime}}{p_{0}}\right),
$$


onde $p_{r m s}^{\prime}$ é a média da raiz quadrada da flutuação e $p_{0}=2 \times 10^{-5} \mathrm{~Pa}$ a pressão de referência que equivale a $20 \mathrm{~dB}$ para o ar e corresponde ao limiar da audição para a freqüência $1 \mathrm{kHz}$. Por outro lado, $p_{r m s}=2 \times 10^{2} \mathrm{~Pa}$ que equivale a $140 \mathrm{~dB}$, é o limite que o ouvido humano pode suportar por curtos intervalos de tempo sem o risco de dano permanente (Rienstra [14]).

Se desprezarmos os termos fontes na equação de Euler (2.1) e assumirmos que não há choques no escoamento, as equações em questão representam um sistema isentrópico reversível, lembrando da primeira lei da termodinâmica para gases perfeitos, $d q=c_{v} d T+$ $p d v=0$, e considerando um processo adiabático $d q=0$ obtemos:

$$
\begin{aligned}
c_{v} d T & =-p d\left(\frac{1}{\rho}\right) \\
d T & =\frac{p}{c_{v} \rho^{2}} d p .
\end{aligned}
$$

Tomando a derivada implícita da equação de estado (2.2) temos:

$$
d p=R T d \rho+\rho R d T
$$

Lembrando que $R=c_{p}-c_{v}, \gamma=\frac{c_{p}}{c_{v}}$ e utilizando a relação (2.7), podemos escrever

$$
\begin{aligned}
d p & =\frac{p}{\rho} d \rho+\rho R \frac{p}{c_{v} \rho^{2}} d \rho, \\
d p & =\frac{p}{\rho} d \rho+(\gamma-1) \frac{p}{\rho} d \rho, \\
d p & =\gamma \frac{p}{\rho} d \rho,
\end{aligned}
$$

obtendo a equação diferencial

$$
\frac{d p}{d \rho}=\gamma \frac{p}{\rho}
$$

e com ela temos condições de comparar a pressão relativa dos fenômenos de interesse. Vamos considerar a pressão atmosférica $p_{0}=10^{5} \mathrm{~Pa}$ e uma potência sonora de $140 \mathrm{~dB}$. Com isso, as flutuações relativas da massa específica e da pressão são dadas por:

$$
\frac{\rho^{\prime}}{\rho_{0}} \approx \frac{p^{\prime}}{\gamma p_{0}}<1,35 \times 10^{-3}
$$

Dessa forma, se adotarmos a linearização quando a perturbação máxima não exceda 
$10 \%$, teremos:

$$
\begin{array}{r}
p_{\max }^{\prime}=0,1 p_{0}=10^{4} \mathrm{~Pa}, \\
\rho_{\text {max }}^{\prime}=\frac{0.1}{\gamma} \rho_{0} \Rightarrow \frac{\rho^{\prime}}{\rho_{0}}=0,071, \\
\mathrm{SPL}_{\max }=174 \mathrm{~dB} .
\end{array}
$$

E este exemplo demonstra que, mesmo para altos níveis de pressão sonora, as perturbações relativas de pressão são pequenas o suficiente para obtermos boas aproximações com a linearização.

\subsection{Aeroacústica}

A propagação do som em um meio contínuo ocorre através de uma onda que percorre o meio com uma velocidade característica. Nesta onda, a pressão representa um campo de tensões muito maior do que o campo de tensões produzido pela viscosidade. A razão entre estes dois campos é o número de Reynolds acústico definido por $R e=2 \pi c_{0} \lambda / \nu=\omega \lambda^{2} / \nu$, onde $c_{0}$ é a velocidade do som no meio, $\nu$ é a viscosidade cinemática, $\lambda$ o comprimento de onda e $\omega$ a velocidade angular da onda. Em problemas de acústica, o número de Reynolds é da ordem de $10^{8}$ para as freqüências audíveis e por essa razão trata-se o som como uma onda em um meio essencialmente invíscido muito embora as fontes sonoras sejam provenientes da turbulência gerada pela viscosidade. A equação de propagação do som em um meio em repouso em uma dimensão é dada porras sejam provenientes da turbulência gerada pela viscosidade. A equação de propagação do som em um meio em repouso em uma dimensão é dada por [25]

$$
\frac{\partial^{2} \rho^{\prime}}{\partial t^{2}}-\frac{\partial^{2} p^{\prime}}{\partial x^{2}}=0
$$

Portanto o som é uma perturbação na qual a pressão $p$ pode ser determinada através do conhecimento da massa específica, $p=p(\rho)$. Em outras palavras é uma onda isentrópica e para uma entropia $S$ constante temos a relação:

$$
\left.\frac{\partial p}{\partial \rho}\right|_{S} \equiv c_{0}^{2}
$$


e podemos reescrever a equação (2.9) como

$$
\frac{\partial^{2} p^{\prime}}{\partial t^{2}}-c_{0}^{2} \frac{\partial^{2} p^{\prime}}{\partial x^{2}}=0
$$

obtendo a equação de uma onda sonora que se movimenta com velocidade $c_{0}$. A solução dessa equação é a solução de d'Alambert que consiste em funções arbitrárias $f\left(x-c_{0} t\right)$ e $g\left(x+c_{0} t\right)$ que representam as ondas viajando na direção positiva e negativa do eixo $x$.

Para estudar a geração e propagação do som devemos considerar que as fontes sonoras são não homogeneidades na equação de onda. Estamos interessados nas fontes sonoras geradas por efeitos aerodinâmicos derivadas de flutuações nas características físicas do escoamento que são grandes o suficiente a ponto de invalidar a linearização feita nas deduções da teoria acústica. Nesse caso, para conciliar o modelo linear, necessário para os fenômenos de propagação, com o modelo não linear, necessário para representar as fontes sonoras, é usual agrupar os termos não-lineares do lado direito da equação o que equivale a interpretar as não linearidades como fontes sonoras que são irradiadas para o campo de propagação.

As bases teóricas desse procedimento foram apresentadas pela primeira vez por Lighthill em 1952 no seu trabalho On Sound Generated Aerodynamically, I - General Theory e desde então é a principal fonte de referência para estudos de aeroacústica. Lighthill mostrou como o som aerodinâmico pode ser compreendido como uma analogia acústica no qual a turbulência proporciona uma distribuição de tipo quadripolo no meio homogêneo que não possui superfícies sólidas. Considerando a presença de superfícies sólidas, Curle em 1955 [26] estendeu a analogia de Lighthill usando superfícies de controle de Kirchhoff para mostrar que elas são equivalentes a distribuições do tipo dipolo. Dez anos depois, Lowson [27] apresentou um modelo sem provas matemáticas onde as superfícies aerodinâmicas móveis podem ser modeladas como multipolos pontuais, mas em 1969, Ffowcs Willians-Hawkings utilizando a teoria de funções generalizadas, publicaram o trabalho Sound generation by turbulence and surfaces in arbitrary motion que ficou conhecido como analogia (ou equação) de Ffowcs Willians-Hawkings (FWH) onde apresentam uma equação de onda não homogênea com fontes sonoras do tipo quadripolo, dipolo e monopolo, onde o quadripolo é o mesmo obtido por Lighthill e proveniente da turbulência, o dipolo e o monopolo são as contribuições das superfícies sólidas provenientes da carga e da espessura da superfície respectivamente. A seguir reproduzimos essa analogia seguindo a idéia original [28], pois o mesmo resultado pode ser obtido com a substituição direta de $\psi H(f)$, onde $H$ é a função de Heaviside, na equação de onda 
(2.10) e desse modo pode ser compreendido como uma extensão da integral de Kirchhoff (Rienstra [14]).

Como a teoria do som aerodinâmico é construída sobre as equações de conservação de massa e de momento dos fluidos compressíveis que são válidas para o domínio infinito, podemos considerar uma superfície fechada arbitrária que contenha as fontes sonoras (não homogeneidades da equação de onda), e mesmo assim os princípios da conservação de massa e de momento são válidos no exterior dessa superfície. Dessa forma o domínio infinito é particionado em superfícies matemáticas onde o fluxo do escoamento através e para fora delas é definido para ser idêntico ao fluxo real, enquanto que no seu interior pode ser definido de forma arbitrária. As descontinuidades introduzidas são tratadas sem maiores dificuldades com o uso de funções generalizadas e a partir da técnica utilizada por Lighthill, possibilita obter novas equações de conservação de massa e momento. Consideremos então um volume fixo $\Omega$ limitado pela superfície $\Gamma$. A região $\Omega$ é dividida nas regiões $\Omega_{1}$ e $\Omega_{2}$ que são limitadas pela descontinuidade $\Gamma_{12}$ que se move com velocidade $\mathbf{v}$. Sejam $\mathbf{l}$ e $\mathbf{n}$ os vetores normais de $\Gamma$ e $\Gamma_{12}$ respectivamente, figura (2.1). Vamos

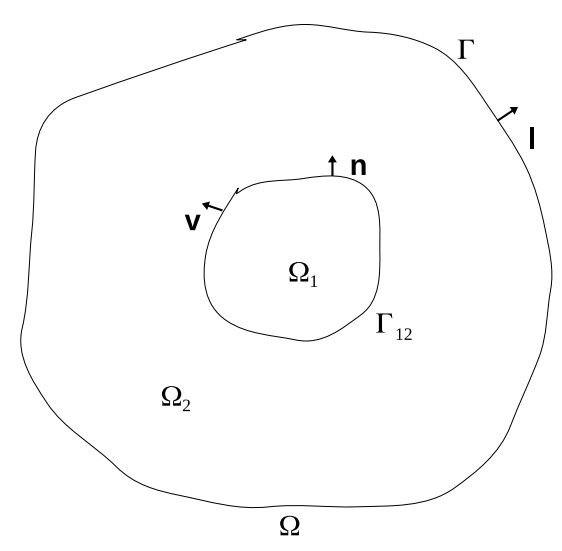

Figura 2.1: Particionamento do domínio matemático para a analogia de Ffowcs Willians-Hawkings

considerar que uma função $f$ define a superfície $\Gamma$ de forma que $f<0$ no seu interior, $f>0$ no seu exterior e $f=0$ sobre $\Gamma$ e com isso definir a massa específica $\bar{\rho}$ no sentido de um função generalizada (o mesmo se aplicará a todas as funções escritas com uma barra horizontal):

$$
\bar{\rho}=\left\{\begin{array}{lll}
\rho_{1} & \text { se } & f>0 \\
\rho_{2} & \text { se } & f<0
\end{array},\right.
$$


e com essas hipóteses escrever a taxa de variação de massa em $\Omega$ :

$$
\frac{\partial}{\partial t} \int_{\Omega} \bar{\rho} d \Omega=\frac{\partial}{\partial t} \int_{\Omega_{1}} \rho_{1} d \Omega_{1}+\frac{\partial}{\partial t} \int_{\Omega_{2}} \rho_{2} d \Omega_{2}
$$

Como as regiões $\Omega_{1}$ e $\Omega_{2}$ possuem uma fronteira comum $\Gamma_{12}$ que se move com velocidade $\mathbf{v}$, devemos escrever a equação de conservação de massa para cada região considerando o fluxo de massa através dessa fronteira:

$$
\begin{gathered}
\frac{\partial}{\partial t} \int_{\Omega_{1}} \rho_{1} d \Omega_{1}=-\int_{\partial \Omega_{1}}\left(\rho u_{j}\right)_{1} l_{j} d \partial \Omega_{1}-\int_{\Gamma_{12}} \rho_{1}\left(u_{j}-v_{j}\right)_{1} n_{j} d \Gamma_{12}, \\
\frac{\partial}{\partial t} \int_{\Omega_{2}} \rho_{2} d \Omega_{2}=-\int_{\partial \Omega_{2}}\left(\rho u_{j}\right)_{2} l_{j} d \partial \Omega_{2}+\int_{\Gamma_{12}} \rho_{2}\left(u_{j}-v_{j}\right)_{2} n_{j} d \Gamma_{12},
\end{gathered}
$$

substituindo (2.12) e (2.13) em (2.11) obtemos a equação da variação de massa total

$$
\frac{\partial}{\partial t} \int_{\Omega} \bar{\rho} d \Omega+\int_{\Gamma} \overline{\rho u_{j}} l_{j} d \Gamma=\int_{\Gamma_{12}}\left[\rho_{2}\left(u_{j}-v_{j}\right)_{2}-\rho_{1}\left(u_{j}-v_{j}\right)_{1}\right] n_{j} d \Gamma_{12},
$$

e se sobre o segundo membro do lado esquerdo aplicarmos o teorema da divergência teremos a equação de conservação de massa generalizada na forma integral

$$
\int_{\partial \Omega}\left(\frac{\partial}{\partial t} \bar{\rho}+\frac{\partial}{\partial x_{j}} \overline{\rho u_{j}}\right)=\int_{\Gamma_{12}}\left[\rho\left(u_{j}-v_{j}\right)\right]_{1}^{2} n_{j} d \Gamma_{12},
$$

onde

$$
\int_{\Gamma_{12}}\left[\rho\left(u_{j}-v_{j}\right)\right]_{1}^{2} n_{j} d \Gamma_{12}=\int_{\Gamma_{12}}\left[\rho_{2}\left(u_{j}-v_{j}\right)_{2}-\rho_{1}\left(u_{j}-v_{j}\right)_{1}\right] n_{j} d \Gamma_{12} .
$$

Pela característica de $f$, integral de superfície pode ser substituída por uma integral de volume com o integrando substituído por uma função generalizada $\delta(f)\left[\left(\partial f / \partial x_{j}\right)^{2}\right]^{1 / 2}$, e como resultado imediato temos $n_{i}\left[\left(\partial f / \partial x_{j}\right)^{2}\right]^{1 / 2}=\partial f / \partial x_{i}$ e com isso obtemos a equação de conservação de massa generalizada

$$
\frac{\partial \bar{\rho}}{\partial t}+\frac{\partial}{\partial x_{j}} \overline{\rho u_{j}}=\left[\rho\left(u_{j}-v_{j}\right)\right]_{1}^{2} \delta(f) \frac{\partial f}{\partial x_{j}} .
$$

Essa equação implica que sob o aspecto da conservação de massa, para manter o estado de um fluido em um domínio ilimitado é necessário um núcleo de distribuição de massa cuja intensidade é a diferença entre os fluxos de massa exigidos em cada região. O mesma 
análise possibilita obter a equação de conservação de momento generalizada

$$
\frac{\partial \overline{\rho u_{i}}}{\partial t}+\frac{\partial}{\partial x_{j}}\left(\overline{\rho u_{i} u_{j}}+\bar{p}_{i j}\right)=\left[p_{i j}+\rho u_{i}\left(u_{j}-v_{j}\right)\right]_{1}^{2} \delta(f) \frac{\partial f}{\partial x_{j}},
$$

onde

$$
p_{i j}=p \delta_{i j}+\tau_{i j} \quad \text { e } \quad \tau_{i j}=\mu\left(\frac{\partial u_{i}}{\partial x_{j}}+\frac{\partial u_{j}}{\partial x_{i}}-\frac{2}{3} \delta_{i j} \frac{\partial u_{k}}{\partial x_{k}}\right)
$$

onde $\mu$ é o coeficiente de viscosidade dinâmica. Essas equações, (2.15) e (2.16), governam o escoamento em domínio ilimitado independentes de descontinuidades, que se não existirem, anulam os termos fontes de forma a obtermos as equações usuais.

Para investigar um campo sonoro arbitrário na presença de descontinuidades vamos tomar $\Omega_{1}$ como a região do fluido correspondente ao volume limitado por $S$ assumindo que o fluido esta em repouso, com densidade $\rho_{0}$, com pressão $p_{0}$ e $p_{i j}=p_{0} \delta_{i j}$ é constante e pode ser interpretado como o tensor de diferenças de tensões a partir de seu valor médio e sob essa condição $p_{i j}=0$ na região interior a $\Omega_{1}$. Substituindo essas hipóteses nas equações (2.12) e (2.16) e desprezando a contribuição da região $\Omega_{2}$ obtemos o sistema:

$$
\begin{aligned}
\frac{\partial \bar{\rho}}{\partial t}+\frac{\partial}{\partial x_{j}} \overline{\rho u_{j}} & =\rho_{0} v_{j} \delta(f) \frac{\partial f}{\partial x_{j}}, \\
\frac{\partial \overline{\rho u_{i}}}{\partial t}+\frac{\partial}{\partial x_{j}}\left(\overline{\rho u_{i} u_{j}}+\bar{p}_{i j}\right) & =p_{i j} \delta(f) \frac{\partial f}{\partial x_{j}} .
\end{aligned}
$$

Subtraindo o divergente de (2.18) da derivada temporal de (2.17)

$$
\frac{\partial^{2} \bar{\rho}}{\partial t^{2}}-\frac{\partial^{2}}{\partial x_{i} \partial x_{j}}\left(\overline{\rho u_{i} u_{j}}+\bar{p}_{i j}\right)=\frac{\partial}{\partial t}\left(\rho_{0} v_{j} \delta(f) \frac{\partial f}{\partial x_{i}}\right)-\frac{\partial}{\partial x_{i}}\left(p_{i j} \delta(f) \frac{\partial f}{\partial x_{j}}\right)
$$

e agora subtraímos

$$
c_{0}^{2} \frac{\partial^{2} \bar{\rho}}{\partial x_{i}^{2}}=c_{0}^{2} \frac{\partial^{2} \bar{\rho}}{\partial x_{i} x_{i}}=\frac{\partial^{2}}{\partial x_{i} x_{j}}\left(c_{0}^{2} \delta_{i j} \bar{\rho}\right)
$$

dos dois lados da equação, lembrando que $p_{i j}=p \delta_{i j}+\tau_{i j}$, podemos escrever

$\frac{\partial^{2} \bar{\rho}}{\partial t^{2}}-c_{0}^{2} \frac{\partial^{2} \bar{\rho}}{\partial x_{i}^{2}}=\frac{\partial^{2}}{\partial x_{i} \partial x_{j}}\left(\overline{\rho u_{i} u_{j}}+\left(\bar{p}-c_{0}^{2} \bar{\rho}\right) \delta_{i j}\right)-\frac{\partial}{\partial x_{i}}\left(p_{i j} \delta(f) \frac{\partial f}{\partial x_{j}}\right)+\frac{\partial}{\partial t}\left(\rho_{0} v_{j} \delta(f) \frac{\partial f}{\partial x_{i}}\right)$,

ou simplesmente

$$
\frac{\partial^{2} \bar{\rho}}{\partial t^{2}}-c_{0}^{2} \frac{\partial^{2} \bar{\rho}}{\partial x_{i}^{2}}=\frac{\partial^{2} \overline{T_{i j}}}{\partial x_{i} \partial x_{j}}-\frac{\partial}{\partial x_{i}}\left(p_{i j} \delta(f) \frac{\partial f}{\partial x_{j}}\right)+\frac{\partial}{\partial t}\left(\rho_{0} v_{j} \delta(f) \frac{\partial f}{\partial x_{i}}\right),
$$


onde $\overline{T_{i j}}=\overline{\rho u_{i} u_{j}}-\tau_{i j}+\left(\bar{p}-c_{0}^{2} \bar{\rho}\right) \delta_{i j}$.

A equação (2.20) mostra que se pode considerar o som como sendo proveniente de 3 fontes distintas. A primeira delas, a função generalizada $\overline{T_{i j}}$ é o conhecido tensor de tensões de Lighthill que tem o valor não nulo fora da superfície $\Gamma$ e é responsável pelas fontes do tipo quadripolo provenientes da turbulência. O segundo termo é uma superfície de distribuição de dipolos com intensidade $p_{i j} n_{j}$ (Curle [26]) e o terceiro termo uma distribuição de monopolos provenientes dos efeitos do descolamento de volume. Temos com essa equação o modelo matemático para representar o ruído aerodinâmico que sabemos ter duas origens principais distintas: o movimento de superfícies sólidas (turbinas ou rotores) ou presença de superfícies sólidas em condições de escoamento turbulento. No primeiro caso, a interação entre o escoamento e a superfície gera flutuações de pressão que são irradiadas como som, dando origem ao que se conhece como ruído impulsivo. Este tipo de ruído é determinístico em casos de deslocamento periódico, como por exemplo em sistemas rotativos, que apresenta componentes tonais dominantes. Estamos interessados no segundo caso onde a natureza do ruído é estocástica e o espectro de freqüências é do tipo banda larga e por isso esse trabalho se propõe a estudar a propagação de fontes sonoras do tipo monopolo, dipolo e quadripolo.

\subsection{Fontes sonoras}

A equação de onda em termos da perturbação de pressão e com uma fonte sonora $\mathbf{S}$ é definida por:

$$
\frac{\partial^{2} p^{\prime}}{\partial t^{2}}-c_{0}^{2} \nabla^{2} p^{\prime}=\mathbf{S}
$$

onde $c_{0}$ é a velocidade do som. Vamos a partir do estudo de $\mathbf{S}$ introduzir o conceito de monopolo, dipolo e quadripolo.

Se a fonte $\mathbf{S}$ estiver concentrada em um ponto do espaço de forma que ela possa ser expressa como $\mathbf{S}=q(t) \delta\left(\mathbf{x}-\mathbf{x}_{\mathbf{0}}\right)$ essa fonte é chamada de monopolo pontual e $q(t)$ é a intensidade da fonte. Um monopolo é multidirecional, ou seja, a intensidade da propagação é a mesma para todos os pontos eqüidistantes da fonte.

Um dipolo orientado na direção de um vetor unitário $\mathbf{n}$ é compreendido como dois monopolos pontuais com intensidade iguais e opostas, separados por distância muito menor que o comprimento de onda e localizados em lados opostos da reta que passa por $\mathbf{x}_{0}$ paralela à $\mathbf{n}$. Como exemplo, seja $\mathbf{n}$ paralelo ao eixo $x$, as fontes pontuais separadas 
pela distância $\epsilon$ e $\mathbf{x}_{0}$ a origem, com isso os dois monopolos são representados por:

$$
\begin{gathered}
q(t) \delta\left(x-\frac{\epsilon}{2}\right) \delta(y) \delta(z)-q(t) \delta\left(x+\frac{\epsilon}{2}\right) \delta(y) \delta(z) \\
\approx-\epsilon q(t) \delta^{\prime}(x) \delta(y) \delta(z) \equiv-\frac{\partial}{\partial x}(\epsilon q(t) \delta(\mathbf{x})) .
\end{gathered}
$$

Essa expressão mostra que o dipolo pode ser interpretado como a divergência de um monopolo e dessa forma sendo $\mathbf{f}=\mathbf{f}(\mathbf{x}, t)$ uma função vetorial, a fonte pontual

$$
\left.\mathbf{S}=\nabla \cdot \mathbf{f}(\mathbf{x}, t) \delta\left(\mathbf{x}-\mathbf{x}_{0}\right)\right)=\frac{\partial}{\partial x_{j}}\left(f_{j}(\mathbf{x}, t) \delta\left(\mathbf{x}-\mathbf{x}_{0}\right)\right)
$$

representa um dipolo localizado em $\mathbf{x}=\mathbf{x}_{0}$.

Se considerarmos quatro monopolos de intensidade igual em módulo eqüidistantes de $\mathbf{x}_{0}$ de forma que a resultante das forças aplicadas no fluido seja zero, a equação (2.22) se torna:

$$
\approx-\epsilon^{2} q(t) \delta^{\prime}(x) \delta^{\prime}(y) \delta(z) \equiv-\frac{\partial^{2}}{\partial x \partial y}(\epsilon q(t) \delta(\mathbf{x}))
$$

e com isso temos um quadripolo pontual que é representado por:

$$
\mathbf{S}=\frac{\partial^{2}}{\partial x_{i} \partial x_{j}}\left(f_{i j}(\mathbf{x}, t) \delta\left(\mathbf{x}-\mathbf{x}_{0}\right)\right)
$$

O quadripolo é interpretado como a divergência de um dipolo ou como a divergência dupla de um monopolo e a forma mais comum encontrada na literatura é:

$$
\mathbf{S}=\frac{\partial^{2} T_{i j}}{\partial x_{i} \partial x_{j}}(\mathbf{x}, t)
$$

onde $T_{i j}$ é o tensor de tensões de Lighthill definido por:

$$
T_{i j}=\rho v_{i} v_{j}+p \delta_{i j}-c_{0}^{2} \rho^{\prime} \delta_{i j}
$$

que substituído na equação (2.21) resulta na equação de Lighthill ou analogia de Lighthill para aeroacústica:

$$
\frac{\partial^{2} p^{\prime}}{\partial t^{2}}-c_{0}^{2} \nabla^{2} p^{\prime}=\frac{\partial^{2} T_{i j}}{\partial x_{i} \partial x_{j}}
$$

Essa equação permite estudar como o campo de escoamento turbulento perturba o campo de propagação sonora. 


\subsection{Equação de Euler linearizada - LEE}

$\mathrm{Na}$ literatura encontramos uma variedade de conjuntos de equações de Euler linearizadas e isso é causado pelas hipóteses de linearização adotadas mas também pelo fato que a equação de Euler pode ser escrita de diversas formas, figura 2.2, e cada uma dessas formas leva a um conjunto de equações linearizadas mas que são todas equivalentes [12].

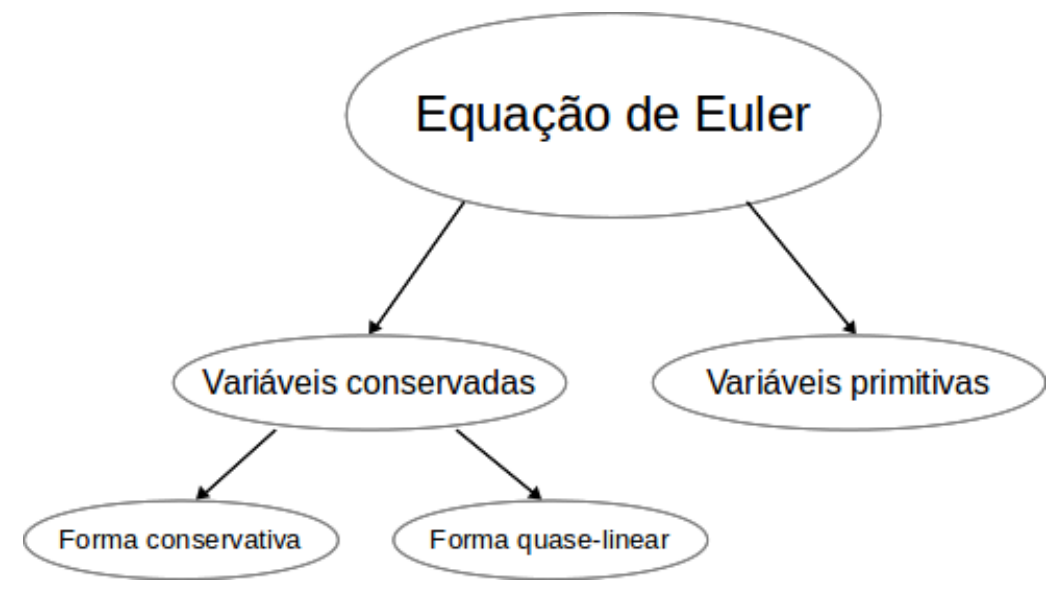

Figura 2.2: Diferentes apresentações da equação de Euler

A seguir apresentamos duas linearizações da equação de Euler, a primeira, baseada em variáveis primitivas que é a linearização mais comum encontrada na literatura. A segunda, baseada nas variáveis conservadas foi utilizada por Billson [11]. Se do ponto de vista matemático essas formas são equivalentes, o mesmo não acontece do ponto de vista computacional. Os dois sistemas foram implementados e testes preliminares produziram resultados semelhantes. Entretanto, o sistema em variáveis conservadas exigiu maior esforço computacional pois, a equação de energia é mais complexa e envolve o campo de pressão que precisa ser calculado a cada iteração. Ambas as abordagens resolveram de forma satisfatória problemas supersônicos onde há a presença de ondas de choque, embora sabemos que para obtermos melhor precisão um mecanismo de dissipação artificial deve ser implementado (Tam [3]). Por este motivo, os resultados apresentados foram obtidos com a LEE em variáveis primitivas.

\subsubsection{Variáveis conservadas}

Para obter a equação de Euler linearizada em variáveis conservadas $(\rho, \rho u, \rho v, \rho w, E)$ vamos relembrar a equação de Euler em variáveis conservadas com uso da notação indicial 
$(2.1)$ :

$$
\begin{gathered}
\frac{\partial \rho}{\partial t}+\frac{\partial \rho u_{j}}{\partial x_{j}}=S_{m} \\
\frac{\partial \rho u_{i}}{\partial t}+\frac{\partial}{\partial x_{j}}\left(\rho u_{i} u_{j}+p \delta_{i j}\right)=S_{i} \\
\frac{\partial \rho e_{0}}{\partial t}+\frac{\partial}{\partial x_{j}}\left(\rho h_{0} u_{j}\right)=S_{e}
\end{gathered}
$$

onde $\left(\rho, \rho u, \rho v, \rho w, \rho e_{0}\right)$ representam respectivamente a massa específica, o momento nas direções $x, y$ e $z$, a energia total por unidade de volume, $\rho h_{0}$ a entalpia por unidade de volume, $S_{m}, S_{i}, S_{e}$ representam os termos de perturbação da massa específica, da velocidade na direção $i$ e da energia respectivamente.

Podemos decompor todas as variáveis em uma média temporal somada a uma flutuação

$$
\begin{aligned}
& \rho=\bar{\rho}+\rho^{\prime} \\
& u_{i}=\tilde{u}_{i}+u_{i}^{\prime \prime} \\
& p=\bar{p}+p^{\prime} \\
& e_{0}=\tilde{e}_{0}+e_{0}^{\prime \prime} \\
& h_{0}=\tilde{h}_{0}+h_{0}^{\prime \prime}
\end{aligned}
$$

onde a barra denota a média temporal, ' a flutuação da variável, ^a média temporal de Favre definida por:

$$
\tilde{u}_{i}^{=} \frac{\overline{\rho u_{i}}}{\bar{\rho}}
$$

e " a flutuação associada à média de Favre.

Aplicando estas decomposições das variáveis conservadas da equação (2.1), a equação de Euler toma a seguinte forma:

$$
\begin{gathered}
\frac{\partial \rho^{\prime}}{\partial t}+\frac{\partial\left(\rho u_{j}\right)^{\prime}}{\partial x_{j}}=0 \\
\frac{\partial\left(\rho u_{i}\right)^{\prime}}{\partial t}+\frac{\partial}{\partial x_{j}}\left(\tilde{u}_{j}\left(\rho u_{i}\right)^{\prime}+\tilde{u}_{i}\left(\rho u_{j}\right)^{\prime}-\tilde{u}_{i} \tilde{u}_{i} \rho^{\prime}+p \delta_{i j}\right)=-\frac{\partial}{\partial x_{j}}\left[\rho u_{i}^{\prime \prime} u_{j}^{\prime \prime}-\overline{\rho u_{i}^{\prime \prime} u_{j}^{\prime \prime}}\right]
\end{gathered}
$$




$$
\frac{\partial\left(\rho e_{0}^{\prime}\right)}{\partial t}+\frac{\partial}{\partial x_{j}}\left[\tilde{h}_{0}\left(\rho u_{j}\right)^{\prime}+\tilde{u}_{j}\left(\rho h_{0}\right)^{\prime}-\tilde{h}_{0} \tilde{u}_{j} \rho^{\prime}\right]=-\frac{\partial}{\partial x_{j}}\left[\rho h_{0}^{\prime \prime} u_{j}^{\prime \prime}-\overline{\rho h_{0}^{\prime \prime} u_{j}^{\prime \prime}}\right]
$$

O sistema de equações de Euler escrito como as equações (2.28) não são de fato lineares, pois apresentam não linearidades do lado direito. Porém, o lado direito pode ser entendido como termos fonte com valores provenientes de LES, DNS ou, como apresentado neste trabalho por métodos semi-empíricos (SNGR) e com isso temos um sistema linear.

\subsubsection{Variáveis primitivas}

Para obter a equação de Euler linearizada em variáveis primitivas $(\rho, u, v, p)$, consideramos a equação de Euler também em variáveis primitivas, que pode ser escrita na notação indicial como:

$$
\begin{gathered}
\frac{\partial \rho}{\partial t}+u_{j} \frac{\partial \rho}{\partial x_{j}}+\rho \frac{\partial u_{j}}{\partial x_{j}}=S_{m} \\
\frac{\partial u_{i}}{\partial t}+u_{j} \frac{\partial u_{i}}{\partial x_{j}}+\frac{1}{\rho} \frac{p}{\partial x_{i}}=\frac{1}{\rho}\left(S_{i}-u_{i} S_{m}\right) \\
\frac{\partial p}{\partial t}+u_{j} \frac{\partial p}{\partial x_{j}}+\gamma p \frac{u_{j}}{\partial x_{j}}=(\gamma-1)\left\{S_{e}-u_{i} S_{i}+\frac{1}{2} u_{i} u_{i} S_{m}\right\}
\end{gathered}
$$

Para facilitar a notação escrevemos o sistema acima na forma vetorial:

$$
\frac{\partial \mathbf{q}}{\partial t}+A_{j} \frac{\partial \mathbf{q}}{\partial x_{j}}=\mathbf{Q}
$$

onde

$$
A_{j}=\left(\begin{array}{ccccc}
u_{j} & \delta_{1 j} \rho & \delta_{2 j} \rho & \delta_{3 j} \rho & 0 \\
0 & u_{j} & 0 & 0 & \frac{\delta_{1 j}}{\rho} \\
0 & 0 & u_{j} & 0 & \frac{\delta_{2 j}}{\rho} \\
0 & 0 & 0 & u_{j} & \frac{\delta_{3 j}}{\rho} \\
0 & \gamma \delta_{1 j} p & \gamma \delta_{2 j} p & \gamma \delta_{3 j} p & u_{j}
\end{array}\right)
$$

e

$$
\mathbf{Q}=\left(\begin{array}{c}
S_{m} / / \frac{1}{\rho}\left(S_{1}-u S_{m}\right) \\
\frac{1}{\rho}\left(S_{2}-v S_{m}\right) \\
\frac{1}{\rho}\left(S_{3}-w S_{m}\right) \\
(\gamma-1)\left\{S_{e}-u_{k} S_{k}+\frac{1}{2}|\vec{u}|^{2} S_{m}\right.
\end{array}\right)
$$


Vamos assumir que conhecemos uma solução q $\mathbf{q}_{0}$ de forma que:

$$
\frac{\partial \mathbf{q}_{0}}{\partial t}+A_{j 0} \frac{\partial \mathbf{q}_{0}}{\partial x_{j}}=\mathbf{Q}_{0}
$$

e escrever o vetor de incógnitas e de fontes como uma parte conhecida mais uma perturbação, $\mathbf{q}=\mathbf{q}_{0}+\mathbf{q}^{\prime}, \mathbf{Q}=\mathbf{Q}_{0}+\mathbf{Q}^{\prime}$, substituir na equação, (2.30). usar a expansão de Taylor em torno de $\mathbf{q}_{0}$ :

$$
A_{j}\left(\mathbf{q}_{0}+\mathbf{q}^{\prime}\right)=A_{j}\left(\mathbf{q}_{0}\right)+\left(\frac{d A_{j}}{d \mathbf{q}}\right)_{0}^{T} \mathbf{q}^{\prime}+\mathbb{O}\left(\epsilon^{2}\right)
$$

e desprezar os termos de ordem quadrática para obter:

$$
\frac{\partial \mathbf{q}^{\prime}}{\partial t}+A_{j 0} \frac{\partial \mathbf{q}^{\prime}}{\partial x_{j}}+A_{j}^{\prime} \frac{\partial \mathbf{q}_{0}}{\partial x_{j}}=\mathbf{Q}^{\prime}
$$

onde

$$
A_{j}^{\prime}=\left(\frac{d A_{j}}{d \mathbf{q}}\right)_{0}^{T} \mathbf{q}^{\prime}
$$

Como estamos interessados em problemas 2D, o sistema acima pode ser escrito na notação indicial obtendo o sistema de equações abaixo que é utilizado em nosso código computacional:

$$
\begin{gathered}
\frac{\partial \rho^{\prime}}{\partial t}+\rho_{0} \frac{\partial u_{j}^{\prime}}{\partial x_{j}}+u_{j 0} \frac{\partial \rho}{\partial x_{j}}=S_{m} \\
\frac{\partial \rho_{0} u_{i}^{\prime}}{\partial t}+\rho_{0} u_{j 0} \frac{\partial u_{i}^{\prime}}{\partial x_{j}}+\frac{\partial p^{\prime}}{\partial x_{j}} \delta i j=\left(S_{i}-u_{i} S_{m}\right) \\
\left.\frac{\partial p^{\prime}}{\partial t}+u_{j 0} \frac{\partial p^{\prime}}{\partial x_{j}}+\gamma p_{0} \frac{\partial u_{j}^{\prime}}{\partial x_{j}}=(\gamma-1)\left\{S_{e}-u_{i} S_{i}\right) \frac{1}{2}|\mathbf{u}|^{2} S_{m}\right\}
\end{gathered}
$$

\subsection{Condições de contorno}

Simular problemas de aeroacústica envolve simular o espaço livre onde as ondas se propagam livremente e são atenuadas na infinito. Para isso, faz-se necessário o uso de condições de contorno não reflexivas. Quando o escoamento próximo à fronteira possui pequenas oscilações de amplitude para um fluxo relativamente uniforme, técnicas analíticas baseadas em linearizações podem ser usadas para resolver as equações no exterior de um domínio truncado. Neste caso, obtem-se condições de contorno artificiais que são consistentes com a solução linear exterior e podem ser diretamente aplicadas com- 
putacionalmente. Entretanto, surgem desafios técnicos relativos a essa implementação (Colonius \& Lele [5]). Na presença de grandes gradientes de fluxo ou grande nível de oscilação de amplitude, as condições de contorno não são facilmente aplicadas no problema computacional e, além disso, elas envolvem linearizações de modelos físicos. Esse técnica é razoável para a condição de entrada onde existem apenas ondas acústicas. Porém, nas condições de saída de fluxo onde encontramos além das ondas acústicas, ondas de entropia e vorticidade, essas linearizações produzem erros consideráveis (Colonius \& Lele [17]) e como alternativa uma variedade de técnicas "ad hoc"de zonas de amortecimento foram desenvolvidas. Em linhas gerais, o desenvolvimento de condições de contorno não reflexiva para a LEE, relativo ao escoamento uniforme da onda sonora segue três abordagens: condições de contorno linearizadas, condições de contorno de radiação e condição de contorno de camada de amortecimento. Todas estas abordagens são aproximadas no sentido de que elas não são efetivamente não reflexivas. Porém, elas formam uma seqüência progressivamente mais precisa para as condições de contorno com o aumento do custo e complexidade computacional.

- Condição de contorno linearizada: Esta condição de contorno baseia-se no fato de que em uma dimensão as curvas características do sistema hiperbólico são trajetórias no plano $(x, t)$ em que a amplitude da onda é governada por uma equação diferencial ordinária. Neste caso, é possível diagonalizar a matriz Jacobiana do fluxo, equação (2.31)

$$
A_{1}=\mathbf{E} \bigwedge \mathbf{E}^{-1}
$$

onde $\Lambda$ é a matriz diagonal dos autovalores e $\mathbf{E}$ a matriz de autovetores. Para mais de uma dimensão as condição de contorno assim obtidas não são exatas pois não é possivel diagonalizar as matrizes $A_{j}$ simultaneamente [18].

- Condição de contorno de radiação: Essa condição de contorno não linear é baseada na hipótese de existir um comportamento assintótico para a solução no campo ao longe. Dessa forma constrói-se uma seqüência assintótica em potências decrescentes de $r^{-1}$, onde $r$ é a distância da fronteira até fonte sonora. Esse tipo de condição de contorno foi estudada e implementada por vários autores e um exemplo em duas dimensões pode ser encontrado em Tam [20] ou em Bayliss \& Turkel [19] que aplicaram a expansão assintótica em termos da pressão.

- Técnicas de zona de amortecimento: Nessa abordagem, zonas de amortecimento podem ser adicionadas ao domínio computacional e nelas as características físicas 
do escoamento são modificadas à jusante ou à montante. As idéias essenciais neste aspecto forma introduzidas por Israeli \& Orszag [21] com o método de dissipação artificial e amortecimento. Essa técnica também é chamada de "camada esponja", "zona de saída"ou "zona de absorção"e podem ser construídas de diversas formas. Como essa técnica não foi obtida à partir de hipóteses físicas, não se sabe como elas afetam a física do escoamento. Entretanto, há de se supor que se elas não produzem reflexão, elas não perturbam o escoamento. Aqui destacamos alguns exemplos

- Dissipação artificial ou amortecimento:

Neste método, uma zona de absorção é anexada ao domínio computacional e nela as equações que governam o escoamento são modificadas para imitar mecanismos de dissipação artificial [21].

- Estiramento da malha e filtragem numérica:

Esticar uma região da malha ou aumentar o tamanho de seus elementos criando "zonas de esponja"ou "zonas de saída"são técnicas puramente numéricas para atenuar a solução, essas abordagens foram utilizadas por Rain \& Moin [22] e Colonius et al. [23].

- Modificação da velocidade convectiva:

É possível modificar o fluxo médio dentro da zona de amortecimento tornandoo supersônico no final do domínio, neste ponto, como o fluxo supersônico está saindo da região ele não causa reflexão à montante. Essa técnica que foi aperfeiçoada por [24] é relativamente simples do ponto de vista computacional.

Apesar de serem de grande importância no aspecto da propagação sonora, essas condições de contorno não estão incluídas no escopo deste trabalho e, em nosso caso, a propagação sonora será analisada antes das ondas atingirem as fronteiras do domínio.

\section{Formulação numérica}

Considera-se um sistema conservativo que genericamente representa a equação de Euler e os termos fonte como a seguinte expressão

$$
\frac{\partial \mathbf{u}}{\partial t}+\frac{\partial}{\partial x_{i}} \mathbf{f}_{i}(\mathbf{u})=\mathbf{S}
$$


e sobre este sistema deve-se ainda incluir as condições iniciais e de contorno.

O procedimento numérico para resolução deste sistema é a discretização espacial seguida da integração numérica. O procedimento de discretização espacial será o método DG e o procedimento de integração numérica é realizado com método clássico de RungeKutta de quatro estágios e ambos os procedimentos são detalhados a seguir.

\subsection{Discretização espacial}

Os métodos de elementos finitos que usam bases polinomiais de alta ordem localmente são chamados métodos de elementos espectrais. Esses métodos buscam agrupar as vantagens da convergência exponencial dos métodos espectrais quando a solução é suave com a generalidade dos métodos de elementos finitos acoplando bases espectrais (polinômios de alta ordem) com suporte local. Essa abordagem leva a uma série de vantagens e podemos afirmar que as principais são a eficiência computacional quando estamos interessados em erros pequenos, como é o caso da propagação sonora, e a generalidade da solução que pode agora ser descontínua. Os métodos de elementos espectrais foram primeiramente introduzidos por Gottlieb \& Orzag [29] como uma alternativa a discretização por diferenças finitas na equação do calor. Esses autores utilizaram uma expansão em séries de Fourier obtendo uma convergência exponencial no erro da aproximação. Os métodos espectrais baseiam-se em representar uma função $u(x)$ por uma série de expansão truncada que é valida localmente em cada elemento da malha

$$
u(x) \approx u^{\tau}(x)=\sum_{i=0}^{P} \widehat{u}_{i} \phi_{i}(x),
$$

onde $P$ é o grau de aproximação desejado, $\widehat{u}_{i}$ são coeficientes e $\phi_{i}(x)$ são as funções analíticas que formam a base de expansão. Matematicamente, a expressão acima indica que estamos projetando uma função definida no espaço de dimensão infinita em um espaço de dimensão finita. Conseqüentemente existe um erro que é a diferença entre a função e sua projeção. O objetivo do método numérico é encontrar a projeção ótima que minimiza o erro. Para realizar a projeção consideremos um funcional linear, $\mathbb{L}(u)=0$, que na maioria dos casos é um operador diferencial sujeito a apropriadas condições iniciais e de contorno. A solução é definida no tempo e no espaço $u=u(x, t)$, e assumimos 
que a solução aproximada $u^{\tau}$ pode ser representada por

$$
u^{\tau}=u_{0}(x, t)+\sum_{i=1}^{P} \widehat{u}_{i}(t) \phi_{i}(x),
$$

onde $u_{0}(x, t)$ é escolhido para satisfazer as condições iniciais e de contorno. Podemos substituir essa expressão no funcional $\mathbb{L}$ e obter

$$
\mathbb{L}\left(u^{\tau}\right)=\mathbb{L}\left(u_{0}\right)+\mathbb{L}\left(\widehat{u}_{1} \phi_{1}\right)+\ldots+\mathbb{L}\left(\widehat{u}_{P} \phi_{P}\right)=R\left(u^{\tau}\right),
$$

onde $R$ é o erro da aproximação. Como a solução aproximada $u_{\tau}$ é dada pela equação (3.3) temos mais de uma forma de determinar os coeficientes $\widehat{u}_{i}(t)$, vamos então colocar uma restrição sobre o resíduo $R$ para reduzir a equação (3.4) a um sistema de equações em $\widehat{u}_{i}(t)$. A restrição sobre erro é obtida multiplicando a expressão (3.4) por uma função $v_{j}(x)$ chamada função teste e calculando o produto interno, que no caso é a integral sobre o domínio de interesse, obtendo a formulação integral do problema diferencial

$$
\int_{\Omega} v_{j} \mathbb{L}\left(u^{\tau}\right) d \mathbf{x}=\int_{\Omega} v_{j} R\left(u^{\tau}\right) d \mathbf{x},
$$

que na notação usual de produto interno torna-se

$$
\left(v_{j}, \mathbb{L}\left(u^{\tau}\right)\right)=\left(v_{j}, R\left(u^{\tau}\right)\right) .
$$

O lado direito desta expressão é chamado resíduo e pode ser nulo se escolhermos um conjunto de funções $v_{i}$ que seja ortogonal ao erro. Com isso obtemos

$$
\left(v_{j}, \mathbb{L}\left(u^{\tau}\right)\right)=0
$$

e isso equivale encontrar a aproximação ótima no espaço de dimensão $P$ uma vez que $u^{\tau} \rightarrow u$ quando $P \rightarrow \infty$. Esse é o método dos resíduos ponderados e a escolha da função teste $v_{i}(x)$, determina o tipo do método numérico. A Tabela 1 mostra algumas funções teste comumente usadas e o método computacional que elas produzem. Do ponto de vista computacional, a expressão (3.5) torna-se um sistema de equações de dimensão $P$ da forma

$$
\left[\begin{array}{ccc}
a_{11} & \cdots & a_{1 P} \\
\vdots & \ddots & \vdots \\
a_{P 1} & \cdots & a_{P P}
\end{array}\right]\left[\begin{array}{c}
\widehat{u}_{1} \\
\vdots \\
\widehat{u}_{P}
\end{array}\right]=\left[\begin{array}{c}
0 \\
\vdots \\
0
\end{array}\right]
$$




\begin{tabular}{|c|c|}
\hline Função teste & Tipo de método \\
\hline$v_{j}\left(\mathbf{x}=\delta\left(\mathbf{x}-\mathbf{x}_{j}\right)\right.$ & Colocação \\
\hline$v_{j}(\mathbf{x})=\left\{\begin{array}{lll}1 & \text { se } & \mathbf{x} \in \Omega_{j} \\
0 & \text { se } & \mathbf{x} \notin \Omega_{j}\end{array}\right.$ & Volumes finitos \\
\hline$v_{j}(\mathbf{x})=\frac{\partial R}{\partial \widehat{u}_{i}}$ & Mínimos quadrados \\
\hline$v_{j}(\mathbf{x})=x^{j}$ & Métodos dos momentos \\
\hline$v_{j}(\mathbf{x})=\phi_{j}(\mathbf{x})$ & Galerkin \\
\hline$v_{j}(\mathbf{x})=\psi_{j}(\mathbf{x}) \neq \phi_{j}(\mathbf{x})$ & Petrov-Galerkin \\
\hline
\end{tabular}

Tabela 1: Funções teste usadas no método dos resíduos ponderados

onde $a_{i j}=\left(v_{j}, \mathbb{L}\left(\phi_{i}\right)\right)$. Se os coeficientes $\widehat{u}_{i}$ não dependem do tempo temos um sistema algébrico e a solução é imediata. Caso contrário, temos um sistema de equações diferenciais ordinárias que pode ser resolvido por exemplo, por um método de Runge-Kutta.

A idéia central do método de Galerkin, também conhecido como Bubnov-Galerkin, é que as funções teste são as mesmas funções de base, ou seja $v_{j}(\mathbf{x})=\phi_{j}(\mathbf{x})$ que é a abordagem utilizada neste trabalho. Outra classe conhecida como método de PetrovGalerkin, ou método de Galerkin generalizado, usa funções teste similares, mas não idênticas às funções de base, mas sim funções obtidas através de perturbações lineares das funções de base com o objetivo de aumentar a estabilidade numérica do método.

Para uma expansão de alta ordem, pode-se utilizar um conjunto qualquer de funções que forme uma base para o espaço de polinômios de ordem $P$. Essa escolha implicará nas estruturas das matrizes do sistema de equações determinando a eficiência do método, pois uma das grandes dificuldades dos métodos de elementos finitos é a inversão de matrizes e a precisão e eficiência desta operação está associada com o número de condicionamento da matriz $\kappa_{2}$ (Issacson [30]).

Os resultados obtidos por Karniadakis [9], mostram que a utilização de polinômios de Legendre garante que o número de condicionamento das matrizes seja linear com a ordem da aproximação e dado por $\kappa_{2}=2 P+1$, enquanto que a utilização de outra base de polinômios leva a uma relação exponencial e torna o método instável. 


\subsubsection{Galerkin Descontínuo}

Na construção do método dos resíduos ponderados, nada se menciona sobre a continuidade das funções teste e de base. Entretanto, na forma clássica dos métodos de elementos finitos, assim como no método de Galerkin, elas são contínuas com primeira derivada descontínua, $v_{j}=\phi_{j} \in \mathbb{C}^{0}$. Pode-se aumentar o espaço das funções candidatas exigindo que elas sejam apenas quadrado integrável, $v_{j}=\phi_{j} \in \mathbb{L}^{2}$ e com essa modificação surge o método conhecido como Galerkin Descontínuo. Do ponto de vista prático, deixamos de exigir que os coeficientes polinomiais na fronteira de dois elementos adjacentes sejam os mesmos e com isso permitimos a presença de descontinuidades entre esses elementos durante o processo numérico. Em primeira análise, possibilitar descontinuidades implica que podemos resolver problemas onde a solução seja descontínua, mas na prática não é isso o que acontece. Para utilizar o caráter descontínuo do método nas descontinuidades da solução, deveríamos ajustar a malha de forma que elas coincidissem com as interfaces dos elementos, processo inviável pois muitas vezes os problemas são transientes. A grande vantagem das descontinuidades surge no aspecto numérico com matrizes que contêm blocos independentes e dessa forma podem ser particionadas para resolver pequenos sistemas locais criando um ambiente propício para o paralelismo computacional. Apesar de possibilitarmos descontinuidades locais, a continuidade da solução é assegurada através de condições de vínculo calculadas de forma explícita e impostas no fluxo dos elementos.

Para construir o método DG vamos considerar a LEE escrita na forma conservativa na região $\Omega \in \mathbb{R}^{2}$

$$
\begin{gathered}
\frac{\partial \mathbf{u}}{\partial t}+\frac{\partial}{\partial x_{k}} \mathbf{f}_{k}(\mathbf{u})=\mathbf{s}, \quad k=1,2 \\
\mathbf{u}(\mathbf{x}, 0)=\mathbf{u}_{0}(\mathbf{x}) \\
\mathbf{x} \in \Omega, t>0
\end{gathered}
$$

onde $\mathbf{u}=\mathbf{u}(x, t)=\left(\rho^{\prime}, \rho_{0} u^{\prime}, \rho_{0} v^{\prime}, p^{\prime}\right)^{T}$ que representam respectivamente a perturbação na massa específica, o momento em relação à perturbação de velocidade $u^{\prime}$ e $v^{\prime}$ e a perturbação de pressão $p^{\prime}$. O subíndice " 0 " indica os valores do campo de escoamento uniforme, $\mathbf{f}_{j}(u)=A_{j}\left(\mathbf{u}_{0}\right) \mathbf{u}$ são as matrizes Jacobianas na vizinhança de $\mathbf{u}_{0}$ definidas na equação (??) e s os termos fonte. Podemos considerar que o funcional linear $\mathbb{L}$ é definido por

$$
\mathbb{L}=\frac{\partial}{\partial t}+\frac{\partial}{\partial x_{k}}, \quad k=1,2
$$


e com isso reescrever a LEE (3.7) como

$$
\begin{array}{r}
\mathbb{L}(\mathbf{u})=\mathbf{s}, \\
\mathbf{u}(\mathbf{x}, 0)=\mathbf{u}_{0}(\mathbf{x}), \\
\mathbf{x} \in \Omega, t>0,
\end{array}
$$

A partir desse momento, para reduzir a quantidade de índice utilizados, assumiremos que a equação (3.8) é escalar, e os resultados obtidos podem ser estendidos para funções e variáveis vetoriais sem perda de generalidade. Definimos o espaço $\mathcal{U}$ que contém as soluções aproximadas $\left(u^{\tau} \in \mathcal{U}\right)$, o espaço $\mathcal{V}$ que contém as funções de base $\phi_{i}$ e as funções teste $v_{i}$

$$
\mathcal{V} \equiv\left\{\phi_{i}=v_{i} \in L^{2}(\Omega)\right\}, \quad i=1,2, \cdots, P,
$$

onde $\mathcal{V} \subset \mathcal{U}$ e particionamos o domínio $\Omega$ em $N_{e l}$ elementos que se sobrepõem apenas na fronteira $\partial \Omega^{e}$

$$
\Omega=\bigcup_{e=1}^{N_{e l}} \Omega^{e}, \quad \bigcap_{e=1}^{N_{e l}} \Omega^{e}=\partial \Omega^{e} .
$$

A variável aproximada $u^{\tau}$ definida para cada elemento $\Omega^{e}$ será substituída na equação (3.7), multiplicada pela função teste $v_{j}^{\tau}$ e integrada sobre o elemento $\Omega^{e}$ resultando na forma fraca da equação diferencial

$$
\int_{\Omega^{e}} v_{j}^{\tau} \frac{\partial u^{\tau}}{\partial t}+v_{j}^{\tau} \frac{\partial f_{k}\left(u^{\tau}\right)}{\partial x_{k}} d \Omega^{e}=\int_{\Omega^{e}} v_{j}^{\tau} s d \Omega^{e}
$$

e substituindo $v^{\tau}$ na primeira integral pela expressão (3.3) podemos escrever

$$
\int_{\Omega^{e}} u_{0} v_{j}^{\tau} d \Omega^{e}+\sum_{i=1}^{P} \frac{\partial \widehat{u}_{i}}{\partial t} \int_{\Omega^{e}} v_{j}^{\tau} \phi_{i} d \Omega^{e}+\int_{\Omega^{e}} v_{j}^{\tau} \frac{\partial f_{k}\left(u^{\tau}\right)}{\partial x_{k}} d \Omega^{e}=\int_{\Omega^{e}} v_{j}^{\tau} s d \Omega^{e} .
$$

A primeira integral é determinada imediatamente pela condição inicial e pode ser movida para o lado direito e incorporada no termo fonte $s$. Lembrando que $v_{i}=\phi_{i}$, a segunda integral também fica determinada e temos neste momento um importante critério de escolha para as funções $v_{i}$, pois, se elas formarem um conjunto ortogonal, a integral será reduzida a $\delta_{i j}$ a menos de uma constante. A integral do lado direito também está determinada pois representa fontes analíticas. Resta-nos um estudo detalhado da terceira integral.

A terceira integral possui o operador divergente aplicado sobre o vetor de fluxo e 
podemos integrá-la por partes

$$
\int_{\Omega^{e}} v_{j}^{\tau} \frac{\partial f\left(u^{\tau}\right)}{\partial x_{k}} d \Omega^{e}=\int_{\Omega^{e}} \frac{\partial}{\partial x_{k}}\left(v_{j}^{\tau} f_{k}\left(u^{\tau}\right)\right) d \Omega^{e}-\int_{\Omega^{e}} f_{k}\left(u^{\tau}\right) \frac{\partial v_{j}^{\tau}}{\partial x_{k}} d \Omega^{e},
$$

e aplicar o teorema da divergência na primeira integral do lado direito

$$
\int_{\Omega^{e}} v_{j}^{\tau} \frac{\partial f_{k}\left(u^{\tau}\right)}{\partial x_{k}} d \Omega^{e}=\int_{\partial \Omega^{e}} v_{j}^{\tau} f_{k}\left(u^{\tau}\right) n_{k} d \partial \Omega^{e}-\int_{\Omega^{e}} f_{k}\left(u^{\tau}\right) \frac{\partial v_{j}^{\tau}}{\partial x_{k}} d \Omega^{e},
$$

onde $n_{k=1,2}$ é o vetor normal unitário orientado para fora do elemento $\Omega^{e}$ e $\partial \Omega^{e}$ a fronteira deste elemento. Substituindo este resultado na equação (3.10) temos

$$
\sum_{i=1}^{P} \frac{\partial \widehat{u}_{i}}{\partial t} \int_{\Omega^{e}} v_{j}^{\tau} \phi_{i} d \Omega^{e}+\int_{\partial \Omega^{e}} v_{j}^{\tau} f_{k}\left(u^{\tau}\right) n_{k} d \partial \Omega^{e}-\int_{\Omega^{e}} f_{k}\left(u^{\tau}\right) \frac{\partial v_{j}^{\tau}}{\partial x_{k}} d \Omega^{e}=\int_{\Omega^{e}} v_{j}^{\tau}\left(s-u_{0}\right) d \Omega^{e}
$$

Trabalhar com descontinuidades exige uma abordagem um pouco diferente para o problema na forma fraca. A equação (3.11) suporta apenas funções teste suaves (Warburton [31]) e para evitar essa exigência devemos integrar por partes novamente a equação (3.11) e obter

$$
\begin{array}{r}
\sum_{i=1}^{P} \frac{\partial \widehat{u}_{i}}{\partial t} \int_{\Omega^{e}} v_{j}^{\tau} \phi_{i} d \Omega^{e}+\int_{\partial \Omega^{e}} v_{j}^{\tau}\left[\widehat{f}\left(u^{+}, u^{-}\right)-f_{k}\left(u^{\tau}\right)\right] n_{k} d \partial \Omega^{e}+ \\
\int_{\Omega^{e}} v_{j}^{\tau} \frac{\partial}{\partial x_{k}} f_{k}\left(u^{\tau}\right) d \Omega^{e}=\int_{\Omega^{e}} v_{j}^{\tau}\left(s-u_{0}\right) d \Omega^{e} .
\end{array}
$$

As expressões (3.11) e (3.12) são as duas formas possíveis do método DG, ambas são formas variacionais de equações diferenciais. Entretanto, a primeira é chamada forma fraca e a segunda, forma forte no sentido da discretização DG. Em nosso caso, como utilizamos polinômios de Legendre para as funções teste, ambas poderiam ser usadas e optamos pela primeira, equação (3.11).

A segunda integral em (3.11) desempenha um papel importante no método. Seu valor deve ser calculado considerando que o fluxo $f_{k}$ é descontínuo através das fronteiras e o tratamento matemático dado à descontinuidade estabelece as condições de vínculo entre os elementos. A notação usada para o fluxo $f_{k}$ é modificada, geralmente por $\widehat{f}\left(u^{+}, u^{-}\right)$, sendo chamado de fluxo numérico para destacar que seu valor é obtido considerando os valores na fronteira dos elementos adjacentes. Neste trabalho a descontinuidade foi tratada como um problema de Riemann e o fluxo numérico calculado com o método upwind HLL. Os detalhes são apresentados no Apêndice C. 
Podemos com a equação (3.11) iniciar a resolução numérica do método DG através da abordagem matricial. Para tanto definimos uma ordem de aproximação $P>0$, escolhemos $j=P$ funções teste, obtendo o sistema de equações diferenciais ordinárias

$$
\mathbf{M} \frac{d \mathbf{U}^{(e)}}{d t}+\mathbf{K} \mathbf{U}^{(e)}=\mathbf{F}^{(e)}
$$

onde $\mathbf{U}^{(e)}$ é o vetor da variável $u$ associado ao elemento $e, \mathbf{K}$ é conhecida na mecânica estrutural como matriz de rigidez, $\mathbf{M}$ a matriz de massa e $\mathbf{F}^{(e)}$ o vetor com a contribuição das fontes e das condições iniciais ou de fronteira. Resolver esse sistema implica em inverter a matriz de massa e esse procedimento tem grande importância na estabilidade e precisão da solução, como apresentado anteriormente, a facilidade no tratamento da matriz de massa está associada ao número de condicionamento da matriz $\kappa_{2}$ (Issacson [30]). Sabendo que os elementos da matriz de massa são dados na notação de produto interno por $m_{i j}=\left(v_{i}, v_{j}\right)$, a escolha de um conjunto de funções $v_{i}$ ortogonais juntamente com o mapeamento polimórfico dos elementos permite que essa matriz seja diagonal (ao menos localmente).

\subsubsection{Mapeamento polimórfico}

Como argumentado na seção 3.1.1, alguma atenção deve ser dada à matriz de massa para que ela seja não singular e invertê-la não aumente a complexidade do método. Além desse fato, as operações de integração e diferenciação numérica necessárias para o cálculo das matrizes K, U e F da equação (3.13) devem também ser otimizadas de alguma forma. Uma técnica eficiente consiste em se utilizar da ortogonalidade da base polinomial, em nosso caso, polinômios de Legendre, que são ortogonais no intervalo $[-1,1]$. Como devemos trabalhar com malhas não estruturadas, um mecanismo de mapeamento entre os elementos reais, definido nas coordenadas $(x, y)$, deve ser construído de forma que, através de transformações de espaço, as operações de integração e diferenciação possam realizadas no elemento padrão, $\Omega^{\text {st }}$, em $2 \mathrm{D}$, um quadrado no espaço de coordenadas $\left(\xi_{1}, \xi_{2}\right)$ definido matematicamente como

$$
\mathcal{Q}^{2}=\left\{\left(\xi_{1}, \xi_{2}\right) \mid-1 \leq \xi_{1}, \xi_{2} \leq 1\right\}
$$

e os resultados possam ser transformados de volta nas coordenadas $(x, y)$. Em analogia com a transformada de Fourier, o espaço das coordenadas $(x, y)$ é conhecido como espaço físico e o espaço da coordenadas $\left(\xi_{1}, \xi_{2}\right)$, espaço dos coeficientes ou espaço transformado, 
e a transformação do espaço físico para o espaço dos coeficientes é chamada por alguns autores de forward transformation e a inversa, backward transformation. A segunda, que a partir dos coeficientes obtêm os valores físicos é mais simples e envolve a multiplicação de matrizes

$$
u^{\tau}(x, y)=\sum_{p=1}^{P} \sum_{q=1}^{Q} \widehat{u}_{p q} \phi_{p}\left(\xi_{1}\right) \phi_{q}\left(\xi_{2}\right),
$$

enquanto que a primeira é mais complexa pois envolve a resolução de um sistema linear.

A figura 3.1(a) mostra um exemplo de mapeamento de quadriláteros a partir da correspondência de vértices entre os elementos, resultando nas transformações de coordenadas:

$$
\begin{array}{rlr}
x=\chi^{e}\left(\xi_{1}\right) & =\frac{\left(1-\xi_{1}\right)}{2} x^{e-1}+\frac{\left(1+\xi_{1}\right)}{2} x^{e}, \quad \xi_{1} \in \Omega^{s t}, \\
\xi_{1} & =\left(\chi^{e}\right)^{-1}(x)=2 \frac{\left(x-x^{e-1}\right)}{\left(x^{e}-x^{e-1}\right)}-1 \quad x \in \Omega^{e},
\end{array}
$$

que podem ser estendidas para $y$ e $\xi_{2}$ considerando que $\chi^{e}$ é o operador de transformação.

Os elementos triangulares também são mapeados no elemento padrão, que neste caso é um triângulo em que os vértices $\mathrm{C}$ e $\mathrm{D}$ do quadrado foram colapsados. As relações de transformação de espaço neste caso são as mesmas do quadrilátero, equação (3.16) mas neste caso a definição os limites de definição do elemento padrão não são mais independentes

$$
\mathcal{T}^{2}=\left\{\left(\xi_{1}, \xi_{2}\right) \mid-1 \leq \xi_{1}, \xi_{2} \leq 1 ; \xi_{1}+\xi_{2} \leq 0\right\} .
$$

Essa pequena modificação traz algumas complicações numéricas como por exemplo as integrais nas variáveis $\xi_{1}$ e $\xi_{2}$ deixam de ser independentes perdendo as vantagens obtidas com a base tensorial (seção 3.1.3). Para contornar esse problema foi elaborado um novo sistema de coordenadas onde os limites do elemento padrão sejam constantes. Esse novo sistema de coordenadas conhecido como coordenadas colapsadas ou coordenadas Duffy (em homenagem à Michael G. Duffy [32]) é definido pela transformação

$$
\begin{aligned}
& \eta_{1}=2 \frac{\left(1+\xi_{1}\right)}{1-\xi_{2}}-1=2\left(\frac{x-x^{e-1}}{y-y^{e-1}}\right)\left(\frac{y^{e}-y^{e-1}}{x^{e}-x^{e-1}}\right) \\
& \eta_{2}=\xi_{2}=2 \frac{\left(y-y^{e-1}\right)}{\left(y^{e}-y^{e-1}\right)}-1
\end{aligned}
$$



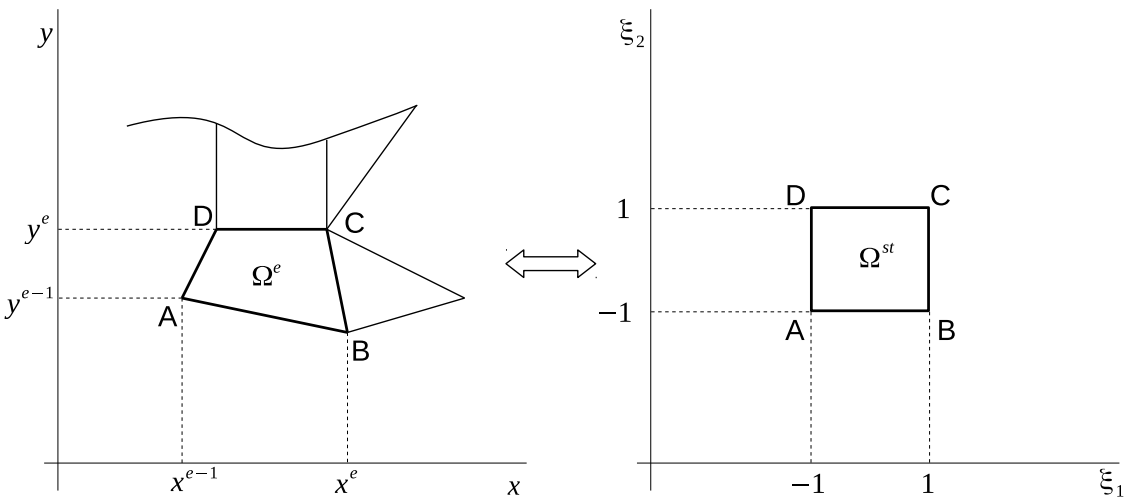

(a) Quadriláteros,
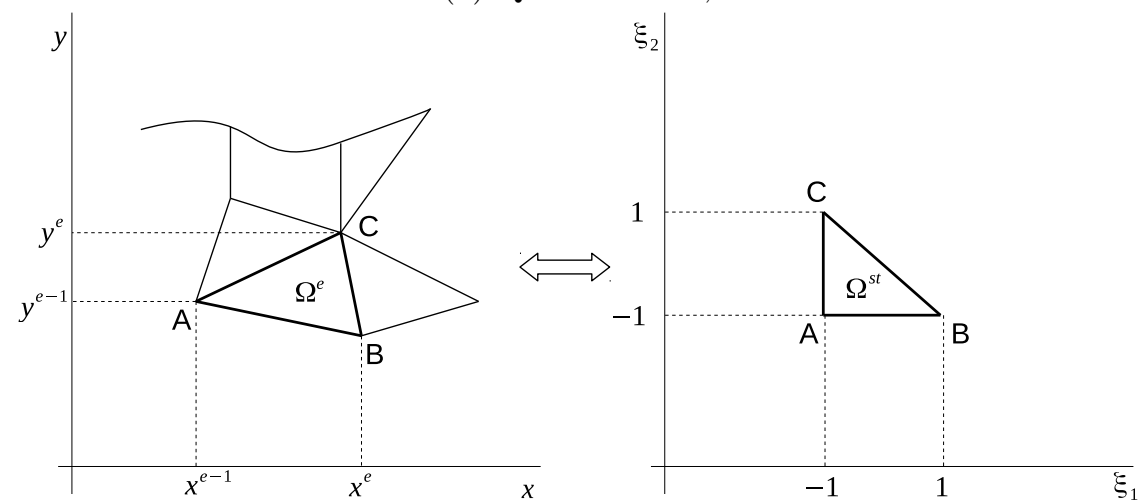

(b) Triângulos.

Figura 3.1: Mapeamento de elementos pela correspondência de vértices.

e pela transformação inversa

$$
\begin{array}{r}
x=\frac{\left(1-\xi_{1}\right)}{2} x^{e-1}+\frac{\left(1+\xi_{1}\right)}{2} x^{e}=\frac{\left(1+\eta_{1}\right)\left(1-\eta_{2}\right)}{4}\left(x^{e}-x^{e-1}\right), \\
y=\frac{\left(1-\xi_{2}\right)}{2} y^{e-1}+\frac{\left(1+\xi_{2}\right)}{2} y^{e}=\frac{\left(1-\eta_{2}\right)}{2} y^{e-1}+\frac{\left(1+\eta_{2}\right)}{2} y^{e},
\end{array}
$$

de forma que o elemento padrão triangular é agora definido por

$$
\mathcal{T}^{2}=\left\{\left(\eta_{1}, \eta_{2}\right) \mid-1 \leq \eta_{1}, \eta_{2} \leq 1\right\},
$$

A definição da região triangular em coordenadas $\left(\eta_{1}, \eta_{2}\right)$ (3.20) é idêntica à definição do quadrilátero padrão em coordenadas $\left(\xi_{1}, \xi_{2}\right)$ (3.14), podemos então interpretar que estamos mapeando as linhas verticais do quadrilátero ( $n_{1}$ constante) em linhas radiais que partem do vértice $(-1,1)$ do triângulo como mostra a figura 3.2. A região triangular 


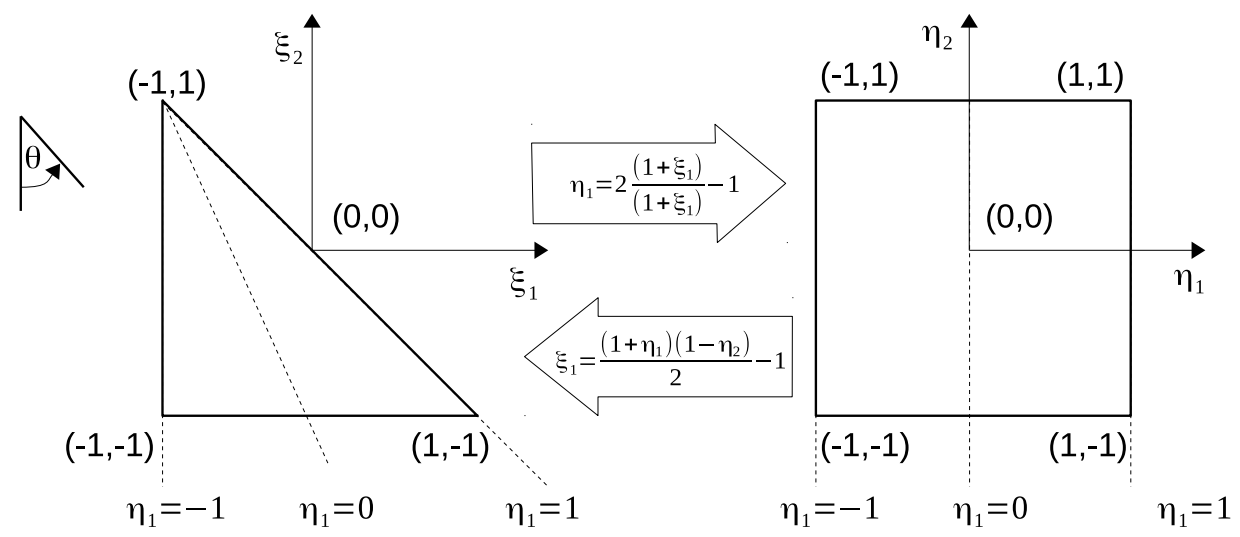

Figura 3.2: Mapeamento do triângulo no quadrilátero padrão.

é agora definida por uma coordenada radial $\left(\eta_{1}\right)$ e uma coordenada horizontal $\left(\eta_{2}\right)$. Pode parecer que existe uma singularidade no vértice $(-1,1)$ do triângulo mas isso não ocorre, basta expressar as coordenadas cartesianas $\left(\xi_{1}, \xi_{2}\right)$ em coordenadas cilíndricas $(\epsilon, \theta)$, obtendo $\xi_{1}=-1+\epsilon \operatorname{sen} \theta$ e $\xi_{2}=\epsilon \cos \theta$ e aplicar a transformação de coordenadas

$$
\left.\eta_{1}\right|_{\xi_{1}=-1, \xi_{2}=1}=\frac{1-1+\epsilon \operatorname{sen} \theta}{1-1+\epsilon \cos \theta}-1=2 \tan \theta-1 .
$$

Como $\theta \leq \pi / 4, \tan \pi / 4 \leq 1$ então $-1 \leq \eta_{1} \leq 1$.

\subsubsection{Base de expansão multidimensional}

O software Nektar ++ utiliza o conceito de base modal para construir a base de polinômios de interpolação. A origem do conceito de base de expansão modal pode ser atribuído à Daniel Bernoulli que desenvolveu a idéia que as vibrações em uma corda podem ser expressas como a sobreposição de um infinito número de vibrações harmônicas (Darrigol [33]). Uma base de expansão modal refere-se a qualquer conjunto formado por modos de expansão (conhecidos na mecânica estrutural como shape functions), enquanto que uma base de expansão nodal denota um conjunto de expansão associado a um conjunto de pontos nodais, ou pontos de controle. A base de expansão de ordem $P$ definida na região $\Omega^{s t}=\left\{-1 \leq \xi_{1} \leq 1\right\}$, construída a partir dos polinômios de Legendre $L_{p}$ (Apêndice $\mathrm{D}$ ) é representada pelo conjunto

$$
\Phi_{p}\left(\xi_{1}\right)=\left\{L_{p}\left(\xi_{1}\right) \mid p=0, \cdots, P\right\}
$$


Essa base forma um conjunto hierárquico no sentido de que as ordens menores estão contidas nas ordens maiores. Matematicamente falando, consideremos $\mathcal{X}_{P}^{\tau}$ o espaço das funções $\phi_{p}\left(\xi_{1}\right)$ formadas por todos os polinômios contidos em $\Phi_{p}$ até a ordem $P$, dessa forma temos $\mathcal{X}_{P}^{\tau} \subset \mathcal{X}_{P+1}^{\tau}$. Esse resultado implica na simplicidade do aumento da ordem polinomial pois basta acrescentar um novo polinômio para obtermos uma expansão de maior grau. Outros conjuntos de polinômios formam bases hierárquicas porém não possuem a ortogonalidade dos polinômios de Legendre. Lembrando que os elementos da matriz de massa são dados por $m_{i j}=\left(\phi_{i}, \phi_{j}\right)$, e que na formulação de Galerkin $v_{i}=\phi_{i}$, obtemos

$$
\left(v_{i}, v_{j}\right)=\int_{-1}^{1} L_{i}\left(\xi_{1}\right) L_{j}\left(\xi_{1}\right) d \xi_{1}=\left(\frac{2}{2 i+1}\right) \delta_{i j}
$$

Esses conceitos e propriedades válidas para 1D podem ser estendidos para 2D considerando que cada função de expansão $\phi_{p}$ é um tensor unidimensional. Dessa forma as funções de expansão 2D são obtidas pelo produto tensorial das funções $1 \mathrm{D}$ em cada uma das coordenadas cartesianas:

$$
\phi_{p q}\left(\xi_{1}, \xi_{2}\right)=\phi_{p}\left(\xi_{1}\right) \phi_{q}\left(\xi_{2}\right), \quad 0 \leq p \leq P, \quad 0 \leq q \leq Q
$$

Imediatamente, deduz-se que a expansão $2 \mathrm{D}$ pode possuir ordens distintas nas direções $\xi_{1}$ e $\xi_{2}$ e isso é verdade, mas em geral toma-se $P=Q$. Com essa escolha, efetuando-se o produto tensorial completo $(0 \leq p, q<P=Q)$ teremos contribuições de termos do tipo $\xi_{1}^{P} \times \xi_{2}^{Q} \approx \mathcal{O}\left(\xi^{2 P}\right)$.

Uma base de expansão largamente utilizada (Karniadakis [9]) é conhecida por $S e$ rendipity expansion que não inclui todas as funções do produto tensorial completo, mas sim aquelas limitadas por:

$$
\phi_{p q}\left(\xi_{1}, \xi_{2}\right)=\phi_{p}\left(\xi_{1}\right) \phi_{q}\left(\xi_{2}\right), \quad 0 \leq p, q \leq P ; p+q \leq P
$$

Esse é o espaço natural de uma região triangular e uma região retangular não pode ser reduzida exatamente à esse espaço, porém, pode aproximá-lo de forma satisfatória (Karniadakis [9]). A figura 3.3 mostra uma representação dos termos presentes nesta base em termos do triângulo de Pascal para $P=Q=4$. Ela não é exatamente uma região triangular uma vez que possui as funções representadas por $\xi_{1}^{4} \xi_{2}$ e $\xi_{1} \xi_{2}^{4}$ que não podem ser removidas, pois elas mantêm o espaço completo, no sentido de que exista ao menos uma função das duas variáveis e que ao menos uma dessas variáveis possua o grau máximo da aproximação, no caso 4 . Esta base de expansão não completa uma região 


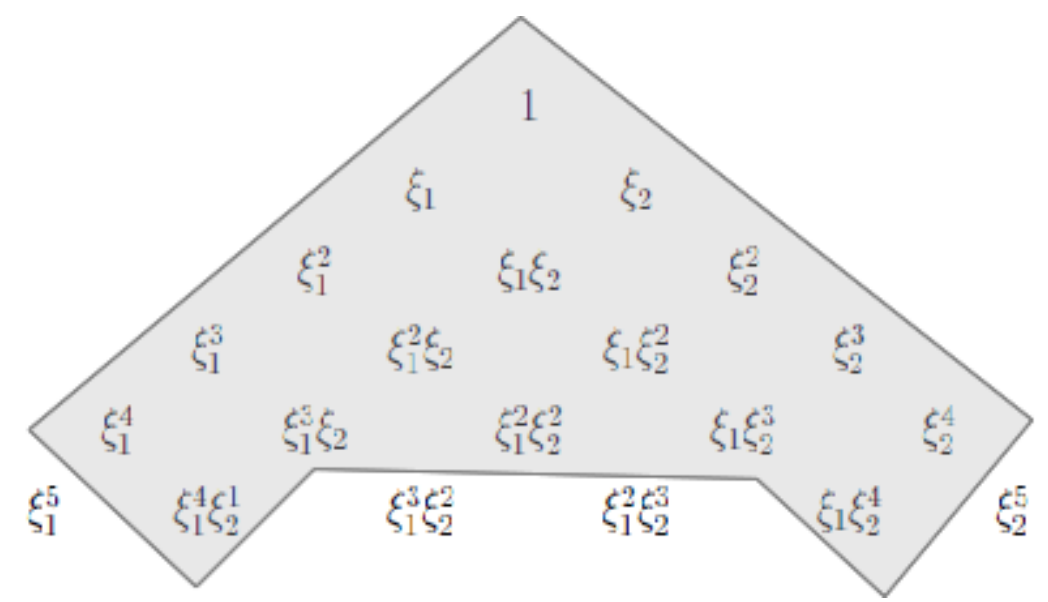

Figura 3.3: Espaço polinomial modificado em termos do triângulo de Pascal.

retangular porém, não só completa, mas também extrapola uma região triangular com as duas funções $\xi_{1}^{4} \xi_{2}$ e $\xi_{1} \xi_{2}^{4}$. Por esse motivo, é de se esperar que as malhas com elementos triangulares forneçam melhores resultados, e esse fato foi verificado nos resultados deste trabalho, seção 4.1.2.

\subsection{Integração temporal}

Em linhas gerais, a integração pode ser realizada por qualquer método conhecido, mas devemos suspeitar que os métodos são mais ou menos adequados para o problema a ser resolvido. Pensando nisso, dois pontos merecem atenção na implementação DG. Primeiro, o caráter descontínuo do método é local e isso muitas vezes leva a estruturas explicitas padrão. Por isso, os métodos explícitos são preferidos para formulações descontínuas em elementos finitos, apesar de não haver impedimentos para a utilização de métodos implícitos (Li [34]). Segundo, uma vez que os métodos explícitos são propensos a instabilidade numérica, a análise de estabilidade é necessária. Por isso, critérios de estabilidade foram estabelecidos para os métodos de integração temporal mais comumente utilizados para problemas de escoamento de fluidos e aplicações de transferência de calor (Li [34]).

Neste trabalho, o sistema de equações diferenciais ordinárias (3.13) foi resolvido de 
forma explícita através do método de Runge-Kutta de 4 passos dado por:

$$
\begin{aligned}
\mathbf{U}^{n+1} & =\mathbf{U}^{n}+\frac{1}{6}\left(f_{1}+2 f_{2}+2 f_{3}+f_{4}\right) \\
f_{1} & =\Delta t H\left(\mathbf{U}^{n}, t^{n}\right) ; \\
f_{2} & =\Delta t H\left(\mathbf{U}^{n}+0,5 f_{1}, t^{n}+0,5 \Delta t\right) ; \\
f_{3} & =\Delta t H\left(\mathbf{U}^{n}+0,5 f_{2}, t^{n}+0,5 \Delta t\right) ; \\
f_{4} & =\Delta t H\left(\mathbf{U}^{n}+f_{3}, t^{n}\right) ;
\end{aligned}
$$

onde $H\left(\mathbf{U}^{n}, t^{n}\right)=\mathbf{M}^{-1}\left[\mathbf{F}\left(\mathbf{U}^{n}, t^{n}\right)-\mathbf{K}\left(\mathbf{U}^{n}, t^{n}\right) \mathbf{U}^{n}\right]$ obtido invertendo a matriz de massa da equação (3.13). O passo de tempo $\Delta t$ foi calculado utilizamos a condição de estabilidade de Courant-Friedrich-Lewy (CFL) definida por:

$$
\sigma=\frac{c_{0} \Delta t}{\Delta x} \leq \sigma_{\max }
$$

onde $c_{0}$ é a velocidade do som, $\Delta x$ o comprimento característico do elemento e $\sigma_{\max }=1$ que é um valor típico para métodos explícitos. Como estudamos problemas transientes, para que a solução tenha sentido físico, o passo de tempo utilizado nas simulações foi

$$
\Delta t=\min \left[\frac{\Delta x^{(e)}}{c_{0}^{(e)}}\right]
$$

onde o índice ${ }^{(e)}$ indica os elementos da malha.

\section{Resultados e Discussões}

Vamos iniciar um processo de verificação do software para avaliar a precisão, ordem de convergência e sensibilidade da malha. Essa verificação é baseada na convergência do erro na norma $L^{2}$ onde aumentamos a ordem dos polinômios (refinamentos $p$ ) e reduzimos o comprimento característico dos elementos da malha (refinamento $h$ ) e assim podemos monitorar o comportamento do software.

Seis problemas foram analisados. O primeiro não tem significado físico pois é uma forma de verificar se o software é capaz de encontrar a solução correta tendo como ponto de partida o lado direito ( $r h s$ ) de um sistema de equações diferenciais. Nesse procedimento, uma função analítica é substituída no sistema de equações, obtendo-se 


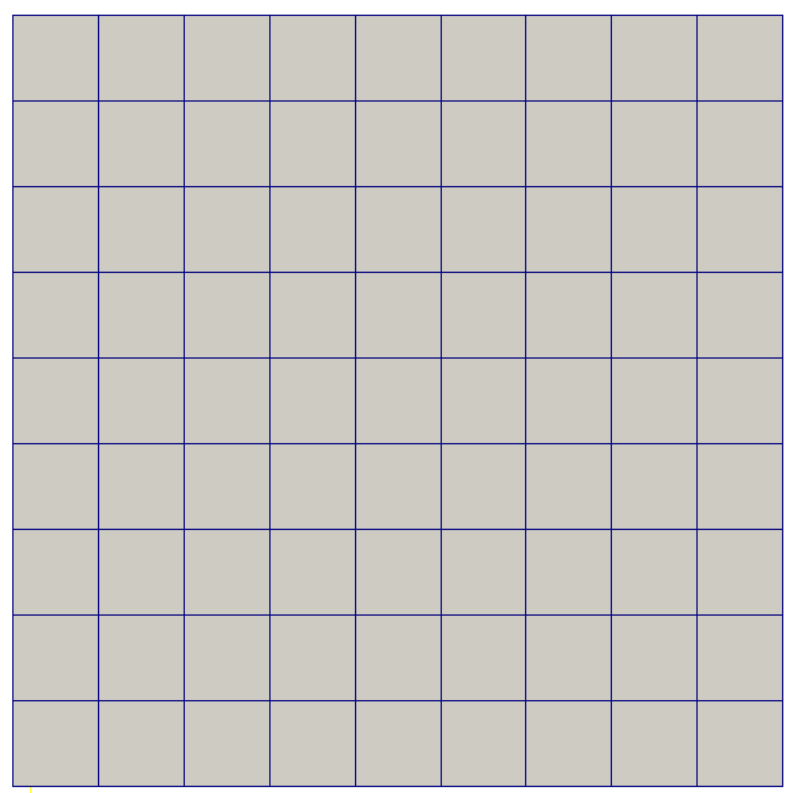

Figura 4.1: Malha estruturada com $9 x 9$ quadrados e dimensão $-100 \leq x, y, \leq 100$

assim o rhs. Em seguida, o rhs é introduzido no software esperando que ele recupere a função analítica utilizada. Os demais problemas são situações reais de propagação sonora:

- Pulso gaussiana em escoamento subsônico,

- Monopolo em escoamento subsônico,

- Monopolo em escoamento supersônico,

- Dipolo em escoamento subsônico,

- Quadripolo em escoamento subsônico.

Estes problemas não possuem solução analítica explícita, mas sim soluções na forma de equações integrais que devem ser calculadas numericamente em cada ponto do plano $(x, y)$. Neste procedimento, encontramos a solução para a pressão como o produto de convolução $p(x, y, t)=f(x, y) * d G / d t(x, y, t)$, onde $G(x, y, t)$ é a função de Green. Em todos os casos foi utilizado uma malha estruturada de 9x9 quadrados, figura 4.1, exceto no estudo de convergência onde vários tipos de malha foram estudados. 


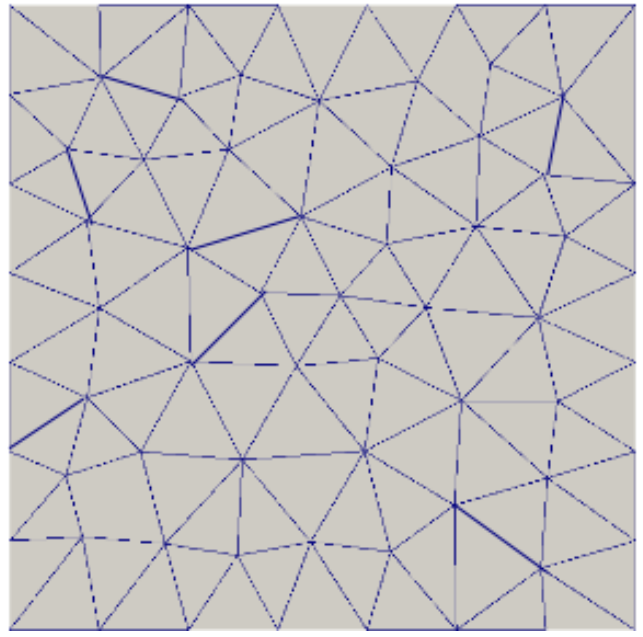

(a) 110 triângulos

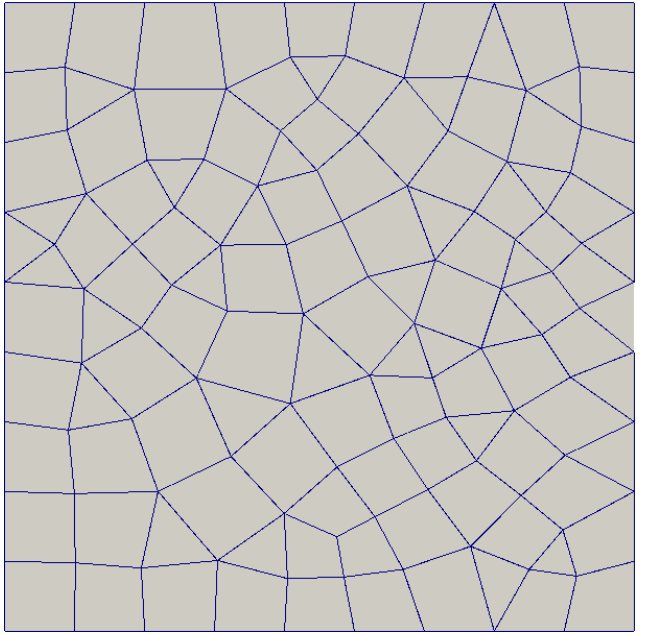

(b) 27 triângulos e 83 quadriláteros

Figura 4.2: Malhas não estruturadas com dimensão $-100 \leq x, y \leq 100$.

\subsection{Validação do método}

Desde a década de 1970, a convergência $h$ dos Métodos de Elementos Finitos foi bem estudada e os resultados tanto teóricos como numéricos demonstram que o erro da solução numérica decai algebricamente com o refinamento da malha, convergência $h$. Como alternativa, temos a convergência $p$, onde o número de elementos da malha é fixo e aumentamos a ordem dos polinômios de interpolação para reduzir o erro numérico. Reconhecendo as vantagens de cada abordagem, Babuska \& Suri [35] propuseram o método conhecido como convergência $h p$ e nessa abordagem aumenta-se a quantidade de elementos da malha e também a ordem do polinômio de interpolação. Estes autores demonstram que para uma função contínua com derivada segunda limitada, em malha com comprimento característico $h$, com ordem de aproximação $P$ e $k \geq 1$, existe um limite superior para o erro dado por:

$$
\|e\|_{E} \leq C h^{\mu-1} P^{(1-k)}\|u\|_{H^{k}}(\Omega)
$$

onde $\mu=\min (k, P+1)$ e $C=C(k)$ e $H^{k}$ o espaço de Sobolev com $k$ derivadas quadrado integrável e $E$ a norma energia.

Percebendo que aumentando o número de elementos da malha o comprimento característico $h$ diminui, concluímos que uma seqüência $h_{n}$ decrescente garante uma seqüência também decrescente para o erro e essa é a vantagem do método $h p$. 
Por outro lado, tomando um $h$ fixo, temos um limite superior para o erro e que demonstra a convergência exponencial para o refinamento $p$

$$
\|e\|_{E} \leq C P^{(1-k)}\|u\|_{H^{k}}(\Omega) .
$$

Procuramos verificar estes resultados nas seções a seguir avaliando a convergência $h, p$ e $h p$. A convergência $p$ para o Método de Elementos Finitos é exponencial. Em particular para o método DG, alguns autores [36] chamam essa convergência de super convergência, já que em casos específicos ela é da ordem de $2 P+1$ chegando a atingir $3 P$. Não atingimos esses resultados, pois estudamos um problema complexo em $2 \mathrm{D}$ grande variação de passos de tempo e ordens polinomiais.

Nos resultados a seguir a medida do erro $e$ foi calculada pela norma $L^{2}$ ou simplesmente norma Euclidiana:

$$
\|e\|_{L^{2}}=\left\|u-u^{\tau}(\mathbf{x})\right\|_{L^{2}}=\sqrt{\sum_{i=1}^{N}\left[u\left(\mathbf{x}_{i}\right)-u^{\tau}\left(\mathbf{x}_{i}\right)\right]^{2}}
$$

\subsubsection{Descrição do problema - solução analítica}

Esse estudo de convergência foi realizado introduzindo uma perturbação periódica no campo de escoamento uniforme com um número de $M a c h=0,5$. Esse tipo de problema é modelado por um termo fonte $S$ acoplado na equação de Euler linearizada que pode ser escrita na forma vetorial

$$
\frac{\partial U}{\partial t}+\frac{\partial E}{\partial x}+\frac{\partial F}{\partial y}=S
$$

onde $U=\left[\rho^{\prime}, \rho_{0} u^{\prime}, \rho_{0} v^{\prime}, p^{\prime}\right]^{T}$ são as variáveis do problema.

Utilizamos a função vetorial $U(x, y, t)$ dada por

$$
U=\left(\begin{array}{c}
10 \\
\operatorname{sen} x \\
\cos y \\
10
\end{array}\right) \beta \operatorname{sen}(t) e^{-\alpha\left(x^{2}+y^{2}\right)},
$$

com $\alpha=10^{-2}$ e $\beta=10^{-3}$ que substituída na equação (4.3) fornece o termo fonte S. O campo de escoamento uniforme possui os valores da tabela 2 .

O problema foi simulado em uma malha estruturada e não estruturada de dimensões $-100 \leq x, y \leq 100$ com 81 quadrados, figura 4.1, malha de 110 triângulos, figura 4.2a, e 


\begin{tabular}{|l|c|}
\hline Variável & Valor \\
\hline$\rho_{0}$ & 1,4 \\
\hline$u_{0}$ & 0,5 \\
\hline$v_{0}$ & 0,0 \\
\hline$p_{0}$ & 1,0 \\
\hline
\end{tabular}

Tabela 2: Campo médio em variáveis primitivas - Validação Mach=0,5.

malha mista de 27 triângulos e 83 quadriláteros, figura 4.2b, com ordens de aproximação variando de 2 a 20 e tempo de simulação $t=10,5$.

\subsubsection{Convergência $p$ - solução analítica}

Nesse estudo de convergência comparamos 200 pontos sobre a reta $y=0$ dos resultados analíticos e numéricos para $P=2-20$.

Entendemos que o programa resolveu o problema de validação da forma esperada e os resultados da convergência do erro para a massa específica, velocidade resultante e pressão são apresentados na figura 4.3 onde foram testadas; malha estruturada de quadrados 4.3(a)-(b); malha não estruturada de triângulos 4.3(c)-(d); malha não estruturada mista 4.3(e)-(f). Esperávamos que a convergência fosse exponencial, mas encontramos um comportamento assintótico para a malha de quadrados, figura 4.3(a)-(b), e para a malha mista, figura 4.3(e)-(f) onde a partir de $\mathrm{P}=12$ a convergência praticamente se estabiliza e isso leva a crer que atingimos erros do processador e que pela quantidade de operações realizadas esses erros se acumularam refletindo no resultado final. Essa hipótese é confirmada avaliando a diferença de magnitude das simulações, pois em 2D a quantidade de pontos de integração, ou graus de liberdade, é de ordem quadrática $N=n p^{2}$ onde $n=81$ é a quantidade de elementos, com isso o caso mais simples, $\mathrm{P}=2$, envolveu 324 pontos de integração com 210 passos de tempo enquanto que o mais complexo, $\mathrm{P}=20$, possui 32400 com 2625 passos de tempo e a quantidade de operações aritméticas (flops) variou de $10^{10}$ até $10^{14}$ para o caso mais simples e o mais complexo, respectivamente. A malha de triângulos apresentou erros menores, figura 4.3(c)-(d). De certa forma esse resultado era esperado pela discussão sobre a base de expansão na seção 3.1.3, onde verificamos que uma região triangular é o espaço natural da base utilizada. 


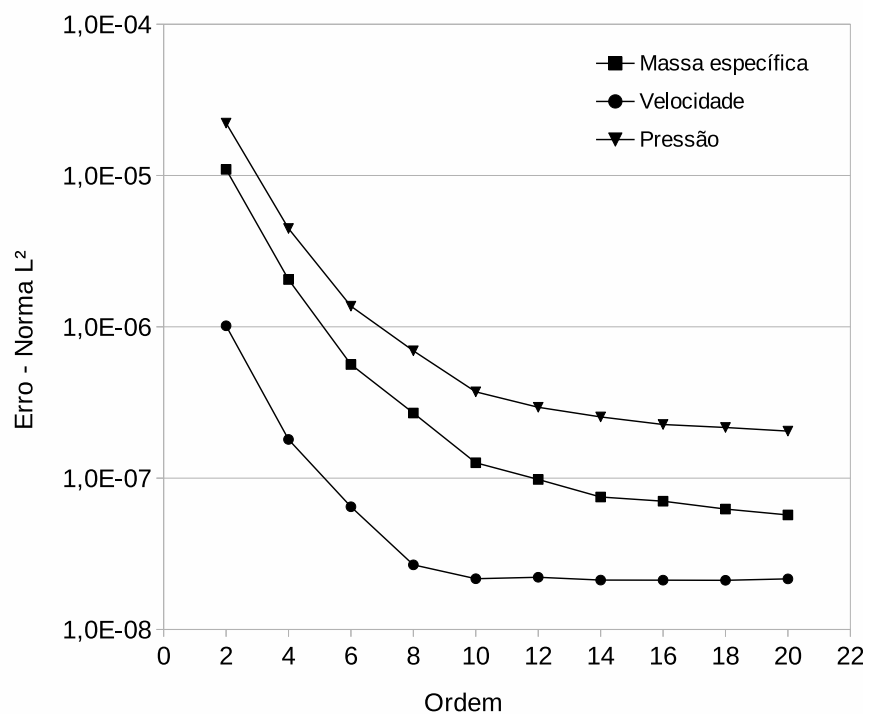

(a) $P$ par

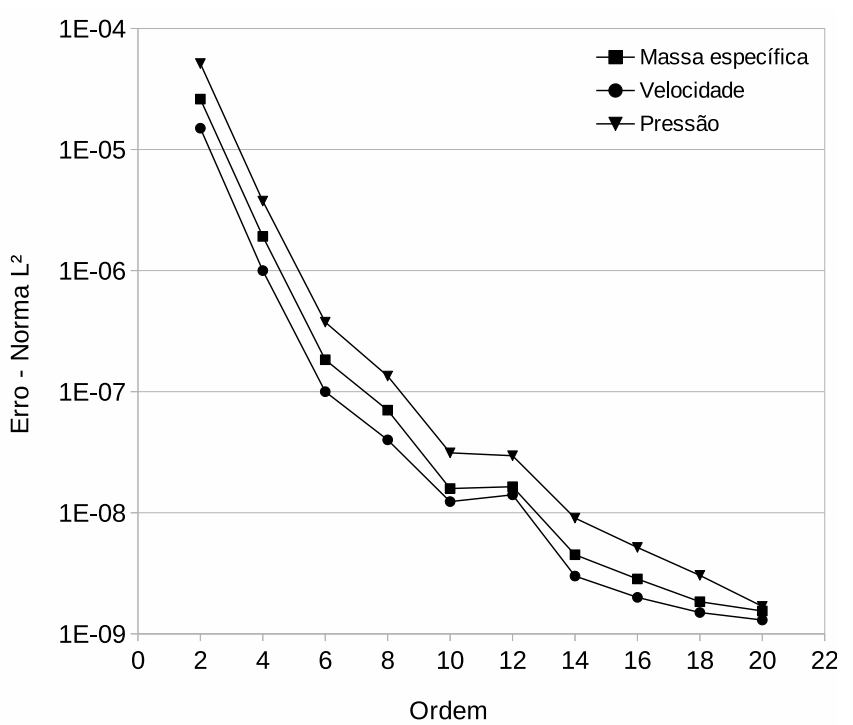

(c) $P$ par

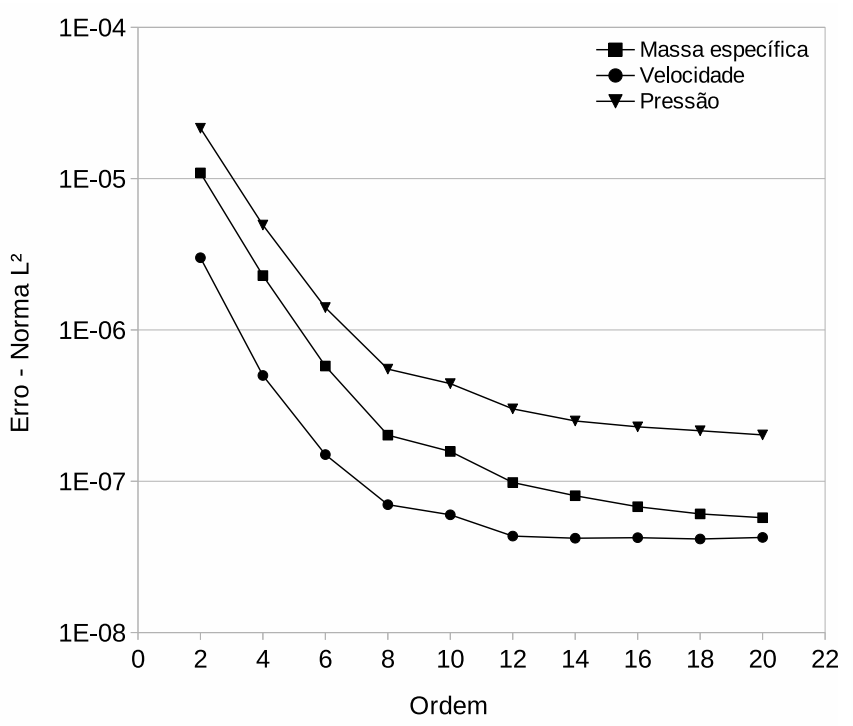

(e) $P$ par

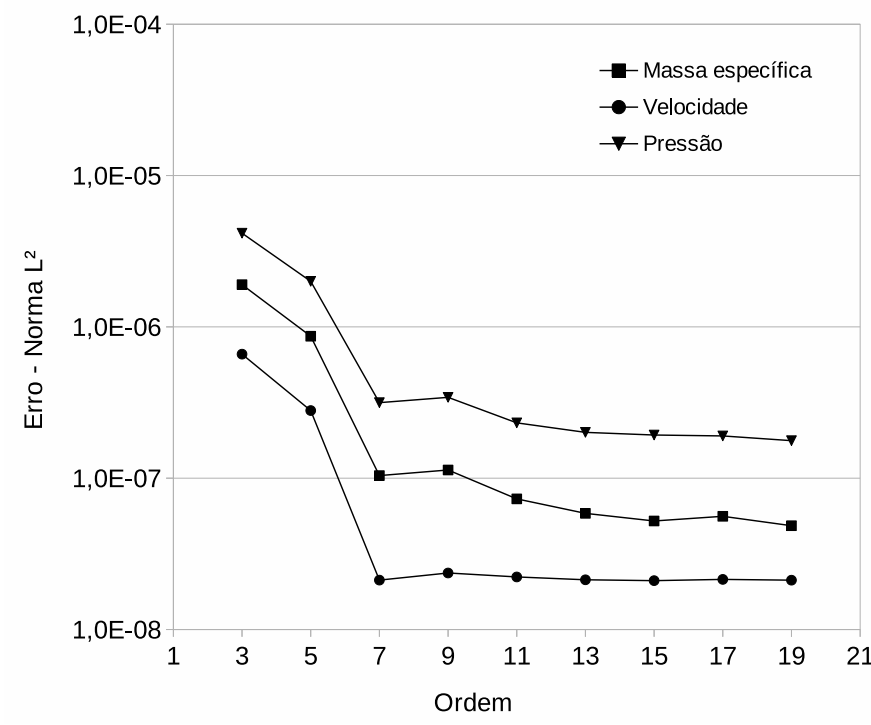

(b) $P$ impar

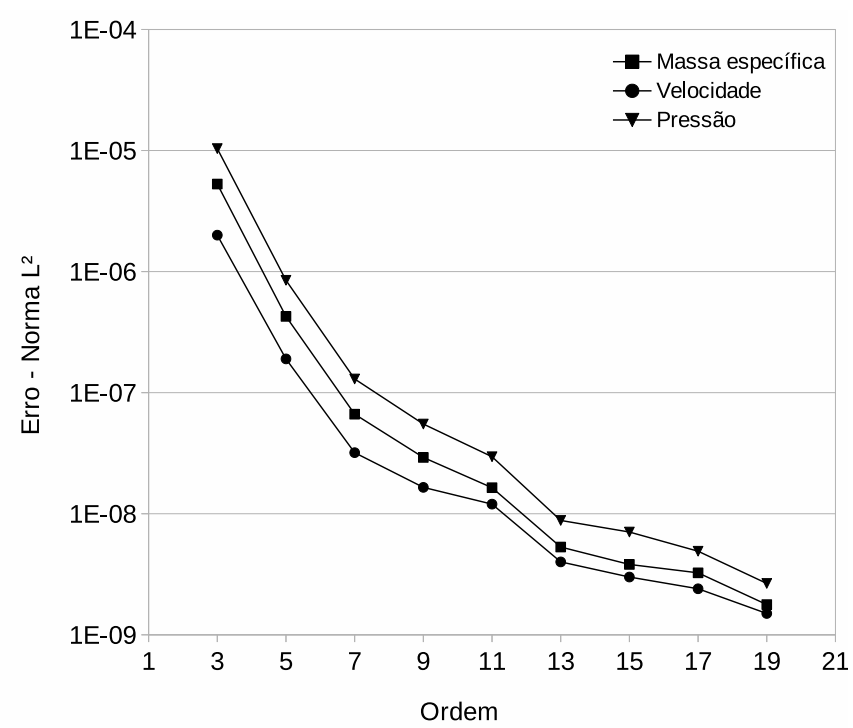

(d) $P$ impar

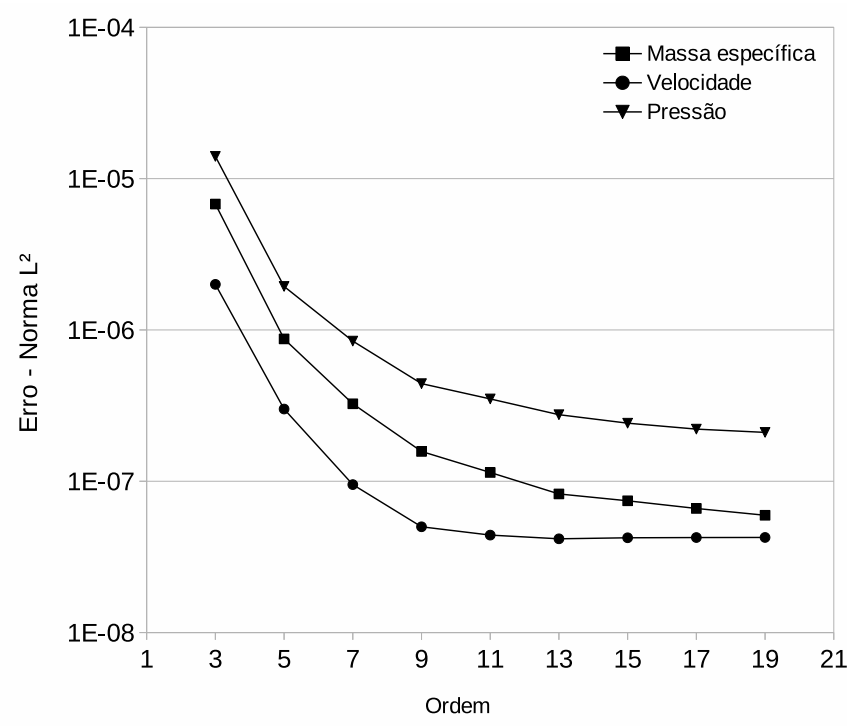

(f) $P$ impar

Figura 4.3: Convergência do erro na norma $L^{2}$ para $P=2-20$. (a)-(b) Malha estruturada de 81 quadrados. (c)-(d) Malha não estruturada de 110 triângulos.

(e)-(f) Malha não estruturada mista de 27 triângulos e 83 quadriláteros. 


\subsubsection{Descrição do problema - monopolo}

Esse estudo de convergência foi realizado com a propagação de um pulso do tipo monopolo em um campo de escoamento uniforme com Mach =0.5. Esse tipo de problema é modelado por um termo fonte $S$ acoplado na equação de Euler linearizada que pode ser escrita na forma vetorial:

$$
\frac{\partial U}{\partial t}+\frac{\partial E}{\partial x}+\frac{\partial F}{\partial y}=S
$$

onde $U=\left[\rho^{\prime}, \rho_{0} u^{\prime}, \rho_{0} v^{\prime}, p^{\prime}\right]^{T}$ são as variáveis do problema, o termo fonte $\mathrm{S}$ é dado por:

$$
S=\left(\begin{array}{c}
\beta \\
0 \\
0 \\
\beta / \gamma
\end{array}\right) \operatorname{sen}(\omega t) e^{-\alpha\left[\left(x-x_{s}\right)^{2}+\left(y-y_{s}\right)^{2}\right]}
$$

com $\alpha=\ln (2) / 2$, amplitude da perturbação $\beta=\rho_{0} / 100$, freqüência angular $\omega=\pi / 15$, a origem da fonte sonora localizada em $\left(x_{s}, y_{s}\right)=(-30,0)$ e o campo de escoamento uniforme possui os valores da tabela 3

\begin{tabular}{|l|c|}
\hline Variável & Valor \\
\hline$\rho_{0}$ & 1,4 \\
\hline$u_{0}$ & 0,5 \\
\hline$v_{0}$ & 0,0 \\
\hline$p_{0}$ & 1,0 \\
\hline
\end{tabular}

Tabela 3: Campo médio em variáveis primitivas - Monopolo Mach=0,5.

O problema foi simulado em uma malha estruturada de dimensões $-100 \leq x, y \leq 100$ com 81 quadrados, figura 4.1, com ordens de aproximação variando de 2 a 20 . O tempo de simulação foi $\mathrm{t}=100$ e os isocontornos de pressão com $\mathrm{P}=20$ é apresentada na figura 4.4. Devemos lembrar que não temos um problema estacionário, mas sim transiente e por isso não atingimos erros da ordem de $10^{-15}$ conhecidos como erro de máquina.

A solução analítica desse problema é obtida por um método integral baseado na convolução da função de Green, seção 4.3.2.

\subsubsection{Convergência $p$ - monopolo}

Nesse estudo de convergência comparamos 100 pontos sobre a reta $y=0$ dos resultados analíticos e numéricos para polinômios de grau par de 2 até 20 . A escolha da reta 


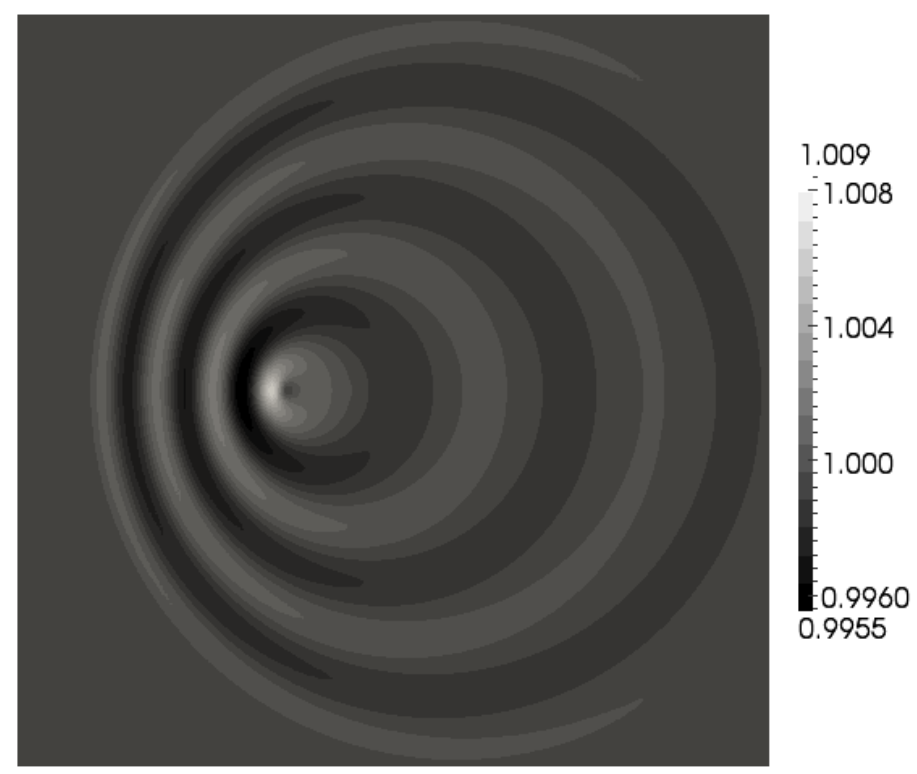

Figura 4.4: Superfície de pressão do monopolo - Mach $=0,5, \mathrm{P}=20$ e t=100.

$y=0$ foi devido à simetria do problema. Além disso, sobre esta reta encontramos os maiores erros. A convergência exponencial é observada na figura 4.5 onde encontramos uma linha de tendência com equação $f(p)=0,02 e^{-0,715 p}$ e coeficiente de correlação $R^{2}=0,97$. Não atingimos correlação perfeita, $R^{2}=1,00$, mas devemos considerar a diferença de magnitude das simulações pois em $2 \mathrm{D}$ a quantidade de pontos de integração, ou graus de liberdade, é de ordem quadrática $N=n p^{2}$ onde $n=81$ é a quantidade de elementos. Com isso, o caso mais simples, $\mathrm{P}=2$, envolveu 324 pontos de integração com 541 passos de tempo enquanto que o mais complexo, $\mathrm{P}=20$, possui $32400 \mathrm{com} 14778$ passos de tempo e variações grandes como esta levam ao acúmulo de erros.

Se por um lado a convergência do erro é exponencial por outro, a quantidade de operações aritméticas (flops) também é exponencial. Na figura 4.6a temos os teraflops e podemos verificar que eles são diretamente proporcionais com a ordem dos polinômios.

Com o aumento de ordem dos polinômios obtemos melhores resultados na convergência, mas isso demandou maior esforço computacional. Quantificar o esforço computacional baseado no tempo de processamento não é tarefa objetiva, pois depende de fatores como capacidade de processamento disponível, recursos de paralelismo utilizados e otimizações do código e do compilador. Mesmo com essas dificuldades, pensando em avaliar a convergência em relação ao custo computacional analisamos o produto erro $\mathbf{x}$ teraflops em relação à ordem de aproximação. Essa análise é motivada pelo fato que os teraflops são diretamente proporcionais à ordem, enquanto o erro é inversamente proporcional e o resultado, figura $4.6 \mathrm{~b}$, mostra que o ganho na convergência é maior que o aumento do custo computacional. 


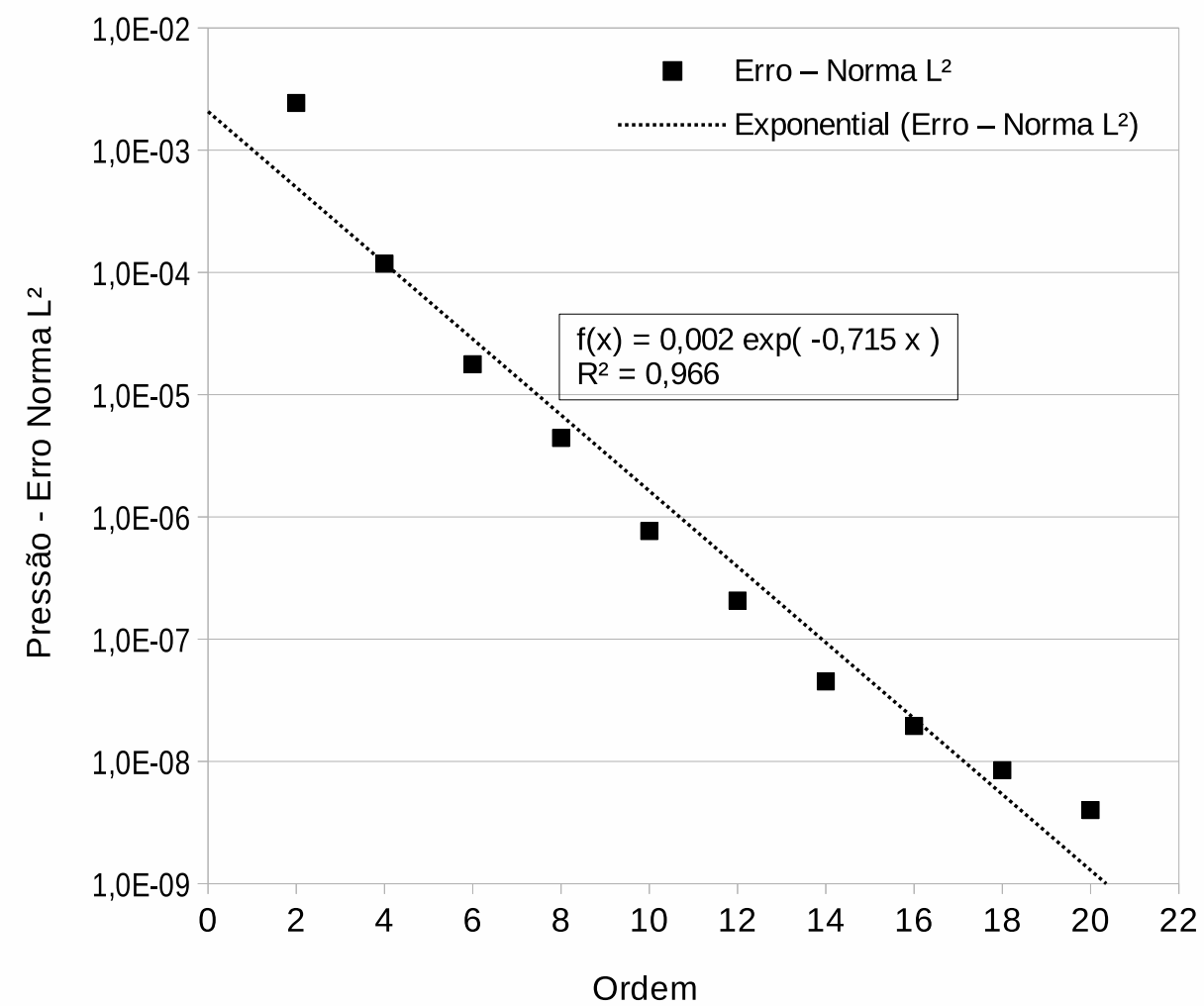

Figura 4.5: Convergência do erro na norma $L^{2}$ para pressão do monopolo - $\mathrm{y}=0$, $P=2-20, t=100$ em malha de $9 \mathbf{x} 9$ quadrados.

\subsubsection{Convergência $h p$ - monopolo}

A técnica $h p$ busca agrupar os resultados da convergência exponencial $p$ e da convergência aritmética $h$. Nesta seção analisamos a convergência $h p$ do problema precedente. Os resultados foram obtidos a partir de 5 divisões sucessivas de uma malha inicial de 4 elementos quadrados de dimensões $-100 \leq x, y \leq 100$ onde foram executadas simulação de ordens $P=2-7$. Na figura 4.7 a verificamos que a convergência do refinamento $p$ é sempre maior que do refinamento $h$.

Analisamos de forma isolada o comportamento da convergência $h$ e da convergência $p$ na figura 4.7b. Neste caso fixamos $P=3$ e refinamos a malha inicial de 4 quadrados obtendo a seqüência decrescente $h=\{1,0,5,0,25,0,125,0,0625\}$, em seguida fixamos a malha de 16 elementos $\operatorname{com} h=0,5$ variando a ordem de aproximação $P=\{2,3,4,7,10,12,20\}$. Os graus de liberdade apresentados nesta figura são da ordem de $(p / h)^{2}$. Como esperado, a convergência tipo $h$ ( $p$ fixo e $h$ variável) apresenta convergência aritmética, enquanto a convergência tipo $p$ ( $h$ fixo e $p$ variável) apresenta convergência exponencial. 


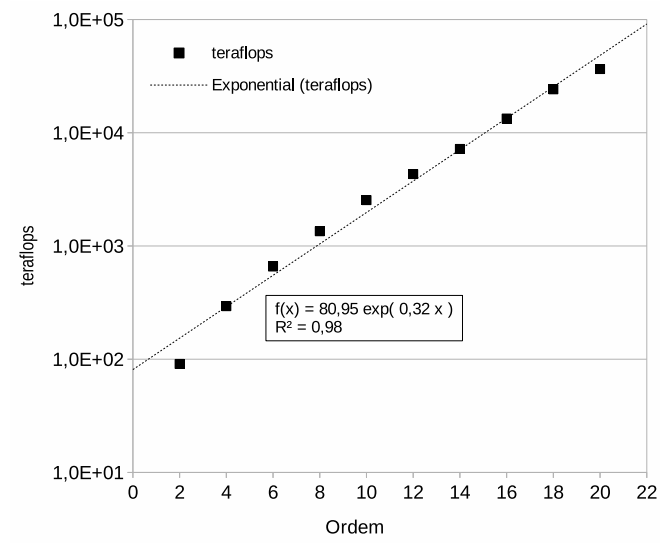

(a) Teraflops.

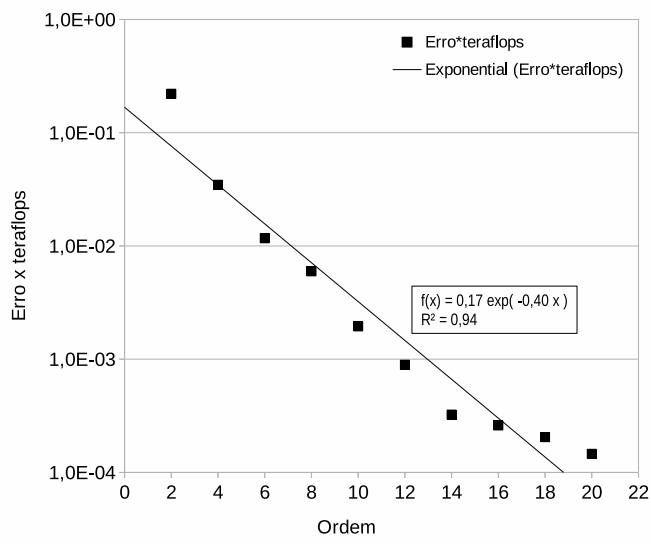

(b) Erro x teraflops.

Figura 4.6: (a)Teraflops $-P=2-20$ e $\mathrm{t}=100$. (b) Produto Erro $\mathrm{x}$ teraflops $P=2-20$ e $\mathrm{t}=100$.

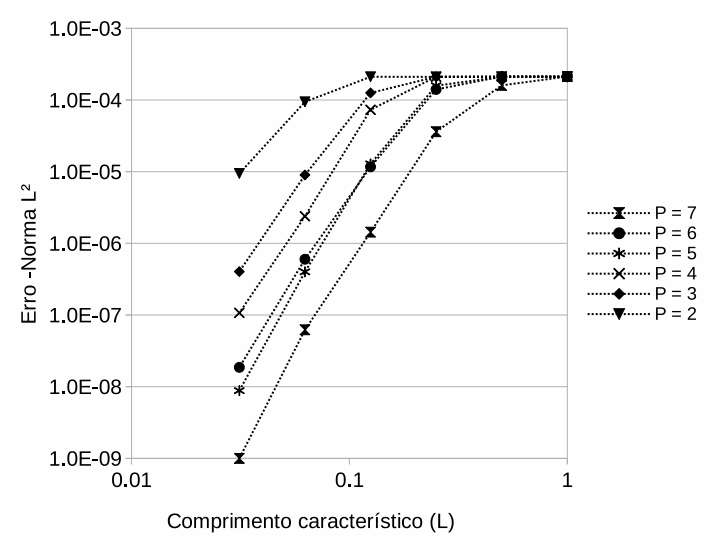

(a) Convergência $h p$.

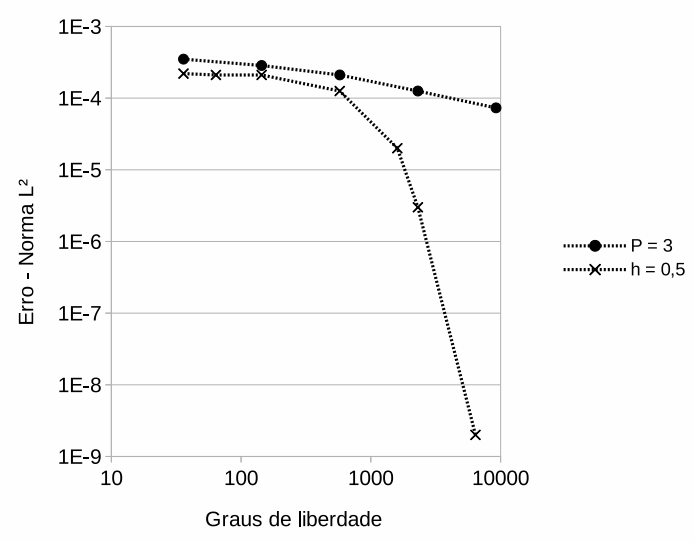

(b) Convergência $h$ e $p$.

Figura 4.7: (a) Convergência $h p$ para $P=2-7$. (b) Convergência $p$ e $h$.

\subsection{Pulso Gaussiana}

\subsubsection{Descrição do problema}

Nesta seção estudamos o comportamento de um pulso gaussiana introduzido na origem do campo de escoamento uniforme. São apresentados dois casos, o primeiro com Mach $=0,0$ e o segundo com Mach $=0,75$. Esse tipo de problema é resolvido por vários autores mas a abordagem que seguiremos é a proposta por Blom [12]. 
O modelo matemático é a equação de Euler linearizada sem termo fonte

$$
\frac{\partial U}{\partial t}+\frac{\partial E}{\partial x}+\frac{\partial F}{\partial y}=0
$$

onde $U=\left[\rho^{\prime}, \rho_{0} u^{\prime}, \rho_{0} v^{\prime}, p^{\prime}\right]^{T}$ são as variáveis do problema e o pulso que deve ser propagado é introduzido como condição inicial $\mathbf{u}_{0}(x, y, t)=\left(\rho^{\prime}, \rho v^{\prime}, \rho u^{\prime}, p^{\prime}\right)^{T}$ :

$$
\mathbf{u}_{0}(x, y, t)=\left(\begin{array}{c}
\rho_{0} \\
u_{0} \\
0 \\
p_{0}
\end{array}\right)+\left(\begin{array}{c}
\beta \\
0 \\
0 \\
\beta / \gamma
\end{array}\right) e^{-\alpha\left(x^{2}+y^{2}\right)}
$$

com $\alpha=\ln (2) / 14$, amplitude da perturbação $\beta=\rho_{0} / 20$ e o campo de escoamento uniforme com valores da tabela 4

\begin{tabular}{|l|c|c|}
\hline Variável & Mach $=0,0$ & Mach $=, 75$ \\
\hline$\rho_{0}$ & 1,4 & 1,4 \\
\hline$u_{0}$ & 0,0 & 0,75 \\
\hline$v_{0}$ & 0,0 & 0,0 \\
\hline$p_{0}$ & 1,0 & 1,0 \\
\hline
\end{tabular}

Tabela 4: Campo médio em variáveis primitivas - Pulso gaussiana.

\subsubsection{Solução analítica}

A LEE podem ser escritas em variáveis primitivas sem os termos fonte como o sistema abaixo:

$$
\begin{aligned}
& \frac{\partial \rho^{\prime}}{\partial t}+M \frac{\partial \rho^{\prime}}{\partial x}+\frac{\partial \rho^{\prime}}{\partial x_{j}}=0 \\
& \frac{\partial u_{i}^{\prime}}{\partial t}+M \frac{\partial u_{i}^{\prime}}{\partial x}+\frac{\partial p^{\prime}}{\partial x_{i}}=0 \\
& \frac{\partial p_{i}^{\prime}}{\partial t}+M \frac{\partial p_{i}^{\prime}}{\partial x}+\frac{\partial u_{j}^{\prime}}{\partial x_{j}}=0
\end{aligned}
$$

e esse sistema resulta em uma equação de onda na forma geral (Apêndice A):

$$
\frac{D^{2} q}{D t^{2}}-\nabla^{2} q=0
$$


A solução é obtida empregando convenientemente a transformada Hankel [12] temos:

$$
\begin{gathered}
p^{\prime}(r, t)=\frac{1}{2 \alpha} \int_{0}^{\infty} \lambda J_{0}(\lambda r)\left[\cos (\lambda t)-\frac{\beta}{2 \alpha} \lambda \sin (\lambda t)\right] e^{-\frac{\lambda^{2}}{4 \alpha}} d \lambda \\
u^{\prime}(r, t)=\frac{x-M t}{2 \alpha} \int_{0}^{\infty} \lambda J_{1}(\lambda r)\left[\sin (\lambda t)+\frac{\beta}{2 \alpha} \lambda \cos (\lambda t)\right] e^{-\frac{\lambda^{2}}{4 \alpha}} d \lambda \\
v^{\prime}(r, t)=\frac{y}{2 \alpha} \int_{0}^{\infty} \lambda J_{1}(\lambda r)\left[\sin (\lambda t)+\frac{\beta}{2 \alpha} \lambda \cos (\lambda t)\right] e^{-\frac{\lambda^{2}}{4 \alpha}} d \lambda
\end{gathered}
$$

onde

$$
r=\sqrt{(x-M t)^{2}+y^{2}} \quad \rho^{\prime}=p^{\prime}
$$

e $J_{0}$ e $J_{1}$ são funções de Bessel do primeiro tipo de ordem zero e um respectivamente.

Podemos tomar $r=0$, lembrando que $r=\sqrt{(x-M t)^{2}+y^{2}}$, e com isso a solução apresentada na equação (4.9) é valida sobre a reta de equações $x=M t, y=0$ para $M$ e $t$ arbitrários.

$$
p^{\prime}(0, t)=1-\beta t+\left[1-\beta t+\frac{\beta}{2 \alpha}\right] i \sqrt{\alpha \pi} \operatorname{erf}(i t \sqrt{\alpha}) e^{-\alpha t^{2}}
$$

$\operatorname{erf}(\tau)$ é a função erro definida por

$$
\operatorname{erf}(\tau)=\frac{2}{\sqrt{\pi}} \int_{0}^{\tau} e^{-t^{2}} d t
$$

\subsubsection{Resultados numéricos}

O problema foi simulado em uma malha estruturada de dimensões $-100 \leq x, y \leq$ 100 com $9 \times 9$ quadrados, figura 4.1, e na figura 4.8 vemos a superfície de pressão com (a) Mach $=0.0$ e (b)Mach=0.75, $\mathrm{P}=14$ e $t=30$, o comportamento do pulso é idêntico em cada caso exceto pelo fato de que com $\mathrm{Mach}=0,75$ o pulso não se deforma e é carregado pela corrente.

Para o estudo do erro realizamos simulações com $\mathrm{Mach}=0.0$, ordens de 2 a 20 e tempo $t=30$, comparando 200 pontos sobre a reta $y=0 \mathrm{com}$ a solução analítica. O resultado é apresentado na figura 4.9a que mostra erros da ordem de $10^{-12}$ para $\mathrm{P}=20$. Esse resultado não surpreende pois o pulso gaussiana é um problema mais simples onde a evolução temporal influencia na propagação do pulso e não no termo fonte da equação como é o caso dos demais problemas analisados, inclusive, o monopolo apresentado neste trabalho é uma seqüência periódica de pulsos aonde obtemos erro da ordem de $10^{-8}$. Faz sentido que ao resolver um único pulso obtenhamos resultados melhores que resolver uma seqüência deles. 


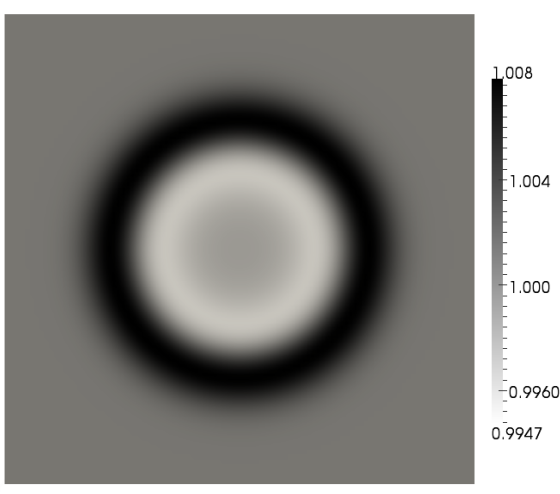

(a) $\mathrm{Mach}=0,0$.

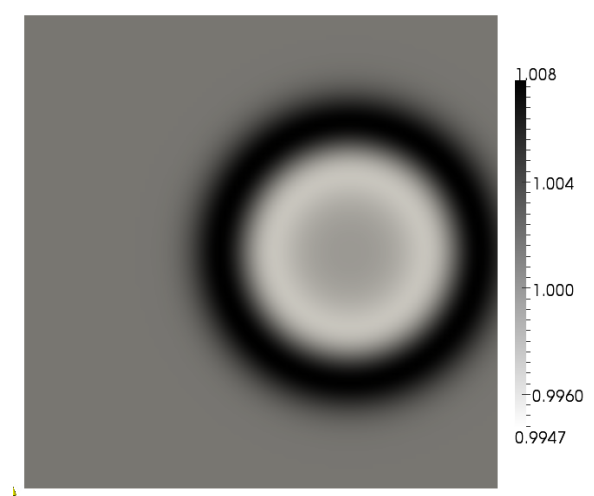

(b) Mach=0,75.

Figura 4.8: Superfície de pressão do pulso gaussiana - Mach $=0.0, \mathrm{P}=20$ e t=50.

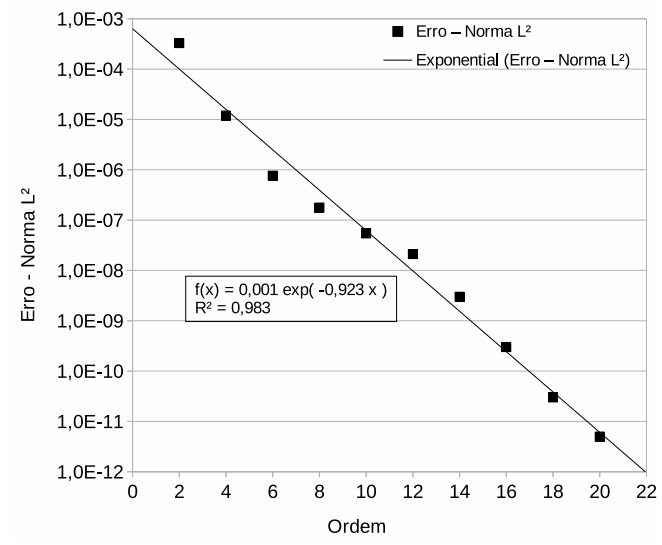

(a) Convergência.

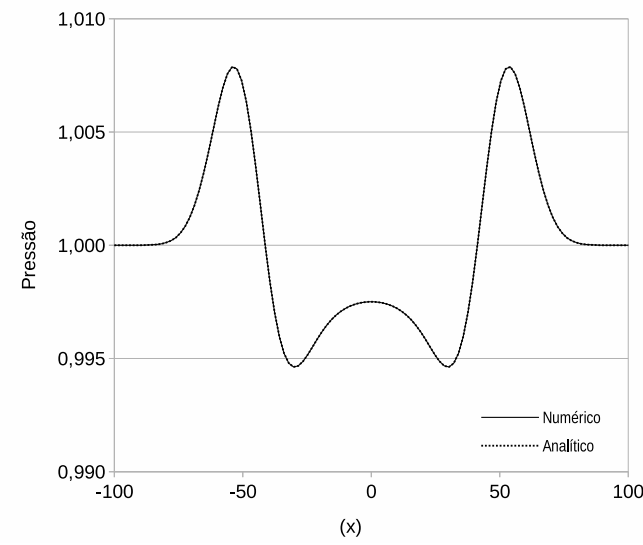

(b) Perfil $y=0$ e $t=30$.

Figura 4.9: Perfil de pressão do pulso gaussiana $-\mathrm{y}=0$, Mach $=0,0, \mathrm{P}=20$ e t $=30$.

A figura $4.9 \mathrm{~b}$ mostra o perfil de pressão obtido com Mach=0, $\mathrm{P}=14$ e tempo $\mathrm{t}=30$ aonde não se distingue a solução numérica da analítica e a figura 4.10 mostra a evolução do pulso para os tempos de $t=0,10,30,45$.

\subsection{Monopolo}

\subsubsection{Descrição do problema}

O problema tratado nessa seção é a propagação de um fonte sonora do tipo monopolo em um campo de escoamento subsônico e supersônico que foi estudado inicialmente por Bailly \& Juvé [13]. O modelo matemático que descreve esse problema é a equação de 


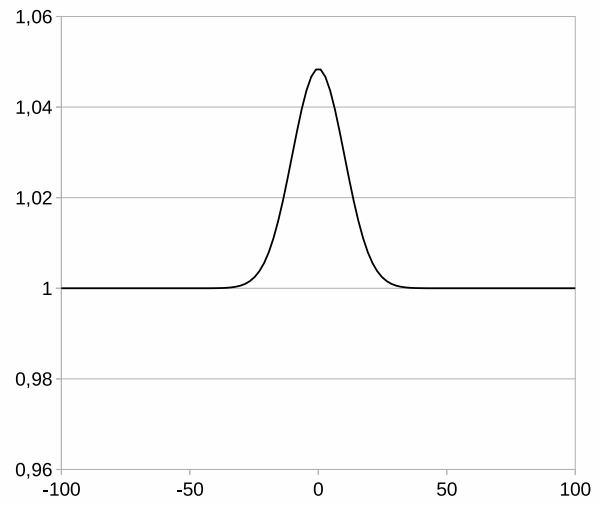

(a) $\mathrm{t}=0$.

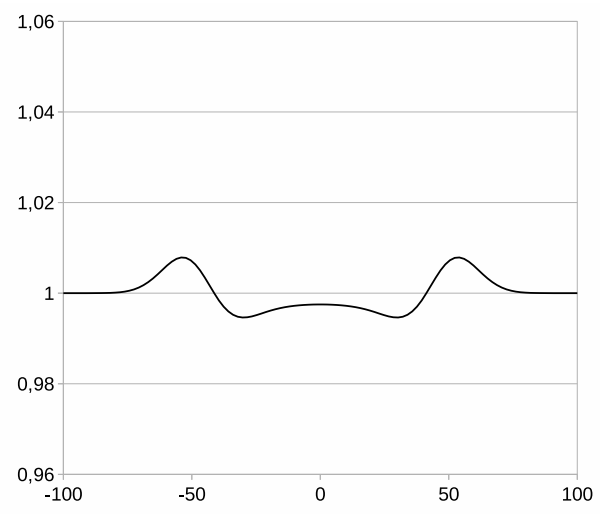

(c) $t=30$.

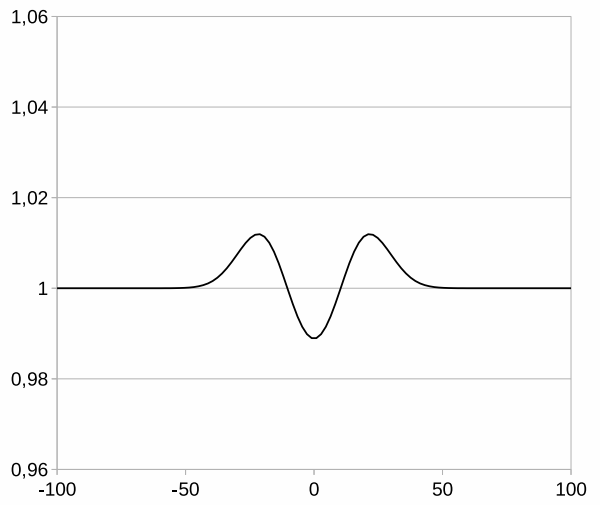

(b) $\mathrm{t}=10$.

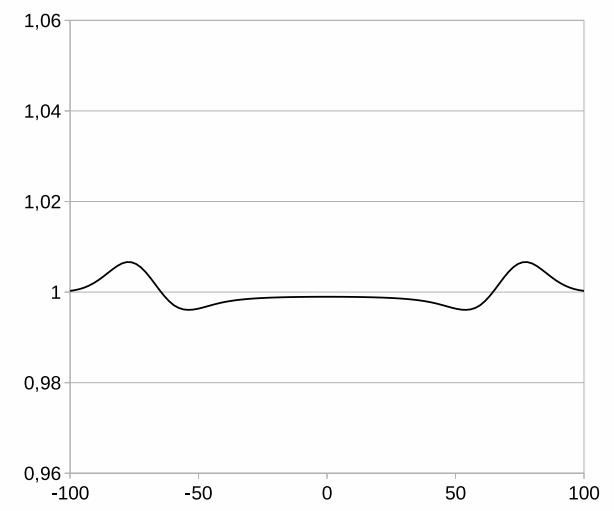

(d) $\mathrm{t}=45$.

Figura 4.10: Perfil de pressão do pulso gaussiana - $\mathrm{y}=0$, Mach=0.0 e $\mathrm{P}=20$.

Euler linearizada:

$$
\frac{\partial U}{\partial t}+\frac{\partial E}{\partial x}+\frac{\partial F}{\partial y}=S
$$

onde $U=\left[\rho^{\prime}, \rho_{0} u^{\prime}, \rho_{0} v^{\prime}, p^{\prime}\right]^{T}$ são as variáveis do problema, o termo fonte $\mathrm{S}$ é um pulso gaussiana periódico dado por:

$$
S=\left(\begin{array}{c}
\beta \\
0 \\
0 \\
\beta / \gamma
\end{array}\right) \operatorname{sen}(\omega t) e^{-\alpha\left[\left(x-x_{s}\right)^{2}+\left(y-y_{s}\right)^{2}\right]}
$$


e domínio computacional em $2 \mathrm{D}$ tem dimensões $-100 \leq x, y \leq 100$ formado por malha de $9 \times 9$ quadrados, figura 4.1 .

\subsubsection{Solução analítica}

A solução apresentadas nesta seção foi desenvolvida por Bailly \& Juvé [13]. Vamos relembrar as LEE que agora possuem um termo fonte $S_{i}$

$$
\begin{aligned}
& \frac{\partial \rho^{\prime}}{\partial t}+M \frac{\partial \rho^{\prime}}{\partial x}+\frac{\partial \rho^{\prime}}{\partial x_{j}}=S_{0}, \\
& \frac{\partial u_{i}^{\prime}}{\partial t}+M \frac{\partial u_{i}^{\prime}}{\partial x}+\frac{\partial p^{\prime}}{\partial x_{i}}=S_{i}, \\
& \frac{\partial p_{i}^{\prime}}{\partial t}+M \frac{\partial p_{i}^{\prime}}{\partial x}+\frac{\partial u_{j}^{\prime}}{\partial x_{j}}=S_{3},
\end{aligned}
$$

O sistema acima resulta em uma equação de onda na forma geral (Apêndice A)

$$
\frac{D^{2} q}{D t^{2}}-\nabla^{2} q=S
$$

$\operatorname{com} S=f(x, y) e^{-i \omega t}$

Adotando um sistema de coordenadas que se move como o campo médio $\tau=t$, $\xi=x-M t$ e $\eta=y$ pode-se mostrar (Apêndice C) que a solução para a perturbação de pressão é obtida pelo produto de convolução

$$
p^{\prime}(x, y, t)=\int_{0}^{x} f(x-\tau, y, t) \frac{d G}{d t}(\tau, y, t) d \tau
$$

onde $G(x, y, t)$ é a função de Green para o caso subsônico

$$
G(x, y, t)=\frac{i}{4 c_{0}} \frac{1}{\sqrt{1-M^{2}}} H_{0}\left[k \frac{\sqrt{x^{2}+\left(1-M^{2}\right) y^{2}}}{1-M^{2}}\right] \exp \left(-i \frac{M}{1-M^{2}} k x-i \omega t\right)
$$

e para o caso supersônico

$$
G(x, y, t)=\frac{1}{2 c_{0}} \frac{1}{\sqrt{M^{2}-1}} J_{0}\left[k \frac{\sqrt{x^{2}+\left(M^{2}-1\right) y^{2}}}{M^{2}-1}\right] \exp \left(-i \frac{M}{M^{2}-1} k x-i \omega t\right)
$$

onde $H_{0}$ é a função de Hankel e $J_{0}$ é a função de Bessel ambas de primeiro tipo e ordem zero.

A equação (4.18) é uma equação integral e não possui solução analítica. Dessa forma, 
nas seções seguintes, quando mencionarmos solução analítica, deve-se entender que para $y=y_{0}$ e $t=t_{0}$ constantes, o valor da pressão para cada ponto de interesse $x_{i}$, foi obtido pela integração numérica de:

$$
p^{\prime}\left(x_{i}, y_{0}, t_{0}\right)=\int_{0}^{x_{i}} f\left(x_{i}-\tau, y_{0}, t_{0}\right) \frac{d G}{d t}\left(\tau, y_{0}, t_{0}\right) d \tau
$$

\subsubsection{Caso Subsônico}

A propagação do monopolo em um campo de escoamento subsônico (Mach=0.5) é obtida resolvendo a equação (4.12) com o termo fonte (4.13) e os parâmetros $\alpha=\ln (2) / 2$, amplitude da perturbação $\beta=\rho_{0} / 100$, freqüência angular $\omega=\pi / 15$ e origem da fonte sonora em $\left(x_{s}, y_{s}\right)=(-30,0)$. O campo de escoamento uniforme possui os valores da tabela 2 .

A evolução das perturbações de pressão para $t=40,70,100,130$ é mostrada na figura 4.11 (a)-(d). Já a figura 4.12 mostra o perfil de pressão sobre a reta $y=0$ e $t=150$ onde não se distingue a solução numérica da solução analítica. Lembrando que a velocidade da onda é $v=2 \pi \lambda / \omega$, verificamos por essa mesma figura que à montante e à jusante as ondas se propagam com velocidades $v_{0}$ e $3 v_{0}$ que correspondem a $(1 \pm M)$ e com esses resultados podemos afirmar que o software resolve esse tipo de problema de forma eficiente.

\subsubsection{Caso Supersônico}

A propagação do monopolo em um campo de escoamento supersônico (Mach=2.0) é obtida resolvendo a equação () e o termo fonte () \{fazer mudança na descrição do problema para referenciar as LEE em variáveis conservadas seção 2.5.1 \} com os parâmetros $\alpha=-\ln (2) / 5, \beta=\rho_{0} / 25$ e $\omega=\pi / 5$, origem da fonte sonora em $\left(x_{s}, y_{s}\right)=(-50,0)$ e o campo de escoamento uniforme com os valores da tabela 5 .

\begin{tabular}{|c|c|}
\hline Variável & Valor \\
\hline$\rho_{0}$ & 1,4 \\
\hline$u_{0}$ & 2,0 \\
\hline$v_{0}$ & 0,0 \\
\hline$p_{0}$ & 1,0 \\
\hline
\end{tabular}

Tabela 5: Campo médio e condições iniciais - Monopolo Mach=2,0.

A evolução das perturbações de pressão para $t=50,100,150,250$ é mostrada na figura 4.13 (a)-(d) onde podemos verificar que o ângulo produzido pelo cone de Mach, definido em coordenadas cilíndricas por $M \operatorname{sen}(\theta)=1$, é aproximadamente $\theta \simeq 29.4$ que 


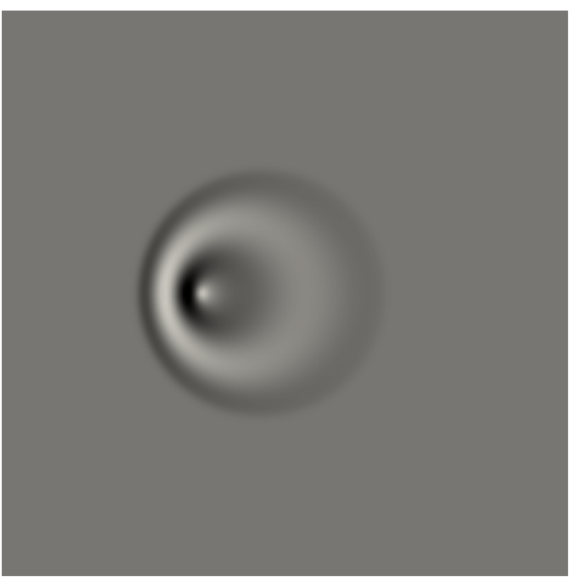

(a) $\mathrm{t}=40$.

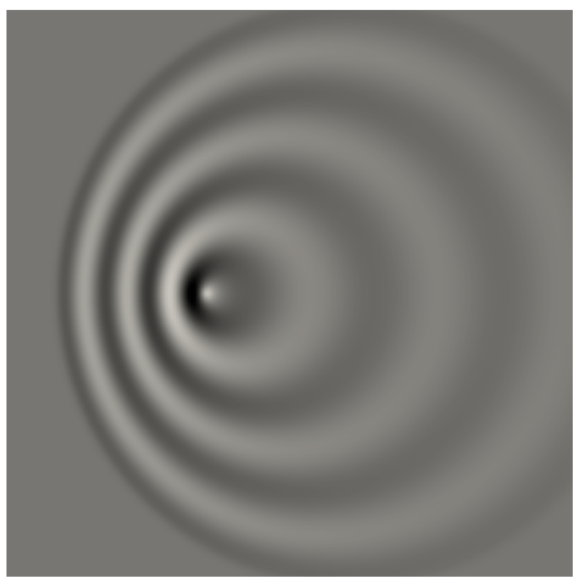

(c) $\mathrm{t}=100$.
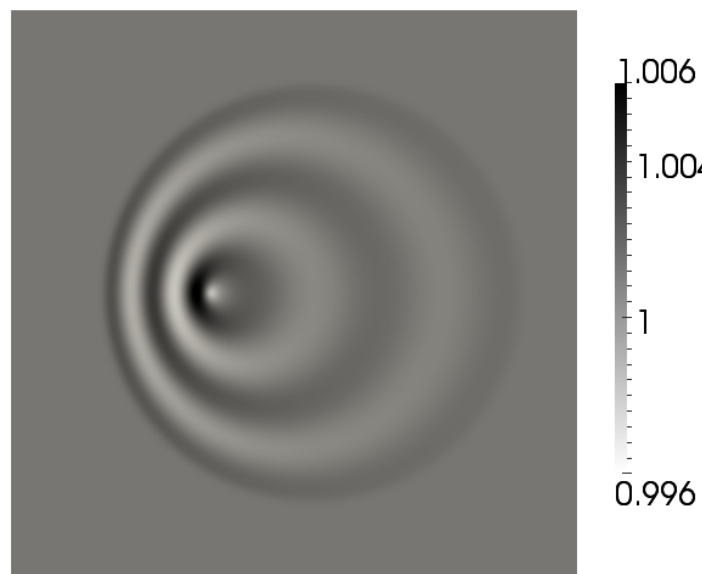

(b) $\mathrm{t}=70$.
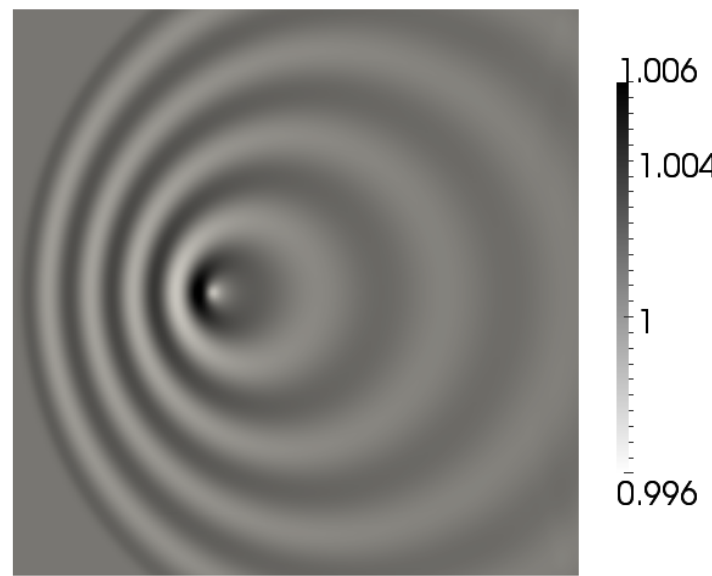

(d) $\mathrm{t}=130$.

Figura 4.11: Superfície de pressão do monopolo - Mach=0.5 e $\mathrm{P}=20$.

está de acordo com Mach=2.0. Também podemos verificar a sobreposição de ondas que se propagam à jusante com velocidades $M \pm 1$. Já a figura 4.14 mostra o perfil de pressão para $y=0$ e $\mathrm{t}=250$, nela verificamos pequenas diferenças entre a solução numérica e a analítica mas em linhas gerais podemos afirmar que o problema foi bem resolvido pois as diferenças aparecem na região próxima à fonte sonora e nesta região as descontinuidades estão concentradas. Teoricamente o método DG trata sem maiores problemas as descontinuidades da solução desde que elas estejam nas interfaces do elemento, uma vez que isso não acontece a descontinuidade é aproximada por um polinômio e nessa situação temos o fenômeno de Gibbs. Na prática garantir que uma descontinuidade esteja na interface do elemento não é algo simples e devemos esperar que ela apareça dentro de 


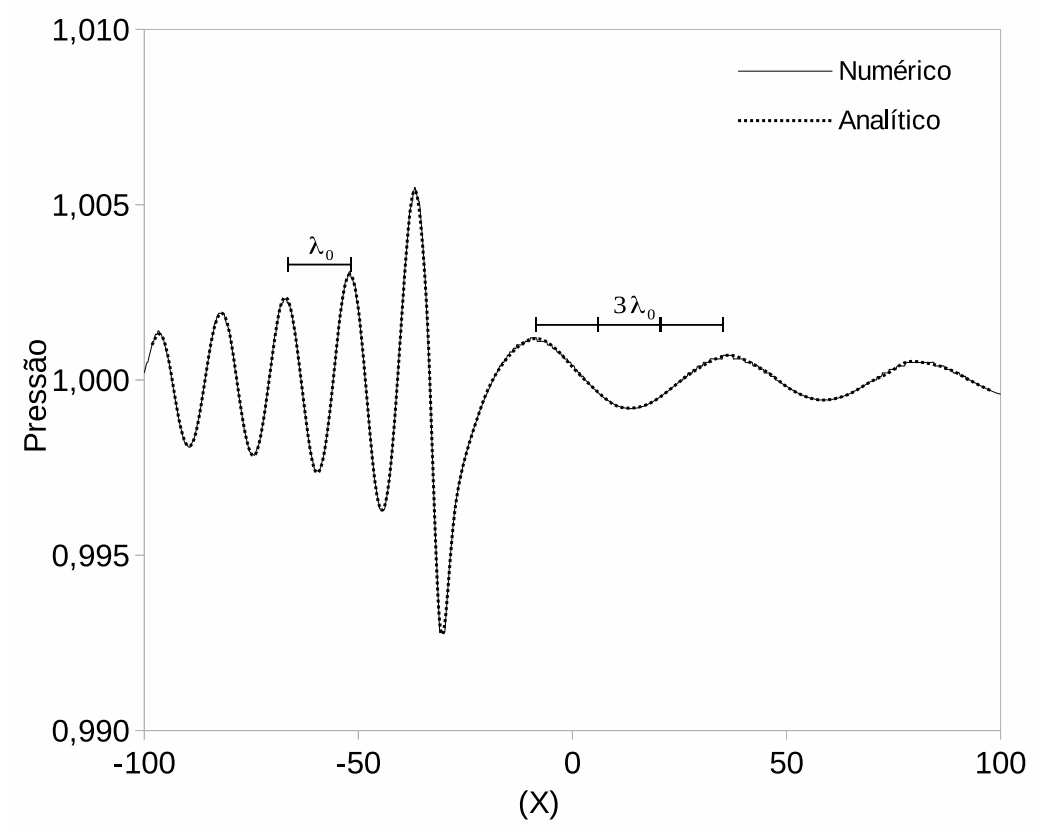

Figura 4.12: Perfil de pressão do monopolo $-\mathrm{y}=0, \mathrm{Mach}=0,5, \mathrm{P}=20$ e $\mathrm{t}=150$.

um elemento, neste caso um método eficiente é um mecanismo de dissipação artificial que ainda não foi implementado no software. Diante dessas observações e com intenção de estudar o comportamento do software na presença de descontinuidades, analisamos o perfil da pressão ao longo da reta $x=59$ em que o cone da Mach está localizado entre $-64 \leq y \leq 64$, o resultado é mostrado na figura 4.15(a)-(b) aonde verificamos que o software resolveu a descontinuidade e apareceram oscilações que é um fenômeno numérico esperado e conhecido. 


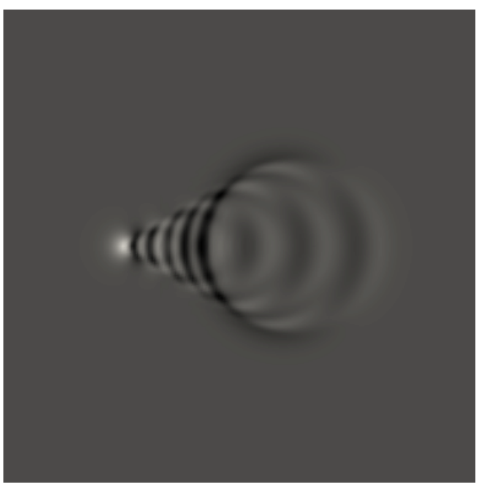

(a) $\mathrm{t}=50$.

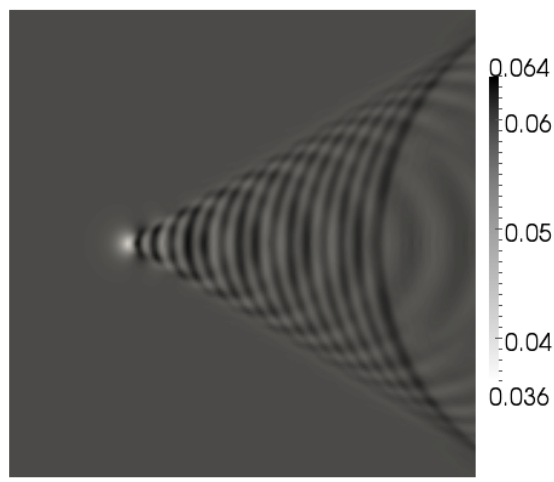

(c) $\mathrm{t}=150$.

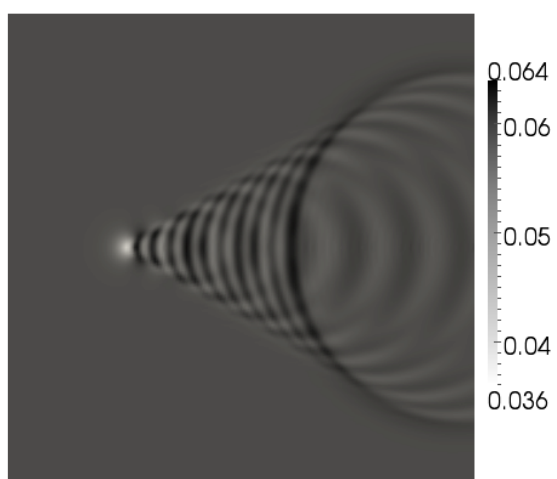

(b) $\mathrm{t}=100$.

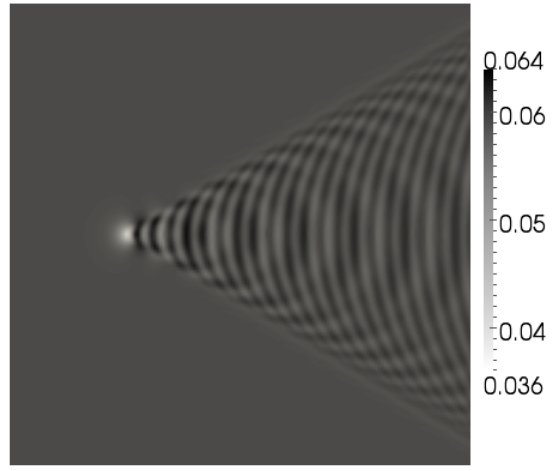

(d) $\mathrm{t}=250$.

Figura 4.13: Superfície de pressão do monopolo - Mach=2,0 e $\mathrm{P}=20$.

\subsection{Dipolo}

A distribuição do tipo dipolo investigada está localizada na origem e é definida pela função

$$
f_{j}(\mathbf{x}, t)=-\frac{5}{\pi} \epsilon \cos \left(\frac{\pi x}{5}\right) e^{-\alpha y^{2}} \operatorname{sen}(\omega t) \delta_{1 j}
$$

que substituída na equação (2.23) resulta no termo fonte:

$$
\mathbf{S}=\left(\begin{array}{l}
0 \\
\beta \\
0 \\
0
\end{array}\right) \operatorname{sen}(\pi x / 5) \operatorname{sen}(\omega t) \mathrm{e}^{-\alpha y^{2}}
$$




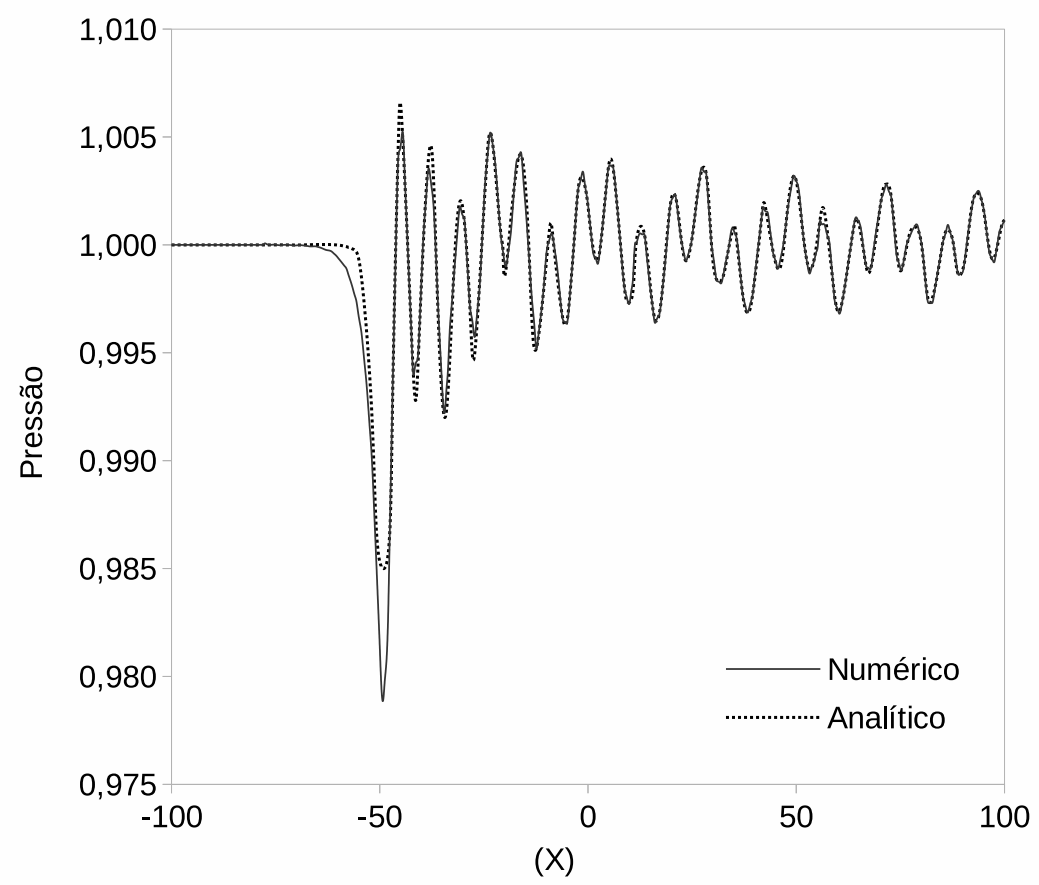

Figura 4.14: Perfil de pressão do monopolo $-\mathrm{y}=0$, Mach=2,0, $\mathrm{P}=20$ e $\mathrm{t}=250$.

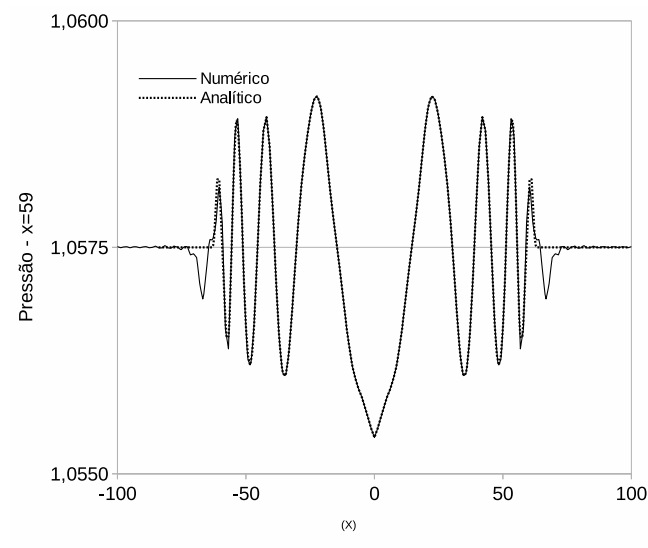

(a)

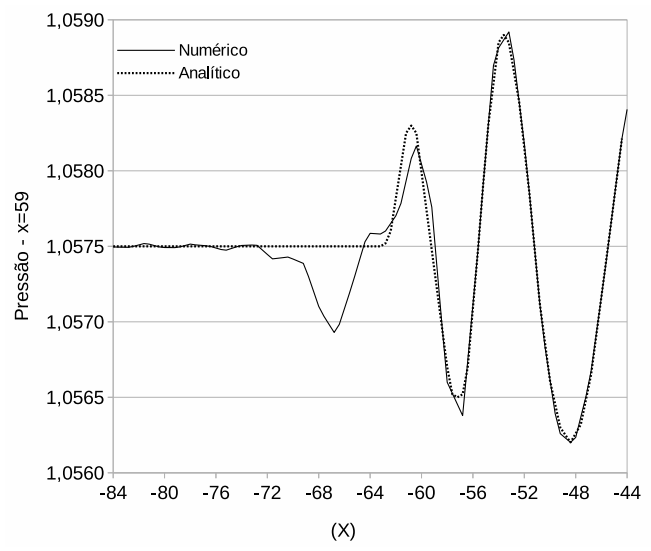

(b)

Figura 4.15: Perfil de pressão do monopolo $-\mathrm{x}=59$, Mach=2,0, $\mathrm{P}=20$ e $\mathrm{t}=250$.

para $[x, y] \in[-5 ; 5] \mathrm{x} \mathbb{R}$, com freqüência angular $\omega=\frac{\pi}{10}$, amplitude $\epsilon=0.01$ e $\alpha=$ $\ln (2) / 2$, acoplado a LEE na forma vetorial:

$$
\frac{\partial U}{\partial t}+\frac{\partial E}{\partial x}+\frac{\partial F}{\partial y}=S
$$


A solução para a perturbação de pressão foi apresentada por Bailly \& Juvé [13]. Ela é obtida pelo produto de convolução

$$
p^{\prime}(x, y, t)=\int_{0}^{x} f(x-\tau, y, t) \frac{d G}{d t}(\tau, y, t) d \tau
$$

onde $G(x, y, t)$ é a função de Green

$$
G(x, y, t)=\frac{i}{4 c_{0}} H_{0}^{(1)}\left[\frac{\omega}{c_{0} \sqrt{x^{2}+y^{2}}}\right] \mathrm{e}^{-i \omega t}
$$

e $H_{0}^{(1)}$ é a função de Hankel ordem zero e primeiro tipo.

Este problema foi resolvido com uma malha estruturada de $9 \times 9$ quadrados, figura 4.1 e com o campo de escoamento uniforme com os valores da tabela 4 com Mach $=0.0$. A figura 4.16 mostra os isocontornos de pressão para o tempo $t=90$ e ordem de aproximação $P=20$. As figuras 4.17 (a)-(b) mostram o perfil de pressão sobre a reta $y=0$ para $t=90,105$ e em ambas não se distingue a solução numérica da analítica.

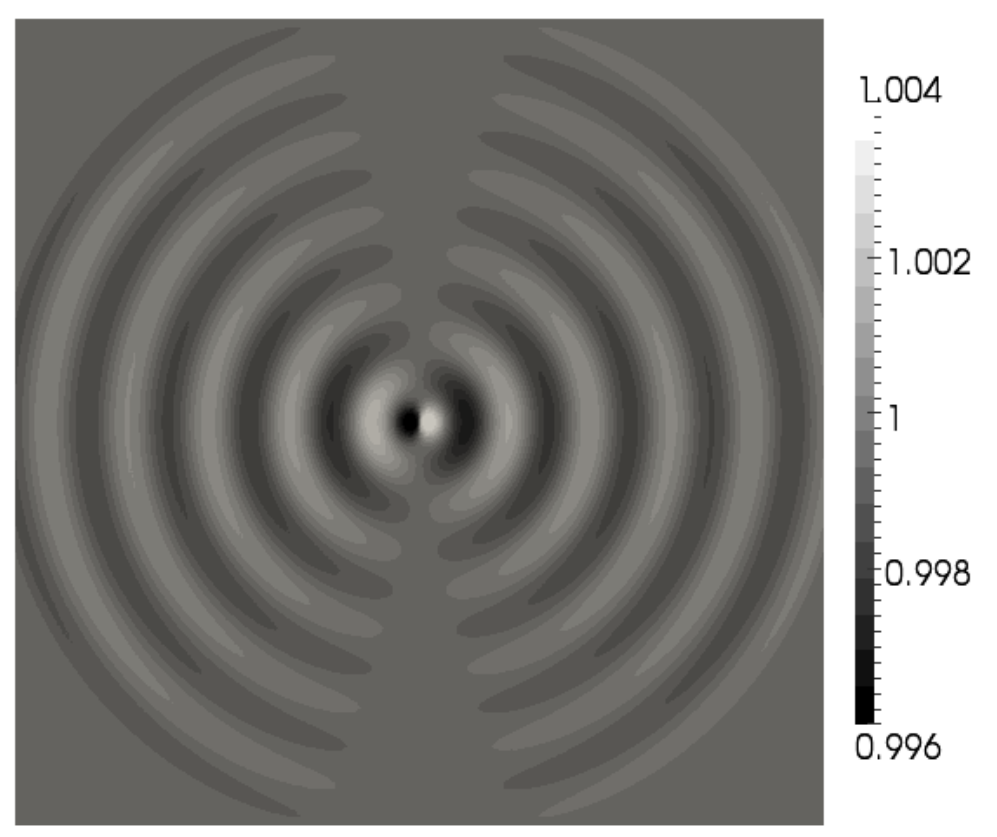

Figura 4.16: Superfície de pressão do dipolo $-\mathrm{Mach}=0,0, \mathrm{P}=20$ e t=90. 


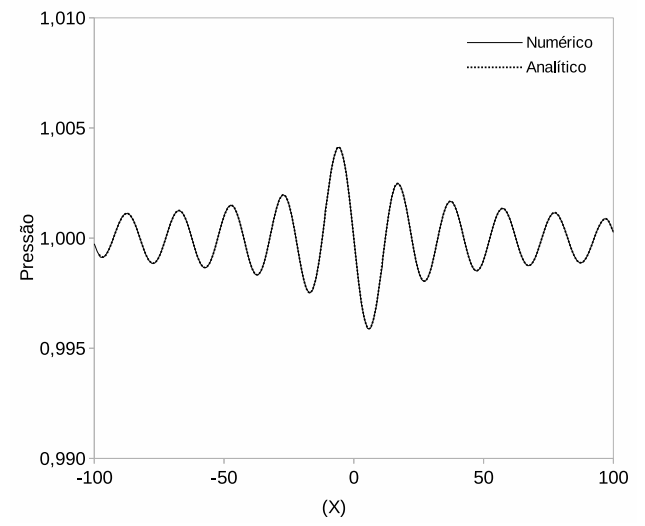

(a) $\mathrm{t}=90$.

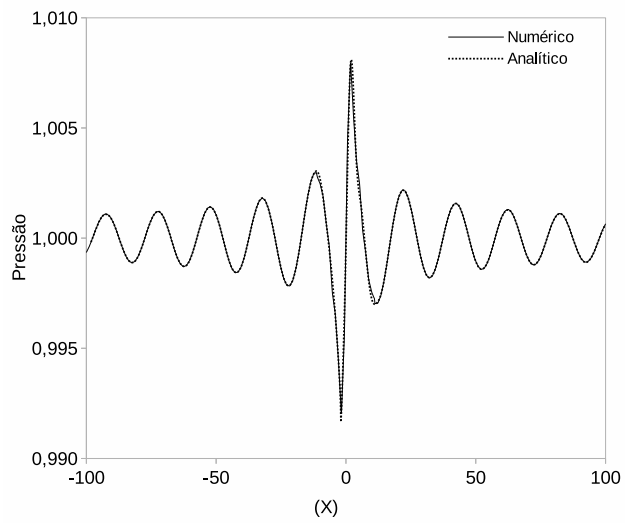

(b) $t=105$.

Figura 4.17: Perfil de pressão do dipolo - $\mathrm{y}=0$, Mach=0,0, $\mathrm{P}=20$.

\subsection{Quadripolo}

A distribuição do tipo quadripolo investigada está localizada na origem e é definida pela tensor:

$$
T_{i j}=\left[\begin{array}{cc}
-\cos [(\pi / 5) x] e^{-\alpha y^{2}} & 0 \\
0 & \cos [(\pi / 5) y] e^{-\alpha x^{2}}
\end{array}\right] \frac{5}{\pi} \epsilon \operatorname{sen}(\omega t),
$$

que substituído na equação (2.24) resulta no termo fonte:

$$
\mathbf{S}=\left(\begin{array}{c}
0 \\
\beta \\
-\beta \\
0
\end{array}\right) \operatorname{sen}(\pi x / 10) \operatorname{sen}(\omega t) \mathrm{e}^{-\alpha y^{2}},
$$

para $-10 \leq x, y \leq 5$, com freqüência angular $\omega=\frac{\pi}{10}$, amplitude $\epsilon=0.01$ e $\alpha=\ln (2) / 2$ que deve ser acoplado a LEE na forma vetorial:

$$
\frac{\partial U}{\partial t}+\frac{\partial E}{\partial x}+\frac{\partial F}{\partial y}=S
$$

A solução para a perturbação de pressão foi apresentada po Bailly \& Juvé [13]. Ela 
consiste na soma de dois produtos de convolução,

$$
p^{\prime}(x, y, t)=-\int_{0}^{x}\left[\frac{\partial T_{x x}}{\partial x}(x-\tau, y, t)+\frac{\partial T_{y y}}{\partial y}(x-\tau, y, t)\right] \frac{d G}{d t}(\tau, y, t) d \tau,
$$

onde $G(x, y, t)$ é a função de Green

$$
G(x, y, t)=\frac{i}{4 c_{0}} H_{0}^{(1)}\left[\frac{\omega}{c_{0} \sqrt{x^{2}+y^{2}}}\right] \mathrm{e}^{-i \omega t},
$$

e $H_{0}^{(1)}$ é a função de Hankel ordem zero e primeiro tipo.

Este problema foi resolvido com uma malha estruturada de $9 \times 9$ quadrados, figura 4.1 e com o campo de escoamento uniforme com os valores da tabela 4 com Mach=0.0. A figura 4.16 mostra os isocontornos de pressão para o $t=90$ e $\mathrm{P}=20$ e as figuras $4.17(\mathrm{a})$-(b) mostram o perfil de pressão sobre a reta $y=0$ para $t=90,105$ onde não se distingue a solução numérica da analítica.

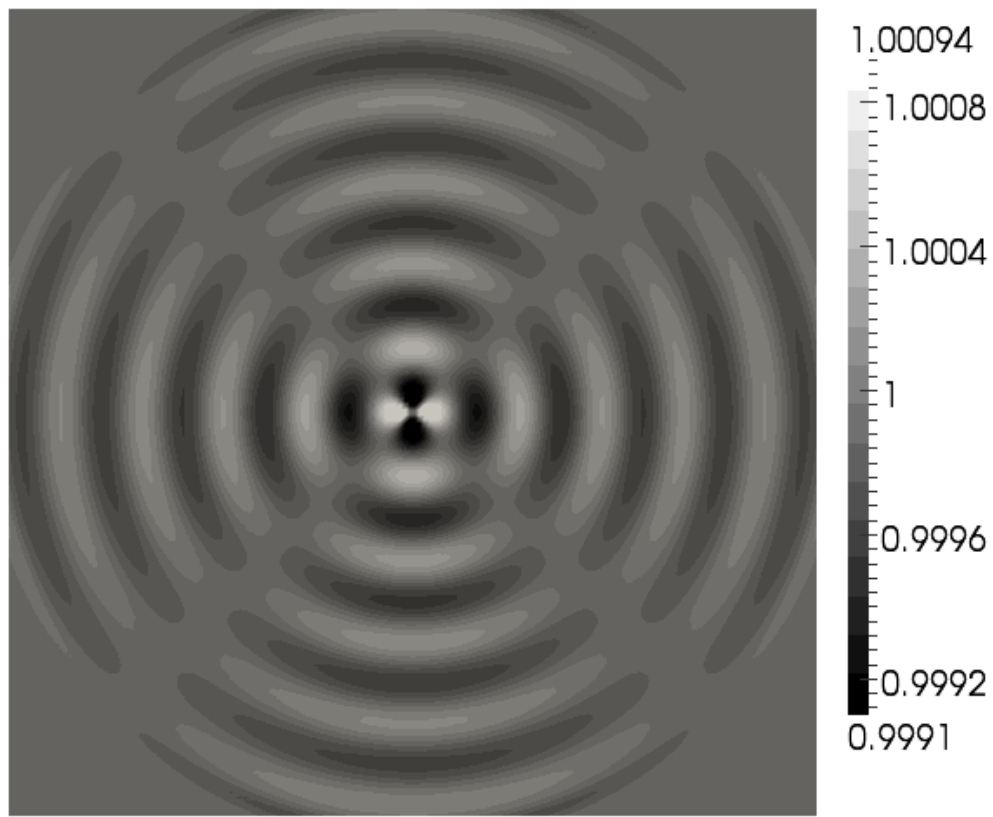

Figura 4.18: Superfície de pressão do quadripolo - Mach $=0,0, \mathrm{P}=20$ e t=90. 


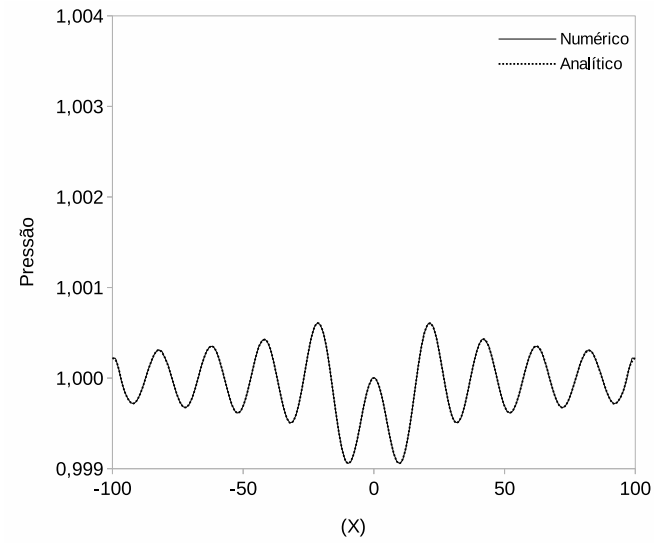

(a) $\mathrm{t}=90$.

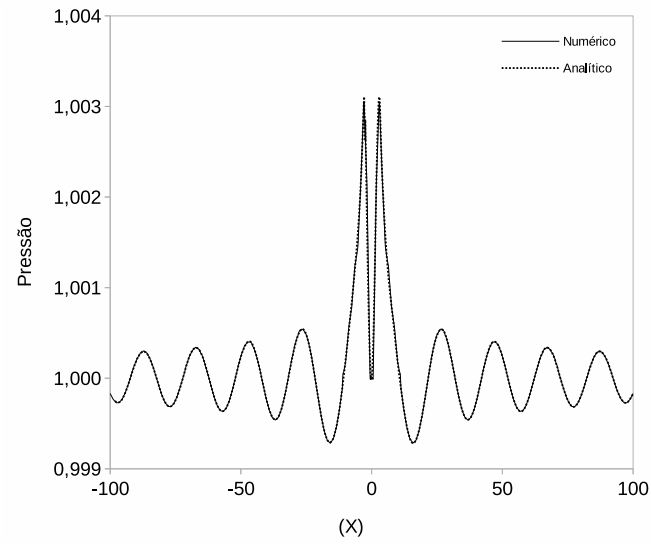

(b) $\mathrm{t}=105$.

Figura 4.19: Perfil de pressão do quadripolo $-\mathrm{y}=0$, Mach $=0,0, \mathrm{P}=20$ e t=90.

\section{Conclusão e trabalhos futuros}

O método DG mostra-se novamente um eficiente ferramenta para problemas de simulação numérica. Sua estabilidade e precisão foram testadas e os resultados estão de acordo com a literatura. Em particular para problemas de CAA ele mostra-se uma ferramenta interessante pois as aproximações de alta ordem são capazes de capturar uma variedade grande de comprimentos de onda. As fontes do tipo monopolo, dipolo e quadripolo estudadas neste trabalho conseguem reproduzir a maioria dos problemas de interesse no contexto de CAA. Dessa forma, para a simulação de problemas reais necessitamos de uma fronteira computacional reflexiva para simular paredes sólidas, não reflexivas para simular o domínio infinito e um mecanismo de dissipação artificial para assegurar a estabilidade do método na presença de ondas de choque. Além disso, a LEE aqui implementada pode ser estendida para 3D.

Neste trabalho, estudamos a propagação sonora baseada em técnicas SNGR, que são técnicas eficientes para desenvolvimento e teste de software. Entretanto, para resolver problemas reais adentrando em outro ramo de estudo, pode-se utilizar a estratégica híbrida onde a fonte sonora é proveniente das tensões de vorticidade e cisalhamento geradas pelos escoamento de jatos ou perfis aerodinâmicos. Para tanto será necessário acoplar o resultado do escoamento em pequena porção do espaço utilizando DNS ou LES com a propagação sonora obtida pelas LEE. Esse é um trabalho desafiador do ponto de vista do desenvolvimento de software, pois o Nektar++ ainda não possui o LES implementado, mas o DNS (utilizado em uma pequena região do domínio computacional) pode ser usado para resolver o escoamento turbulento. Uma vez resolvido o campo de escoamento, outro desafio será transformar as flutuações de pressão e de vorticidade em 
fontes sonoras, porém trata-se de um desafio de implementação e validação do software pois o tensor de Lighthill $T_{i j}$ pode ser tratado como condição de contorno imposta ao campo de propagação sonora sem o conhecimento detalhado do campo de escoamento turbulento. 


\section{Referências}

[1] ESCOBAR, M. Finite Element Simulation of Flow-Induced Noise using Lighthill's Acoustic Analogy. 2007. Tese (Doutorado em Física) - Universität ErlangenNürnberg, Erlangen, Germany, 2007.

[2] LIGHTHILL, M. J. On Sound Generated Aerodynamically II. Turbulence as a Source of Sound. Proceedings of the Royal Society of London. Series A, Mathematical and Physical Sciences, v. 222-1148, p. 1.32, 1954.

[3] TAM, C. K. Computational aeroacoustics: An overview of computational challenges and applications. International Journal of Computational Fluid Dynamics, v. 18, n. 2, p. 547-567, aug 2004.

[4] SARKAR, S.; HUSSAINI, M. Y. Computation of the sound generated by isotropic turbulence. Technical Report 93-74, ICASE, 1993.

[5] COLONIUS, T.; LELE, S. K. Computational aeroacoustics: progress on nonlinear problems of sound generation. Progress in Aerospace Sciences, v. 40, p. 345-416, 2004 .

[6] BECHARA, W.; BAILly, C.; CANDEL, S. M.; LAFON, P. Stochastic approach to noise modeling for free turbulent flows. AIA A Journal, v. 32, p. 455-463, 1994.

[7] LELE, S. K. Computational aerocoustics - A review. AIAA-Paper 97-0018, Aerospace Sciences Meeting and Exhibit, Reno, jan 1997.

[8] E.MAHONA; REDONNET, S.; TERRACOL, M.; GUéNANFF, R. Numerical simulation of aeroacoustics noise. ECCOMAS, v. 28, 2004.

[9] KARNIADAKIS, G. E.; SHERWIN, S. J. Spectral/hp element methods for computational fluid dynamics. Oxford University Press, 2005.

[10] BAILLY, C.; JUVé, D. A stochastic approach to compute subsonic noise using linearized Euler equations. AIAA Journal, v. 99-1872, 1999.

[11] BILLSON, M.; ERIKSSON, L.-E.; DAVIDSON, L. Acoustics source terms for the linear Euler equations on conservative form. AIAA Journal, v. 2582, 2002.

[12] BLOM, C. Discontinuous galerkin method on tetrahedral elements for aeroacoustics. 2003. Tese (Doutorado em Física) - University of Twente, Enschede, Netherlands, 2003.

[13] BAILLY, C.; JUVé, D. Numerical solution of acoustic propagation problem using linearized Euler equations. AIAA Journal, v. 38, 2000. 
[14] RIENSTRA, S.; HIRSCHBERG, A. An introduction to aeroacoustics. Eindhoven University of Technology, 2004.

[15] ANDERSON, J. D. J. Computational Fluid Dynamics: The basics with applications. Mac-Graw Hill, 1995.

[16] GOLDSTEIN, M. E. Aeroacoustics. New York: McGraw-Hill International Book Company, 1976.

[17] COLONIUS, T.; LELE, S. K. Boundary conditions for direct computation of aerodynamic sound generation. 14th AIAA Aeroacoustics Conference, v. 1, p. 438-447, May 1992.

[18] WAGNER, C.; HUTTL, T.; SAGAUT, P. Large-eddy simulation for acoustics. Cambridge: Cambridge University Press, 2006.

[19] BAYLISS, A.; TURKEL, E. Far field boundary conditions for compressible flows. Journal of Computational Physics, v. 48, n. 2, p. 182 - 199, 1982.

[20] TAM, C. K. W. Advances in numerical boundary conditions for computational aeroacoustics. AIAA Journal, v. 1774, 1997.

[21] ISRAELI, M.; ORSZAG, S. A. Approximation of radiation boundary conditions. Journal of Computational Physics, v. 41, n. 1, p. 115 - 135, 1981.

[22] RAI, M. M.; MOIN, P. Direct simulations of turbulent flow using finite-difference schemes. Journal of Computational Physics., San Diego, CA, USA, v. 96, p. 15-53, Oct. 1991.

[23] COlOniUS, T.; LELE, S. K.; MOIN, P. Boundary conditions for direct computation of aerodynamic sound generation. AIAA Journal, v. 1, n. 438-447, May 1992.

[24] FREUND, J. B. Proposed Inflow/Outflow Boundary Condition for Direct Computation of Aerodynamic Sound. AIAA Journal, v. 35, n. 4, p. 740-742, Apr. 1997.

[25] DOWling, A.; FFOWCS WILliAnS, J. E. Sound and source of sound. New York, USA: Ellis Horwood Limited, 1983.

[26] CURLE, N. The influence of solid boundaries upon aerodynamic sound. Proceedings of the Royal Society of London. Series A. Mathematical and Physical Sciences, v. 231, n. 1187, p. 505-514, 1955.

[27] LOWSON, M. V. The sound field for singularities in motion. Proceedings of the Royal Society of London. Series A. Mathematical and Physical Sciences, v. 286, n. 1407, p. 559-572, 1965. 
[28] FFWOCS WILLIANS, J. E.; HAWKINGS, D. L. Sound generation by turbulence and surfaces in arbitrary motion. Royal Society of London Philosophical Transactions Series A, v. 264, p. 321-342, May 1969.

[29] GOTTLIEB, D.; ORSZAG, S. A. Numerical analisys of spectral methods: Theory and applications. Philadelphia, PA, USA: SIAM, 1993.

[30] ISSACSON, E.; KELLER, E. B. Analysis of numerical methods. London-New York: John Wiley and Sons, 1966.

[31] WARBURTON, T.; HESTHAVEN, J. S. Nodal discontinuous Galerkin methods: Algorithms, analysis, and applications. Springer, 2008.

[32] DUFF, M. G. Quadrature Over a Pyramid or Cube of Integrands with a Singularity at a Vertex. Siam Journal on Numerical Analysis, v. 19, 1982.

[33] DARRIGOL, O. The acoustic origins of harmonic analysis. Archive for History of the Exact Sciences, v. 61, p. 35-61, 2007.

[34] LI, B. Q. Discontinuous finite elements in fluid dynamics and heat transfer. Germany: Springer, 2006.

[35] BABUSKA, I.; SURI, M. The $p$ and $h p$ versions of the finite element method, basic principles and properties. SIAM Review, v. 36, n. 4, p. 578-632, 1994.

[36] XIE, Z.; ZHANG, Z. Superconvergence of DG method for one-dimensional singularly perturbed problems. Journal of Computational Mathematics, v. 25, n. 2, p. 185-200, 2007.

[37] LUSH, P. A. Measurements of subsonic jet noise and comparison with theory. Journal of Fluid Mechanics, v. 46, p. 477-500.

[38] AHUJA, K.; BUSHELL, K. An experimental study of subsonic jet noise and comparison with theory. Journal of Sound and Vibration, v. 30, n. 3, p. 317-341, 1973.

[39] PHILLIPS, O. M. On the generation of sound by supersonic turbulent shear layers. Journal of Fluid Mechanics, v. 9, p. 1-28.

[40] LILLEY, G. On the noise from jets. Noise Mechanisms. AGARD-CP, v. 131, p. 13.1-13.13, 1974.

[41] HOWE, M. S. Contributions to the theory of aerodynamic sound, with application to excess jet noise and the theory of the flute. Journal of Fluid Mechanics, v. 71, p. $625-673,1975$. 
[42] DOWling, A. P.; FFWOCKS WILliAns, J. E.; GOLDSTEIN, M. Sound production in a moving stream. Philosophical Transactions of the Royal Society of London. Series A, Mathematical and Physical Sciences, v. 288, n. 1353, p. 321-349, 1978.

[43] GOLDSTEIN, M. E. Aeroacoustics of turbulent shear flows. Annual Review of Fluid Mechanics, v. 16, p. 263-285, 1984.

[44] MANKBADI, R.; HIXON, R.; POVINELLI, L.; SHIH, S. Use of linearized Euler equations for supersonic jet noise prediction. AIAA Journal, v. 36, p. 140-174, 1998.

[45] BOGEY, C.; BAILLY, C.; JUVé, D. Computation of flow noise using source terms in linearized Euler's equations. Aiaa Journal, v. 40, p. 235-243, 2002.

[46] EWERT, R.; MEINKE, M.; SCHRODER, W. Comparison of source term formulations for a hybrid CFD/CAA method. AIAA Paper, v. 2001-2200, p. -, 2001.

[47] TAM, C. K. W. Computational aeroacoustics: An overview of computational challenges and applications. International Journal of Computational Fluid Dynamics, v. 8, p. 547-567, 2004.

[48] VICHNEVETSKY, R.; BOWLES, J. Fourier analysis of numerical approximations of hyperbolic equations. Philadelphia: SIAM, 1982.

[49] TAM, C.; WEBB, J.; DONG, Z. A study of the short wave components in computational acoustics. Journal of Computational Acoustics, v. 1, p. 1-30, 1993.

[50] KENNEDY, C. A.; CARPENTER, M. H. Several new numerical methods for compressible shear-layer simulations. Applied Numerical Mathematics, Amsterdam, The Netherlands, v. 14, n. 4, p. 397-433, June 1994.

[51] LELE, S. K. Compact finite difference schemes with spectral-like resolution. Journal of Computational Physics, v. 103, 1992.

[52] TAM, C.; WEBB, J.; DONG, Z. Dispersion-relation- preserving finite difference schemes for computational acoustics. Journal of Computational Physics, v. 107, p. 262-281, 1993.

[53] WELLS, V. L.; RENAUT, R. A. Computing aerodynamically generated noise. Annual Review of Fluid Mechanics, v. 29, p. 161-199, 1997.

[54] HU, F. Q.; ATKINS, H. L. Eigensolution analysis of the discontinuous Galerkin method with nonuniform grids: Part 1; One space dimension. Journal of Computional Physics, v. 182, n. 2, p. 516-545, Nov. 2002. 
[55] LONNY L., T. A review of finite-element methods for time-harmonic acoustics. Journal of The Acoustical Society of America, v. 119, 2006.

[56] CRIVELLINI, A.; BASSI, F. A three-dimensional parallel discontinuous Galerkin solver for acoustic propagation studies. International Journal of Aeroacoustics, v. 2, p. 157-173, Apr. 2003.

[57] WilcoX, L. C.; STAdleR, G.; BuRstedde, C.; GHATtAS, O. A highorder discontinuous Galerkin method for wave propagation through coupled elasticacoustic media. Journal of Computational Physics., v. 229, n. 24, p. 9373-9396, Dec. 2010.

[58] NOGUEIRA, X.; CUETO-FELGUEROSO, L.; COLOMINAS, I.; GóMEZ, H.; NAVARRINA, F.; CASTELEIRO, M. On the accuracy of finite volume and discontinuous Galerkin discretizations for compressible flow on unstructured grids. International Journal for Numerical Methods in Engineering, v. 78, n. 13, p. 1553-1584, 2009.

[59] CHU, C. K. Numerical methods in fluid mechanics, advances in applied mechanics. Academic Press, 1978.

[60] ROE, P. L. Approximate Riemann solvers, parameter vectors and difference schemes. Journal of Computational Physics, 1981.

[61] HARTEN, A.; LAX, P. D.; VAN LEER, B. On upstream differencing and Godunov-type schemes for hyperbolic conservation laws. SIAM Review, v. 1, n. 25, p. 35-61, 1983.

[62] TORO, E. F. Riemann solvers and numerical methods for fluid dynamics - a practical introduction. New York, USA: Springer, 2009.

[63] ABRAMOWIT, M.; STEGUN, I. A. Handbook of Mathematical functions. USA: Dover, 1972.

\section{A Solução analítica - Pulso gaussiana}

Neste apêndice desenvolvemos a solução para o pulso gaussiana. Vamos primeiro relembrar o sistema de equações de Euler linearizadas em variáveis primitivas na forma indicial, equação (2.33):

$$
\begin{gathered}
\frac{\partial \rho^{\prime}}{\partial t}+\rho_{0} \frac{\partial u_{j}^{\prime}}{\partial x_{j}}+u_{j 0} \frac{\partial \rho}{\partial x_{j}}=S_{m} \\
\frac{\partial u_{i}^{\prime}}{\partial t}+u_{j 0} \frac{\partial u_{i}^{\prime}}{\partial x_{j}}+\frac{1}{\rho_{0}} \frac{\partial p^{\prime}}{\partial x_{j}} \delta i j=\frac{1}{\rho_{0}}\left(S_{i}-u_{i} S_{m}\right)
\end{gathered}
$$




$$
\left.\frac{\partial p^{\prime}}{\partial t}+u_{j 0} \frac{\partial p^{\prime}}{\partial x_{j}}+\gamma p_{0} \frac{\partial u_{j}^{\prime}}{\partial x_{j}}=(\gamma-1)\left\{S_{e}-u_{i} S_{i}\right) \frac{1}{2}|\vec{u}|^{2} S_{m}\right\}
$$

Pode-se verificar que a equação de continuidade (A.1) e a equação da pressão (A.3) possuem a mesma forma a menos de uma constante e do termo fonte, dessa forma vamos desenvolver a solução para a equação da pressão e estender o resultado para a equação de continuidade.

Tomamos o divergente da equação (A.2):

$$
\frac{\partial^{2} u_{i}}{\partial x_{j} \partial t}+u_{0 j} \frac{\partial^{2} u_{i}}{\partial x_{j}^{2}}+\frac{\partial^{2} p}{\partial x_{j}^{2}} \delta_{i j}=\frac{1}{\rho_{0}} \frac{\partial}{\partial x_{j}}\left(S_{i}-u_{i} S_{m}\right)
$$

e tomando a derivada material $\frac{D}{D t}=\frac{\partial}{\partial t}+u_{0 j} \frac{\partial}{\partial x_{j}}$ de (A.3)

$$
\begin{array}{r}
\frac{\partial^{2} p}{\partial t^{2}}+2 u_{0 j} \frac{\partial^{2} p}{\partial x_{j} \partial x_{j}}+u_{0 j}^{2} \frac{\partial^{2} p}{\partial x_{j}^{2}}+u_{0 j}^{2} \frac{\partial^{2} p}{\partial x_{j}^{2}}+\gamma p_{0} \frac{\partial^{2} u_{j}}{\partial x_{j} \partial t}= \\
\left.\left(\frac{\partial}{\partial t}+u_{0 j} \frac{\partial}{\partial x_{j}}\right)(\gamma-1)\left\{S_{e}-u_{i} S_{i}\right) \frac{1}{2}|\vec{u}|^{2} S_{m}\right\}
\end{array}
$$

multiplicando (A.4) por $\gamma p_{0}$, subtraindo de (A.5) e chamando os lado direito de $\mathcal{F}(\mathbf{x}, t)$ :

$$
\begin{gathered}
\frac{\partial^{2} p}{\partial t^{2}}+2 u_{0 j} \frac{\partial^{2} p}{\partial x_{j} \partial x_{j}}+u_{0 j}^{2} \frac{\partial^{2} p}{\partial x_{j}^{2}}-\gamma \frac{p_{0}}{\rho_{0}} \frac{\partial^{2} \rho}{\partial x_{j}^{2}} \delta_{i j}=\mathcal{F}(\mathbf{x}, t) \\
\frac{D^{2} p}{D t^{2}}-c_{0}^{2} \frac{\partial^{2} p}{\partial x_{j}^{2}}=\frac{D^{2} \rho}{D t^{2}}-c_{0}^{2} \nabla^{2} \rho=\mathcal{F}(\mathbf{x}, t)
\end{gathered}
$$

ou de forma mais geral:

$$
\frac{D^{2} q}{D t^{2}}-c^{2} \nabla^{2} q=\mathcal{F}(\mathbf{x}, t)
$$

que é valida para as variáveis $\rho^{\prime}, u^{\prime}, v^{\prime}, p^{\prime}$.

Para obter a solução para o pulso gaussiana tomamos $\mathcal{F}(\mathbf{x}, t)=0$ e um sistema de coordenadas que se move junto com o campo médio $\tau=t, \xi_{i}=x_{i}-u_{0 i} t$, que simplifica o operador $\frac{D}{D t}$ :

$$
\frac{\partial}{\partial t}=\frac{\partial}{\partial \tau}-u_{0 j} \frac{\partial}{\partial \xi}=\frac{D}{D t}, \quad \frac{\partial}{\partial x_{i}}=\frac{\partial}{\partial \xi_{i}},
$$

obtendo a equação (A.6) na forma:

$$
\frac{\partial^{2} q}{\partial \tau^{2}}-\frac{\partial^{2} q}{\partial \xi_{j} \partial \xi_{j}}=0, \quad \xi_{1}=\xi, \quad \xi_{2}=\eta
$$

Esta equação pode ser resolvida para a velocidade potencial $\phi$ em coordenadas polares 
$(r, \theta)$, e com $u^{\prime}=\frac{\partial \phi}{\partial x}$ e $v^{\prime}=\frac{\partial \phi}{\partial y}$ relacionamos as variáveis primitivas com a velocidade potencial:

$$
\frac{\partial \phi}{\partial r}=u_{r}^{\prime}, \quad \frac{\partial \phi}{\partial \tau}=-p^{\prime}
$$

onde $u_{r^{\prime}}=\sqrt{u^{\prime 2}+v^{\prime 2}}$. As condições iniciais são obtidas pelas relações

$$
\begin{gathered}
\phi(r, 0)=\int_{-\infty}^{r} u^{\prime}(\epsilon) d \epsilon=-\frac{\beta}{2 \alpha} e^{-\alpha r^{2}} \\
\frac{\partial \phi}{\tau}(r, 0)=-p^{\prime}(r, 0)=-e^{-\alpha r^{2}}
\end{gathered}
$$

$\mathrm{E}$ a equação de onda para a velocidade potencial, que independe de $\theta$, é agora dada por

$$
\frac{\partial^{2} \phi}{\partial \tau^{2}}-\left(\frac{\partial^{2} \phi}{\partial r^{2}}+\frac{1}{r} \frac{\partial^{2} \phi}{\partial r^{2}}\right)=0
$$

com as condições iniciais (A.9) e (A.10).

A solução é obtida empregando convenientemente a transformada de Hankel ( apêndice $\mathrm{B})$, onde temos finalmente:

$$
\begin{array}{r}
p^{\prime}(r, t)=\frac{1}{2 \alpha} \int_{0}^{\infty} \lambda J_{0}(\lambda r)\left[\cos (\lambda t)-\frac{\beta}{2 \alpha} \lambda \sin (\lambda t)\right] e^{-\frac{\lambda^{2}}{4 \alpha}} d \lambda \\
u_{i}^{\prime}(r, t)=\frac{x_{i}-u_{0 i} t}{2 \alpha} \int_{0}^{\infty} \lambda J_{1}(\lambda r)\left[\sin (\lambda t)+\frac{\beta}{2 \alpha} \lambda \cos (\lambda t)\right] e^{-\frac{\lambda^{2}}{4 \alpha}} d \lambda
\end{array}
$$

onde

$$
r=\sqrt{\left(x_{j}-u_{0 j} t\right)^{2}}, \quad \rho^{\prime}=p^{\prime}
$$

e $J_{0}$ e $J_{1}$ são funções de Bessel do primeiro tipo de ordem zero e um respectivamente.

Em nosso caso temos $u_{01}=u_{0}$ e $u_{02}=0$, com isso podemos tomar $r=0$ e a solução apresentada na equação (A.12) é valida sobre a reta de equações $x=u_{0} t, y=0 \operatorname{com} u_{0}$ e $t$ arbitrários:

$$
p^{\prime}(0, t)=1-\beta t+\left[1-\beta t+\frac{\beta}{2 \alpha}\right] i \sqrt{\alpha \pi} \operatorname{erf}(i t \sqrt{\alpha}) e^{-\alpha t^{2}}
$$

e $\operatorname{erf}(\tau)$ é a função erro definida por

$$
\operatorname{erf}(\tau)=\frac{2}{\sqrt{\pi}} \int_{0}^{\tau} e^{-t^{2}} d t
$$




\section{B Transformada de Hankel}

A transformada de Hankel é uma transformação integral equivalente a transformada de Fourier em duas dimensões onde o núcleo da transformada é a função de Bessel, e essa transformada é também conhecida como transformada de Fourier-Bessel. A função de Bessel possui simetria radial e por esse motivo ela é aplicada na solução de equações de onda que possuam essa característica. Seja uma função $\phi(x, y)$ que possui simetria axial e que pode ser escrita em coordenadas polares $\phi(r \cos (\theta), r \operatorname{sen}(\theta))=f(r, \theta)$ com $f(r, \theta)$ independente de $\theta$. A transformada de Fourier de $\phi$ é:

$$
\Phi(u, v)=\frac{1}{2 \pi} \int_{-\infty}^{+\infty} \int_{-\infty}^{+\infty} \phi(x, y) e^{-i(x u+v y)} d x d y
$$

introduzindo as coordenadas polares:

$$
\begin{array}{ll}
x=r \cos \theta, & y=r \operatorname{sen} \theta \\
u=s \cos \varphi, & y=s \operatorname{sen} \varphi
\end{array}
$$

temos:

$$
\begin{aligned}
\Phi(s \cos \varphi, s \operatorname{sen} \varphi) \equiv \mathcal{F}(s, \varphi) & =\frac{1}{2 \pi} \int_{0}^{\infty} \int_{0}^{2 \pi} e^{-i r s \cos (\theta-\varphi)} f(r, \theta) d \theta r d r \\
& =\frac{1}{2 \pi} \int_{0}^{\infty} f(r) r d r \int_{0}^{2 \pi} e^{-i r s \cos (\theta-\varphi)} d \theta \\
& =\frac{1}{2 \pi} \int_{0}^{\infty} f(r) r d r \int_{0}^{2 \pi} e^{-i r s \cos \alpha} d \alpha
\end{aligned}
$$

Sabendo que a função de Bessel de ordem zero e primeiro tipo pode ser representada na forma integral por:

$$
J_{0}(x)=\frac{1}{2 \pi} \int_{0}^{2 \pi} e^{-i x \cos \alpha} d \alpha
$$

encontramos a partir da equação (B.1) a transformada de Hankel definida em termos da função de Bessel:

$$
\mathcal{F}(s, \varphi) \equiv \mathcal{H}(s)=\int_{0}^{\infty} f(r) J_{0}(r s) r d r
$$

e a transformada inversa é definida por:

$$
f(r)=\int_{0}^{\infty} \mathcal{H}(s) J_{0}(s r) s d s
$$




\section{Fluxo numérico - HLL e HLLC}

No método DG a condição de vínculo entre elementos da malha é feita pelo fluxo numérico $\widehat{f}\left(u^{+}, u^{-}\right)$que é o segundo membro da equação (3.11):

$\sum_{i=1}^{P} \frac{\partial \widehat{u}_{i}}{\partial t} \int_{\Omega^{e}} v_{j}^{\tau} \phi_{i} d \Omega^{e}+\int_{\partial \Omega^{e}} v_{j}^{\tau} \widehat{f}\left(u^{+}, u^{-}\right) n_{k} d \partial \Omega^{e}-\int_{\Omega^{e}} f_{k}\left(u^{\tau}\right) \frac{\partial v_{j}^{\tau}}{\partial x_{k}} d \Omega^{e}=\int_{\Omega^{e}} v_{j}^{\tau}\left(s-u_{0}\right) d \Omega^{e}$,

onde $u^{+}$e $u^{-}$representam o valor da variável $u$ nos dois elementos que possuem fronteira comum. Pode acontecer que os valores de $u^{+}$e $u^{-}$sejam diferentes e neste caso a descontinuidade é tratada como um problema de Riemann que pode ser resolvido com métodos upwind, dentre eles podemos destacar Lax-Friedrichs, [59], Roe [60], HLL e HLLC [61]. Neste apêndice apresentamos uma pequena introdução dos métodos Roe e Lax-Friedrichs e alguns detalhes dos métodos HLL e HLLC.

Para descrever o problema de Riemann consideremos a equação de Euler como um sistema de equações diferencias na forma conservativa com a condição inicial descontínua:

$$
\begin{aligned}
& \mathbf{u}_{t}+F(\mathbf{u})_{x}=0 \\
& \mathbf{u}(\mathbf{x}, 0)=\mathbf{u}^{(0)}(\mathbf{x}) \\
& \mathbf{u}(0, t)=\left\{\begin{array}{l}
\mathbf{u}_{L}(t) \\
\mathbf{u}_{R}(t)
\end{array}\right.
\end{aligned}
$$

Uma forma conservativa de discretização consiste em determinar o valor de $\mathbf{u}^{n+1}$ no elemento $i$ como:

$$
\mathbf{u}_{i}^{n+1}=\mathbf{u}_{i}^{n}-\frac{\Delta t}{\Delta x}\left[\mathbf{F}_{i+\frac{1}{2}}-\mathbf{F}_{i-\frac{1}{2}}\right]
$$

A dificuldade consiste em determinar o fluxo numérico $\mathbf{F}_{i+\frac{1}{2}}$ e para tanto faremos uso das variáveis características de um sistema linear na forma $\mathbf{u}_{t}+A \mathbf{u}=0$ onde $A$ é aproximado pela matriz Jacobiana $A(\mathbf{u})=\partial F / \partial \mathbf{u}$.

Considerando a equação de Euler em uma dimensão:

$$
\mathbf{u}=\left[\begin{array}{c}
\rho \\
\rho u \\
E
\end{array}\right], \quad \mathbf{F}=\left[\begin{array}{c}
\rho u \\
\rho u^{2}+p \\
\rho u H
\end{array}\right]
$$

onde $p=(\gamma-1)\left(E-\frac{1}{2} \rho u^{2}\right)$ a pressão e $H=(E+p) / \rho$ a entalpia, a matriz Jacobiana 
$A$ é:

$$
A=\left[\begin{array}{ccc}
0 & 1 & 0 \\
(\gamma-3) u^{2} & (3-\gamma) u & (\gamma-1) \\
(\gamma-1) u^{3}-\gamma \frac{u E}{\rho} & \gamma \frac{E}{\rho}+\frac{3(\gamma-1) u^{2}}{\rho} & \gamma u
\end{array}\right]
$$

que pode ser decomposta em autovetores e autovalores:

$$
A=\mathbf{R} . \mathbf{D} . \mathbf{L}
$$

que são, $\mathbf{D}$ matriz diagonal dos autovalores, $\mathbf{R}$ e $\mathbf{L}$ matriz dos autovetores da direita e da esquerda com R.L $=\mathbf{I}$ e $\mathbf{L}$ definida por:

$$
\mathbf{L}=\left[\begin{array}{ccc}
\frac{\frac{1}{2} u^{2} \beta c_{0}+u}{2 c_{0}} & -\frac{1+u \beta c_{0}}{2 c_{0}} & \frac{\beta}{2} \\
1-\frac{1}{2} \beta u^{2} & \beta u & -\beta \\
\frac{1}{2} u^{2} \beta c_{0}-u & \frac{1+u \beta c_{0}}{2 c_{0}} & \frac{\beta}{2}
\end{array}\right]
$$

com $c_{0}=\sqrt{\frac{\gamma p}{\rho}}$ a velocidade do som, $\beta=\frac{(\gamma-1)}{c_{0}^{2}}$ e $\mathbf{D}$ a matriz dos autovalores:

$$
\mathbf{D}=\left[\begin{array}{ccc}
u-c_{0} & 0 & 0 \\
0 & u & 0 \\
0 & 0 & u+c_{0}
\end{array}\right]
$$

Com alguma álgebra matricial podemos escrever o sistema em termo das variáveis características $\mathbf{v}=\mathbf{L u}$ :

$$
\begin{aligned}
& \mathbf{u}_{t}+F(\mathbf{u})_{x} \quad=0 \\
& \mathbf{u}_{t}+\mathbf{R D L u} \mathbf{u}_{x}=0 \\
& \mathbf{R}^{-1} \mathbf{U}_{t}+\mathbf{D L} \mathbf{U}_{x}=0 \\
& \mathbf{L} \mathbf{u}_{t}+\mathbf{D L} \mathbf{u}_{x}=0 \\
& \mathbf{v}_{t}+\mathbf{D} \mathbf{v}_{x}=0
\end{aligned}
$$

E sobre esse sistema podemos aplicar o método upwind.

Pode-se calcular o fluxo numérico $\mathbf{F}_{i+\frac{1}{2}}$ na interface de dois elementos diretamente pelo fluxo de Roe [60].

$$
\mathbf{F}_{i+\frac{1}{2}}=\frac{\mathbf{F}\left(\mathbf{u}_{i+1}\right)+\mathbf{F}\left(\mathbf{u}_{i}\right)}{2}-\mathbf{R}|\mathbf{D}| \frac{\mathbf{v}_{i+1}-\mathbf{v}_{i}}{2}
$$


ou pelo fluxo de Lax-Friedrichs [59]

$$
\mathbf{F}_{i+\frac{1}{2}}=\frac{\mathbf{F}\left(\mathbf{u}_{i+1}\right)+\mathbf{F}\left(\mathbf{u}_{i}\right)}{2}-\alpha \frac{\mathbf{u}_{i+1}-\mathbf{u}_{i}}{2}
$$

onde $\alpha$ é o maior autovalor da matriz Jacobiana $A$, ou seja, o maior valor de $\mathbf{D}$.

O fluxo HLL, proposto por Harten, Lax e van Leer [61] considera que os autovalores definem velocidades características $u+c_{0}$ e $u-c_{0}$, com as quais podemos definir $S_{L}=$ $\max \left(u \pm c_{0}\right)$ e $S_{R}=\min \left(u \pm c_{0}\right)$ e utilizá-las para separar o plano $x \times t$ das variáveis características em 3 estados, figura (C.1), definindo então o fluxo numérico HLL:

$$
\mathbf{F}_{i+\frac{1}{2}}^{H L L}=\left\{\begin{array}{cl}
\mathbf{F}_{L} & \text { se } \quad S_{L} \leq 0 \\
\frac{S_{R} \mathbf{F}_{L}-S_{L} \mathbf{F}_{R}+S_{R} S_{L}\left(\mathbf{U}_{R}-\mathbf{U}_{L}\right)}{S_{R}-S_{L}} & \text { se } \quad S_{L} \leq 0 \leq S_{R} \\
\mathbf{F}_{R} & \text { se } \quad S_{R} \leq 0
\end{array}\right.
$$

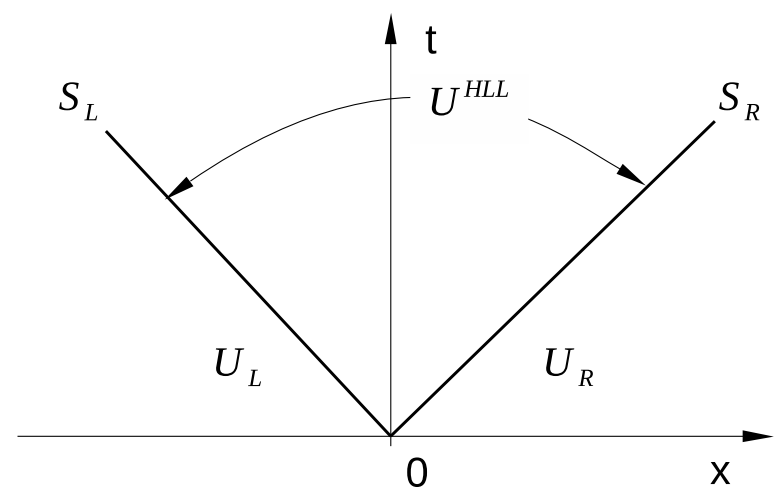

Figura C.1: Plano $x \times t$ dividido em 3 estados pelas velocidades características $S_{R}=\max \left(u \pm c_{0}\right)$ e $S_{L}=\min \left(u \pm c_{0}\right)$

Já o fluxo HLLC, onde a letra C significa "contato", foi proposto pelos mesmos autores e considera uma velocidade característica intermediária $S_{L}<S_{*}<S_{R}$ que divide o plano $x \times t$ em 4 estados, figura (C.2) definindo então o fluxo HLLC: 


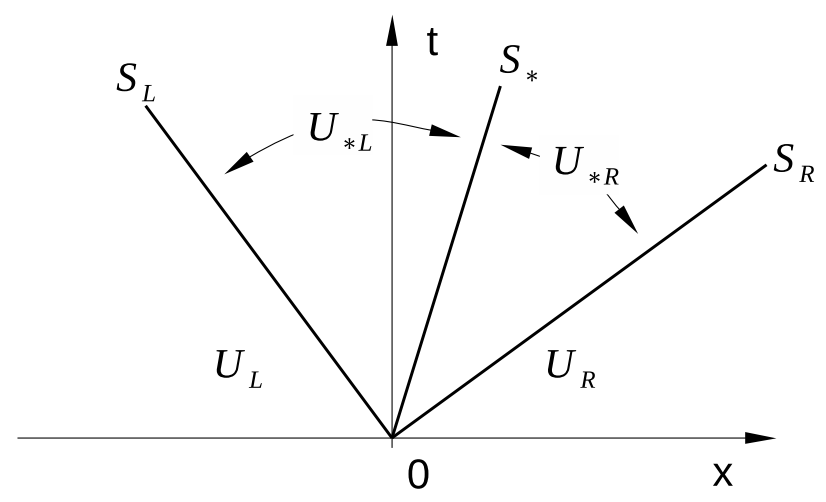

Figura C.2: Plano $x \times t$ dividido em 4 estados pelas velocidades características $S_{R}$, $S_{*}$ e $S_{L}$

$$
\mathbf{F}_{i+\frac{1}{2}}^{H L L C}=\left\{\begin{array}{cll}
\mathbf{F}_{L} & \text { se } & S_{L} \leq 0 \\
\mathbf{F}_{* L} & \text { se } & S_{L} \leq 0 \leq S_{*} \\
\mathbf{F}_{* R} & \text { se } & S_{*} \leq 0 \leq S_{R} \\
\mathbf{F}_{R} & \text { se } & S_{R} \leq 0
\end{array}\right.
$$

e os fluxos intermediários $\mathbf{F}_{* L}$ e $\mathbf{F}_{* R}$ são determinados com integrais apropriadas sobre os volumes de controle ou aplicando as condições de Rankine-Hugoniot através de cada velocidade característica $S_{L}, S_{*}$ e $S_{R}[62]$ para obter:

$$
\begin{array}{r}
\mathbf{F}_{* L}=\mathbf{F}_{L}+S_{L}\left(\mathbf{U}_{* L}-\mathbf{U}_{L}\right) \\
\mathbf{F}_{* R}=\mathbf{F}_{R}+S_{R}\left(\mathbf{U}_{* R}-\mathbf{U}_{R}\right)
\end{array}
$$

ainda é necessário determinar $\mathbf{U}_{*}$ e $\mathbf{S}_{*}$ que em particular para as equações de Euler em 1D, são definidos em termo das variáveis de estado por [62]:

$$
\begin{gathered}
S_{*}=\frac{p_{R}-p_{L}+\rho_{L} u_{L}\left(S_{L}-u_{L}\right)-\rho_{R} u_{R}\left(S_{R}-u_{R}\right)}{\rho_{L}\left(S_{L}-u_{L}\right)-\rho_{R}\left(S_{R}-u_{R}\right)} \\
\mathbf{U}_{* K}=\rho_{k}\left(\frac{S_{K}-u_{k}}{S_{K}-S_{*}}\right)\left[\begin{array}{c}
1 \\
S_{*} \\
\frac{E_{k}}{\rho_{k}}+\left(S_{*}-u_{k}\left[S_{*}+\frac{p_{k}}{\rho_{k}\left(S_{k}-u_{k}\right)}\right]\right.
\end{array}\right]
\end{gathered}
$$


para $K=R$ ou $K=L$.

\section{Polinômios de Legendre}

Os polinômios de Legendre, $h_{n}(x)$, são casos especiais dos polinômios de Jacobi $P_{n}^{\alpha, \beta}(x)$ quando $\alpha=\beta=0$ e são as soluções das equações diferenciais de Legendre

$$
\frac{d}{d x}\left[\left(1-x^{2}\right) \frac{d}{d x} L_{n}(x)\right]+n(n+1) L_{n}(x)=0 .
$$

A contribuição desses polinômios é a sua ortogonalidade no intervalo $[-1,1]$ e as relações diferenciais, seguem aqui algumas propriedades úteis e tantas outras podem ser encontradas em Abramowits [63].

Fórmula recursiva diferencial:

$$
(2 n+1) L_{n}(x)=\frac{d}{d x}\left[L_{n+1}(x)-L_{n-1}(x)\right]
$$

Ortogonalidade:

$$
\int_{-1}^{1} L_{m}(x) L_{n}(x) d x=\frac{2}{2 n+1} \delta_{m n}
$$

Fórmula de Rodrigues:

$$
L_{n}=\frac{(-1)^{n}}{2^{n} n !} \frac{d^{n}}{d x^{n}}\left(x^{2}-1\right)^{n} .
$$

Fórmula recursiva de Bonnet:

$$
\begin{gathered}
L_{0}(x)=1, \quad L_{1}(x)=x, \\
(n+1) L_{n+1}(x)=(2 n+1) x L_{n}(x)-n L_{n-1}(x)
\end{gathered}
$$

Representação explícita:

$$
L_{n}(x)=\frac{1}{2^{n}} \sum_{k=0}^{n}\left(\begin{array}{l}
n \\
k
\end{array}\right)^{2}(x-1)^{n-k}(x+1)^{k}
$$

Simetria-Antissimetria:

$$
L_{n}(-x)=(-1)^{n} L_{n}(x)
$$

